\title{
Resto zero
}

Talles Eduardo Nazar Cerizza 

Data de Depósito:

Assinatura:

\section{Talles Eduardo Nazar Cerizza}

\section{Resto zero}

Dissertação apresentada ao Instituto de Ciências Matemáticas e de Computação - ICMC-USP, como parte dos requisitos para obtenção do título de Mestre - Programa de Mestrado Profissional em Matemática. VERSÃO REVISADA.

Área de Concentração: Matemática, Probabilidade Orientador: Rafael Andrés Rosales Mitrowsky

USP - São Carlos

Março 2017 
Ficha catalográfica elaborada pela Biblioteca Prof. Achilles Bassi e Seção Técnica de Informática, ICMC/USP, com os dados fornecidos pelo(a) autor(a)

\begin{tabular}{|c|c|}
\hline \multirow[t]{3}{*}{ C415r } & $\begin{array}{l}\text { Cerizza, Talles Eduardo Nazar } \\
\text { Resto zero / Talles Eduardo Nazar Cerizza; } \\
\text { orientador Rafael Andrés Rosales Mitrowsky - São } \\
\text { Carlos - SP, } 2017 \text {. } \\
\quad 51 \text { p. }\end{array}$ \\
\hline & $\begin{array}{l}\text { Dissertação (Mestrado - Programa de } \\
\text { Pós-Graduação em Mestrado Profissional em } \\
\text { Matemática em Rede Nacional) - Instituto de } \\
\text { Ciências Matemáticas e de Computação, Universidade } \\
\text { de São Paulo, } 2017 \text {. }\end{array}$ \\
\hline & $\begin{array}{l}\text { 1. Probabilidade. 2. Combinatória. 3. Jogo } \\
\text { Pedagógico. I. Rosales, A. Rafael, orient. II. } \\
\text { Resto zero }\end{array}$ \\
\hline
\end{tabular}




\title{
Talles Eduardo Nazar Cerizza
}

\section{Residue zero}

\begin{abstract}
Master dissertation submitted to the Instituto de Ciências Matemáticas e de Computação ICMC-USP, in partial fulfillment of the requirements for a degree of the Programa de Mestrado Profissional em Matemática. FINAL VERSION.
\end{abstract}

Concentration Area: Mathematics, Probability Advisor: Rafael Andrés Rosales Mitrowsky 

Aos meus avós Ary e Dalva, Jaime e Ilda por acreditarem na educação dos filhos. Aos meus pais Mônica e Antônio de Pádua que fizeram valer este empenho nos educando.

À minha amada esposa e filhos.

Um apelo à estes ùltimos: eduquem!, façam valer a dedicação de muitas gerações. 



\section{Agradecimentos}

Agradeço ao Sr. Deus, que me proporcionou a realização deste curso e por confiar a mim novas tarefas, que só foram possíveis de serem percebidas e desenvolvidas pelo conhecimento adquirido.

Agradeço aos meus pais, por terem acreditado e apoiado a busca pelo conhecimento, certamente ainda no plano espiritual, onde planejamos os compromissos desta vida.

Agradeço à minha esposa, que nas circunstâncias de ansiedade, procurou mostrar-me, com tranquilidade no olhar, que o dia da conclusão deste trabalho chegaria em tempo hábil, por acreditar na minha capacidade de superar as dificuldades. Palavras que vieram como lenitivo aos momentos de inquietude.

Agradeço ao meu professor e orientador Rafael, por propor desafios que inicialmente considerei impossíveis de serem transpostos. Ele acreditou mais em mim do que fui capaz de acreditar. Sem sua confiança e apoio teria trabalhado na superficialidade. Ele possibilitou aflorar minha capacidade com seus ensinamentos, encaminhamentos, tranquilidade, paciência e muita experiência. Postura essa que me permitiu reconhecer nele um amigo.

Agradeço à família e pessoas amigas que estão felizes por saberem que estou feliz. Não pode haver nada maior que isso para definir uma amizade.

Tantos foram os que contribuiram para esse passo. Muitos foram os colaboradores, com palavras de incentivo e sorrisos em dias difíceis.

A todos que ajudaram e acreditaram nesta realização, ao lerem esta página de agradecimentos, peço que se identifiquem com alguma das pessoas mencionadas e, junto à estas, recebam minha eterna gratidão. 



\section{Resumo}

Esta dissertação descreve um jogo de baralho com caráter pedagógico, Resto Zero, o qual apresenta forte ligação com probabilidade, divisibilidade, análise combinatória e operações aritméticas elementares. Especificamente calculamos a probabilidade de alguns eventos principais que ocorrem no desenvolvimento do jogo. Apresentamos também uma relação do uso do Resto Zero aos anos/séries em que pode ser trabalhado.

Palavras-chave: Probabilidade, Combinatória, Jogo Pedagógico. 



\begin{abstract}
In this dissertation we present and develop a simple game based upon a deck of cards which we call Residue Zero. We study and describe some characteristics of this game by observing its strong connections with probability, combinatorics and basic arithmetic operations. In particular, we compute the probability of several events that occur during the development of this game. We finally provide a relation of the scholar grades in which some features of this game could be worked out.
\end{abstract}

Key-words: Probability, Enumerative Combinatorics, Pedagogical Game. 



\section{Lista de Figuras}

1 Probabilidade de acertos nas habilidades propostas ao $7^{\circ}$ ano do Ensino Fundamental ... 5

2 Probabilidade de acertos nas habilidades propostas ao $9^{\circ}$ ano do Ensino Fundamental ... 6

3 Probabilidade de acertos nas habilidades propostas à $3^{a}$ série do Ensino Médio . . . . . . 6

4 Um evento elementar do Exemplo $2.1 \ldots \ldots \ldots \ldots \ldots \ldots \ldots \ldots \ldots \ldots \ldots \ldots \ldots \ldots \ldots$

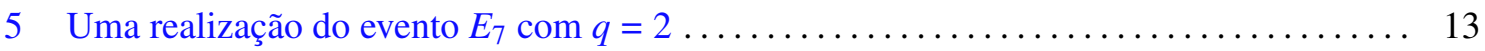

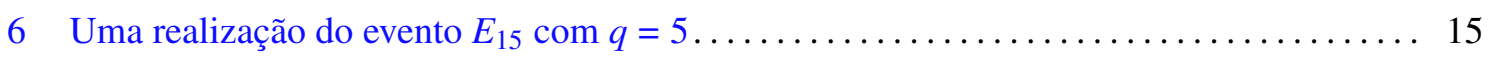

7 Um evento elementar no problema da divisão da soma $\ldots \ldots \ldots \ldots \ldots \ldots \ldots \ldots \ldots$

8 Exemplo para interseções entre $G_{i}(q), i \in\{1, \ldots, 8\} \ldots \ldots \ldots \ldots \ldots \ldots \ldots \ldots \ldots \ldots$ 



\section{Lista de Tabelas}

1 Indicação do jogo Resto Zero de acordo a série/ano................... 5

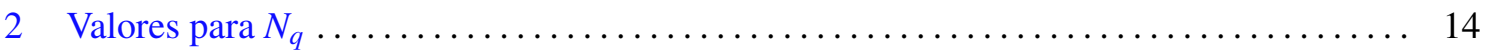

3 Cardinalidade de alguns subconjuntos no problema da divisão da soma ........... 22

4 Eventos do problema da divisão composta pela soma ................... 24

5 Cardinalidade do conjuntos $H_{q}, H_{q}^{\prime}, H_{q}^{\prime \prime}$ e $H_{q}^{\prime \prime \prime} \ldots \ldots \ldots \ldots \ldots \ldots \ldots \ldots \ldots \ldots \ldots$ 



\section{Conteúdo}

Lista de Figuras $\ldots \ldots \ldots \ldots \ldots \ldots \ldots \ldots \ldots \ldots \ldots \ldots \ldots \ldots \ldots \ldots \ldots \ldots \ldots$

Lista de Tabelas $\ldots \ldots \ldots \ldots \ldots \ldots \ldots \ldots \ldots \ldots \ldots \ldots \ldots \ldots \ldots \ldots \ldots \ldots \ldots \ldots \ldots \ldots \ldots$

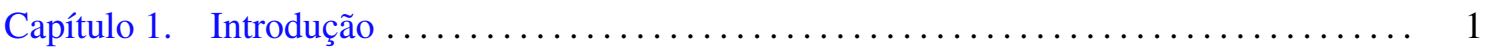

1. Sobre o Currículo do Estado de São Paulo . . . . . . . . . . . . . . . . . . . . 3

2. Dados referentes ao desenvolvimento das habilidades dos alunos $\ldots \ldots \ldots \ldots \ldots \ldots . .4$

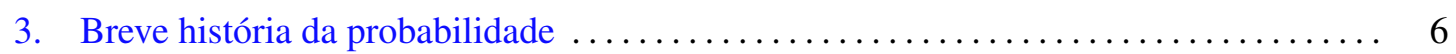

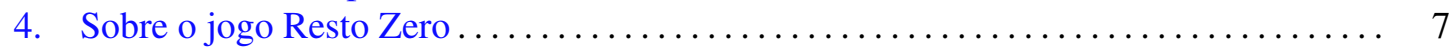

Capítulo 2. Probabilidade no jogo Resto Zero $\ldots \ldots \ldots \ldots \ldots \ldots \ldots \ldots \ldots \ldots \ldots \ldots \ldots \ldots \ldots$

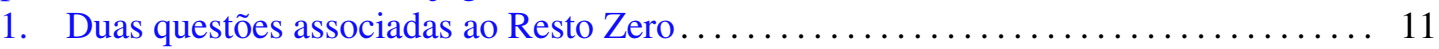

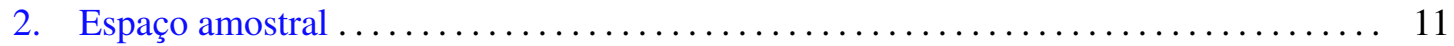

3. O problema da divisão simples $\ldots \ldots \ldots \ldots \ldots \ldots \ldots \ldots \ldots \ldots \ldots \ldots \ldots \ldots \ldots \ldots \ldots$

4. Probabilidade das divisões simples $\ldots \ldots \ldots \ldots \ldots \ldots \ldots \ldots \ldots \ldots \ldots \ldots \ldots \ldots \ldots \ldots$

5. O problema da divisão composta pela soma $\ldots \ldots \ldots \ldots \ldots \ldots \ldots \ldots \ldots \ldots \ldots \ldots \ldots . \ldots$

6. Probabilidade da divisão composta pela soma...................... 23

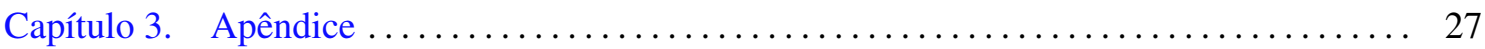

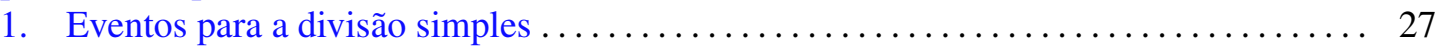

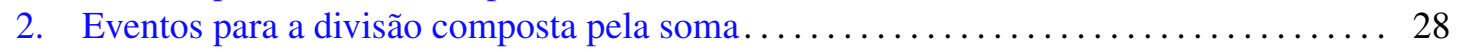

3. Demonstração dos Lemas relativos ao problema da divisão composta pela soma. . . . 29

4. Pré-requisitos: Divisibilidade e Probabilidade ..................... 46

Capítulo 4. Considerações Finais . . ............................. 49

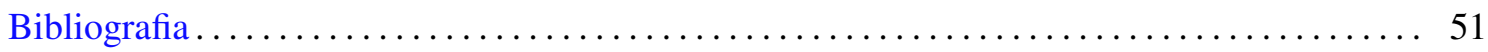





\section{CAPíTULO 1}

\section{Introdução}

Evidente e comprovada por meio de avaliações do cotidiano escolar, por avaliações nacionais e internacionais é a ineficiência dos alunos brasileiros em relação a resolução de questões simples envolvendo as quatro operações básicas, a saber: adição, subtração, multiplicação e, principalmente, divisão.

Dentre as avaliações nacionais podemos destacar o Simave, Saresp e Saeb. Destaque este por se tratar de sistemas consolidados e ao mesmo tempo em constante evolução. O Simave foi criado no estado de Minas Gerais no ano de 2000 e significa Sistema Mineiro de Avaliação das Escolas Públicas. O Saresp é o sistema que foi criado em 1996 no estado de São Paulo e significa Sistema de Avaliação de Rendimentos do Estado de São Paulo. Ambos sistemas são caracterizados como sistemas de avaliação externa, o que quer dizer que são elaborados fora das escolas em que são aplicados e sem influência das mesmas. Outros estados também avaliam suas escolas, mas Minas Gerais e São Paulo são os que envolvem mais alunos e escolas em todo o Brasil. O Saeb é o Sistema de Avaliação da Educação Básica que avalia em âmbito nacional. Quando aplicado com foco na gestão dos sistemas educacionais chama-se Avaliação Nacional da Educação Básica (Aneb) e é aplicado por amostragem, mas por manter as mesmas características é divulgada como Saeb. Quando tem o intuito de avaliar cada unidade escolar é utilizada a Avaliação Nacional do Rendimento Escolar (Anresc), divulgada como Prova Brasil. Internacionalmente, a educação é avaliada pelo Pisa que é o Programa de Avaliação de Estudantes que em inglês se lê Programme for International Student Assessment. Este programa tem como foco de avaliação alunos na faixa etária de 15 anos. A Organização para Cooperação e Desenvolvimento Econômico (OCDE) o desenvolve e coordena, porém no Brasil é o Instituto Nacional de Estudos e Pesquisas Educacionais Anísio Teixeira (Inep) que o coordena.

As dificuldades dos alunos são remanescentes das séries iniciais da educação básica e se arrastam por toda sua vida escolar. A recuperação contínua não consegue reverter todos os casos, pois o professor fica entre apresentar o conteúdo previsto para o ano letivo e recuperar alunos com diferentes estágios de aprendizagem. Alunos do ensino médio apresentam dificuldades que deveriam ser características de alunos dos anos finais do ensino fundamental.

Não é o intuito deste trabalho enumerar e, menos ainda, julgar a metodologia de ensino nas séries iniciais e finais do ensino fundamental e do ensino médio, bem como a qualidade do mesmo. Queremos apresentar uma alternativa prática que possa apoiar a recuperação da aprendizagem destes alunos que, por diversos fatores, foi prejudicada ao longo do processo.

A Lei de Diretrizes e Bases da Educação $n^{\circ}$ 9394, LDB, 1996, prevê em seu artigo 13², respectivamente nos itens III e IV, que os docentes incumbir-se-ão de 'zelar pela aprendizagem do aluno' e 'estabelecer estratégias de recuperação para os alunos de menor rendimento'. Como uma dessas alternativas apresentamos um jogo de cartas, utilizando um baralho convencional, ao qual a maioria das pessoas têm acesso e que para a instituição de ensino representa um gasto pouco significativo. Elaborar estratégias como esta pode e deve ser feito uma vez que no mesmo documento, artigo $3^{\circ}$, diz que o ensino será ministrado com base em alguns princípios e dentre eles, ítem III, 'pluralismo de ideias e de concepções pedagógicas'.

Os Parâmetros Curriculares Nacionais, PCN, 2010, também apoiam o uso de jogos na educação com ressalva: 
Alguns recursos didáticos como jogos, livros, vídeos, calculadoras, computadores e outros materiais têm um papel importante no processo de ensino e aprendizagem. Contudo, eles precisam estar integrados a situações que levem ao exercício da análise e da reflexão, em última instância, a base da atividade matemática, caminhos para "fazer Matemática na sala de aula".

Sobre a importância dos jogos na aprendizagem, os Parâmetros Curriculares Nacionais ainda mencionam:

...Em estágio mais avançado, as crianças aprendem a lidar com situações mais complexas (jogos com regras) e passam a compreender que as regras podem ser combinações arbitrárias que os jogadores definem; percebem também que só podem jogar em função da jogada do outro (ou da jogada anterior, se o jogo for solitário). Os jogos com regras têm um aspecto importante, pois neles o fazer e o compreender constituem faces de uma mesma moeda. A participação em jogos de grupo também representa uma conquista cognitiva, emocional, moral e social para a criança e um estímulo para o desenvolvimento do seu raciocínio lógico. Finalmente, um aspecto relevante nos jogos é o desafio genuíno que eles provocam no aluno, que gera interesse e prazer. Por isso, é importante que os jogos façam parte da cultura escolar, cabendo ao professor analisar e avaliar a potencialidade educativa dos diferentes jogos e o aspecto curricular que se deseja desenvolver.

Em Gusmão, 1996, pág. 12, Valdir Gusmão esclarece o verdadeiro objetivo da utilização de jogos com vistas a aprendizagem.
Ao falarmos de "JOGOS" estamos nos referindo a processos que dinamizem e não a processos infantis por que passamos, são na verdade, processos de atividade com realidades em formas estruturadas, com objetivos definidos que não o de passar o tempo.
Entre nossa população, a própria palavra "jogos" acaba recebendo uma atri- buição cotidiana de marginalidade em alguns casos, e com vários significados. Queremos aqui definí-lo como um processo que desenvolve a capacidade de usar abstrações para que obtenhamos atuações eficientes.

Na educação, o jogo deve ter enfoque pedagógico. É necessário ficar claro para os alunos qual é o objetivo e se seu uso está convenientemente relacionado com o que se está sendo ensinado.

Sobre a utilização de jogos na educação Dinello, 2007, diz que 'é algo que a criança realiza com alegria' e notamos em nosso cotidiano como professores que esta afirmação também é verdadeira quando tratamos de pré-adolescentes e adolescentes. Diz ainda que mesmo estando fora da realidade objetiva faz com que o jogador incorpore um valor pessoal e que assumindo uma postura ativa se exercita e consequentemente se aperfeiçoa. Esta situação de prova faz com que o indivíduo busque e organize os recursos pessoais adormecidos.

Neste sentido, segundo Smole et al., 2006, pág. 10,

...e o incômodo por não controlar os resultados. Esse aspecto lúdico faz do jogo um contexto natural para o surgimento de situações-problema cuja superação exige do jogador alguma aprendizagem e um certo esforço na busca por uma solução.

Com a utilização do jogo nas aulas de matemática o aluno desenvolve sua capacidade de observar, de analisar, levantar hipóteses, procurar suposições, refletir, tomar decisão, argumentar e se organizar, pois seu sucesso depende destas questões.

Como será exposto adiante, o jogo, denominado convenientemente de Resto Zero, apresenta continuamente situações em que o aluno deva utilizar pelo menos uma das quatro operações básicas. Este é seu verdadeiro trunfo. Em um meio onde as dificuldades com raciocío lógico e com as operações básicas são evidentes, surge como uma opção que atende as necessidades de alunos de 
todas as séries, seja para recuperar alunos com dificuldades ou para ampliar os conhecimentos e habilidades daqueles alunos que se afinam com a Matemática.

Mais do que ter um bom rendimento escolar, devemos levar em consideração os desafios do cotidiano do aluno. Deve ser permanente a preocupação de se formar cidadãos independentes. de Carvalho, 1994, pág. 79 diz que:

...É indiscutível a utilidade de cálculos mentais, se não na escola, ao menos fora dela. Na vida diária, a memorização é utilizada a partir da heurísticas específicas diante dos problemas que se apresentam.

Queremos que os alunos do ensino médio possam ser motivados, utilizando-se o Resto Zero, para estudar e desenvolver suas habilidades nos processos de contagem e probabilidade e que outros níveis de ensino e séries/anos possam usufruir das possibilidades de aprendizagem oferecidas pelo mesmo. Principalmente em se tratando de critérios de divisibilidade, assunto abordado na primeira série/ano dos anos finais do ensino fundamental.

Ao final do trabalho esperamos que o leitor sinta-se apto para aplicar nossas sugestões em suas prática docente e, se não for este o caso, que o mesmo possa aprimorar suas habilidades e competências no domínio das operações básicas e lógica.

\section{Sobre o Currículo do Estado de São Paulo}

Com o intuito de melhorar o ensino na sua rede pública A Secretaria da Educação do Estado de São Paulo propôs em 2008 um currículo único a ser seguido pelas escolas públicas estaduais do Ensino Fundamental II (anos finais) e do Ensino Médio. Considerou neste documento os princípios orientadores para que a escola seja capaz de fazer com que o alunado desenvolva as competências cabíveis a cada série/ano e nível de ensino. Espera-se que, seguindo as orientações do mesmo, o aluno consiga, além das competências previstas, desenvolver outras necessárias para um bom desempenho na vida e trabalho. Sendo único em todo o estado, os alunos que se transferem de uma escola para outra acabam por serem menos prejudicados. Mais que isso, a Secretaria da Educação pode avaliar toda a sua rede e propor ações de desenvolvimento.

Como consequência, a mesma secretaria lançou os cadernos do Gestor, do Professor e do Aluno. Os dois primeiros são compostos de orientações para uma boa gestão pedagógica dentro e fora da sala de aula de forma que o currículo seja cumprido de forma integral e principalmente com qualidade. O Caderno do Aluno é composto de exercícios e alguns textos auxiliares. Sua divisão é feita através de situações de aprendizagem que, passo a passo, levam professores e alunos a fundamentarem conceitos através de exemplos do cotidiano e exercitar o que foi discutido. Muitas vezes requer o apoio do livro didático, pois há turmas que conseguem desenvolver as atividades do caderno, outras estão aquém ao nível de dificuldade das mesmas e também por não apresentarem a parte teórica.

$\mathrm{Na}$ apresentação do currículo está claro que mesmo com pontos de partida iguais, a escola deve diversificar o tratamento de acordo com sua clientela.

Ainda neste sentido, na página 13 do Currículo Oficial do Estado de São Paulo, temos:

...Quando os pontos de partida são diferentes, é preciso tratar diferentemente os desiguais para garantir a todos uma base comum

A Matemática está inserida em uma grande área: Ciências da Natureza e Matemática. Esta área abrange a Física, a Química, a Biologia e a Matemática. Também é dividido em Linguagens e Códigos (Língua Portuguesa e Estrangeira, a educação Física e a Arte) e Ciências Humanas (História, Geografia, Sociologia e a Filosofia).

Localizaremos na Tabela 1 onde o jogo Resto Zero pode ser diretamente utilizado de acordo o currículo em questão.

$\mathrm{Na} 5^{a}$ série $\left(6^{\circ}\right.$ ano) o jogo pode ser utilizado diretamente quando se pretende ensinar os critérios de divisibilidade. De maneira lúdica o aluno poderá aplicar este conteúdo, momento em que conceitos são reforçados e dúvidas aparecem. Na inquetação de esclarecer essas dúvidas e 
resolver os desafios é que a aprendizagem ganha campo fértil para se desenvolver. Com o auxílio do professor e de amigos de classe, ou mesmo sozinhos, os alunos poderão perceber a importância de se ter um Ás, um dois ou uma carta baixa em mãos e que é interessante a presença de cartas altas na mesa. Perceberão também, por exemplo, que um número primo na mesa pode se tornar difícil de ser captado, pois isto acontece em três situações: se o aluno possuir um Ás; se o aluno possuir o mesmo primo que queira captar; se conseguir envolver este primo em uma combinação com outra carta, realizando assim a divisão. Contudo poderão entender que utilizando de combinações entre duas cartas da mesa suas chances podem aumentar significativamente. Assim mútiplos e divisores, números primos e as operações básicas ganham um contexto significativo para serem utilizados.

$\mathrm{Na} 8^{a}$ série $\left(9^{\circ}\right.$ ano) a probabilidade é trabalhada realçando os conceitos básicos, como espaço amostral, eventos simples e resolução de probabilidades simples envolvendo processos multiplicativos e aditivos. Uma ferramenta como jogo Resto Zero pode ser utilizada de maneira introdutória. Pode-se apresentá-lo aos alunos como uma opção de se estudar algumas probabilidades. Pode ser interessante passar algumas probabilidades já calculadas, como por exemplo, a de que, tendo um Ás nas cartas presentes na mão do jogador, a probabilidade de se concluir uma divisão é de $100 \%$ e explicando porque de fato isso ocorre. Outros exemplos podem ser considerados, sempre levando em consideração as facilidades e dificuldades apresentadas pela turma.

No $2^{a}$ série do Ensino Médio, estudando parte específica da Matemática, o uso do jogo Resto Zero é oportuno. Neste momento espera-se alunos capazes de abstrair melhor informações envolvendo análise combinatória e probabilidade. O jogo pode ser apresentado, como no $9^{\circ}$ ano, para criar situações de aprendizagem que agucem a curiosidade e o raciocínio lógico. Esperamos que, com algo concreto, o aluno se sinta mais interessado e estimulado a realizar as atividades e interiorizar os conceitos. Para as turmas que apresentem defazagem de aprendizagem deve-se iniciar com cáculos do espaço amostral e de eventos simples. Mas alunos deste nível devem estar áptos a compreender isto e algo mais, como por exemplo, a constituição da fórmula capaz de calcular a propabilidade de existir uma carta presente na mesa que possa ser divisível por uma carta em de posse do jogador, que apresentaremos no decorrer do trabalho.

Observando a grade de todas as séries/anos podemos ver que em outras situações o jogo Resto Zero pode ser utilizado. No $9^{\circ}$ ano, por exemplo, ao se ensinar como encontrar a fração geratriz de um número decimal muitas vezes fica clara a deficiência que os alunos apresentam em simplificar as frações. Eis um momento que o jogo pode auxiliar tanto para relembrar critérios de divisibilidade, como para exercitá-los.

\section{Dados referentes ao desenvolvimento das habilidades dos alunos}

Dizemos anteriormente que os alunos apresentam dificuldades elementares. Corroborando com esta afirmação, apresentamos alguns gráficos que apontam o desenvolvimento dos alunos da Diretoria de Ensino de algumas habilidades presentes nas Matrizes de Referência do Estado de São Paulo. Esses gráficos, chamados de "Mapa de Habilidades", foram retirados da plataforma Foco Aprendizagem, FOCO (2017), disponibilizada pela Secretaria da Educação do Estado de São Paulo. A partir dos dados disponibilizados nessa plataforma sobre o SARESP e sobre a Avaliação de Aprendizagem em Processo ${ }^{1}$, é possível fazer várias análises e programar ações. De forma clara e abrangente, na plataforma pode-se analisar o desempenho por diretoria de ensino, escola e por ano/série.

Todas esses pontos na figura $1 \mathrm{em}$ formas geométricas planas com inscrições que iniciam com a letra $\mathrm{H}$ dizem respeito à posição que se encontram as habilidades dos alunos de acordo com o desenvolvimento das mesmas. Tomando como exemplo a habilidade H02, ainda na figura 1 , na qual espera-se que o aluno possa estabelecer relações entre números naturais tais como ser múltiplo de, ser divisor de e reconhecer números primos e números compostos, temos que a probabilidade de acerto destes alunos frente a uma questão simples, estruturante (Etapa 1), é de

\footnotetext{
${ }^{1}$ Sigla AAP. Avaliação aplicada em 3 edições anuais em todos os anos/série.
} 


\begin{tabular}{|c|c|c|c|}
\hline Nível & Série/Ano & Conteúdo & Habilidades \\
\hline $\begin{array}{l}\text { Ensino Fun- } \\
\text { damental }\end{array}$ & $5^{a} / 6^{\circ}$ & Números naturais & $\begin{array}{l}\text { Conhecer as características e propriedades dos } \\
\text { números naturais: significado dos números } \\
\text { primos, de múltiplos e de divisores; Saber rea- } \\
\text { lizar operações com números naturais de modo } \\
\text { significativo (adição, subtração, multiplicação, } \\
\text { divisão e potenciação) }\end{array}$ \\
\hline $\begin{array}{l}\text { Ensino Fun- } \\
\text { damental }\end{array}$ & $8^{a} / 9^{\circ}$ & Probabilidade & $\begin{array}{l}\text { Saber resolver problemas envolvendo proces- } \\
\text { sos de contagem - princípio multiplicativo; Sa- } \\
\text { ber resolver problemas que envolvam ideias } \\
\text { simples sobre probabilidade. }\end{array}$ \\
\hline $\begin{array}{l}\text { Ensino Mé- } \\
\text { dio }\end{array}$ & & $\begin{array}{l}\text { Análise combina- } \\
\text { tória e probabili- } \\
\text { dade }\end{array}$ & $\begin{array}{l}\text { Compreender os raciocínios combinatórios } \\
\text { aditivo e multiplicativo na resolução de } \\
\text { situações-problema de contagem indireta do } \\
\text { número de possibilidades de ocorrência de um } \\
\text { evento; Saber calcular probabilidades de even- } \\
\text { tos em diferentes situações-problema, recor- } \\
\text { rendo a raciocínios combinatórios gerais, sem } \\
\text { a necessidade de aplicação de fórmulas espe- } \\
\text { cíficas; }\end{array}$ \\
\hline
\end{tabular}

TABEla 1. Indicação do jogo Resto Zero de acordo a série/ano.

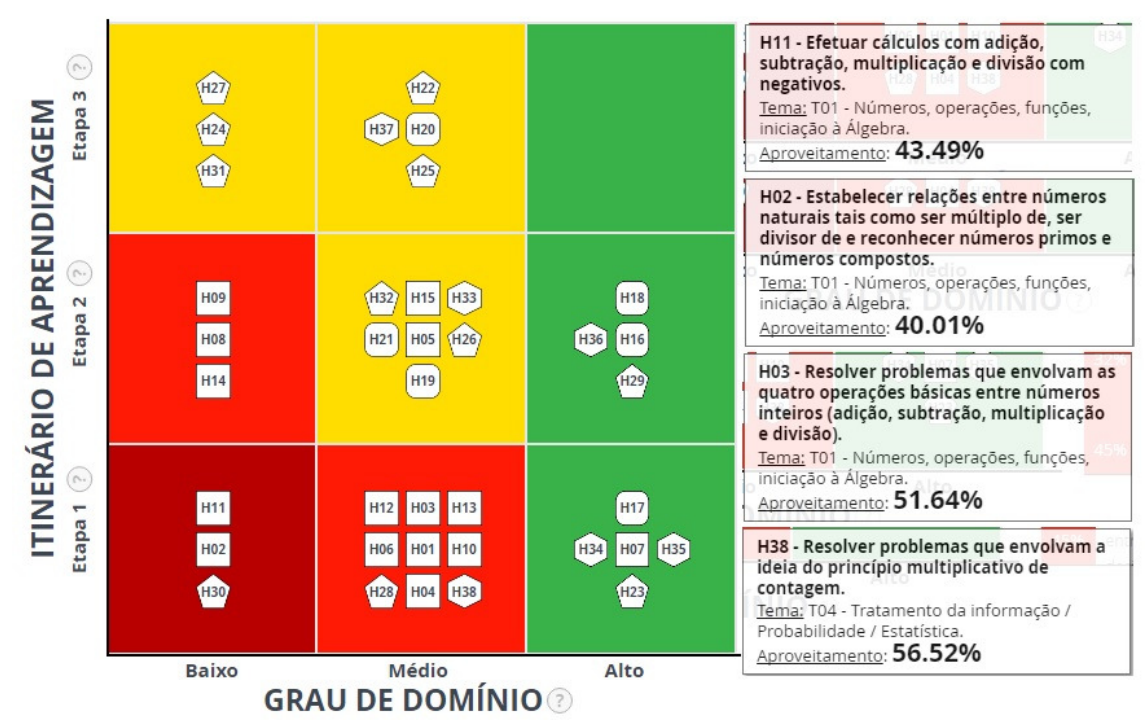

FIGURA 1. Probabilidade de acertos nas habilidades propostas ao $7^{\circ}$ ano do Ensino Fundamental

40,01\% na Diretoria de Ensino de Franca. Isso indica claramente que estes alunos precisam de apoio em suas aprendizagens, de forma a deixarem de terem um desenvolvimento baixo desta habilidade e passarem pelo desenvolvimento médio até alcaçarem um desenvolvimento alto da mesma. Para tanto, novas estratégias de ensino devem ser criadas e aplicadas objetivando uma melhor aprendizagem.

As figuras 2 e 3 nos mostram o desenvolvimento das habilidades dos alunos de forma análoga à figura 1. Contudo a primeira faz referência ao $9^{\circ}$ ano do EF e a segunda à $3^{a}$ série do EM. 


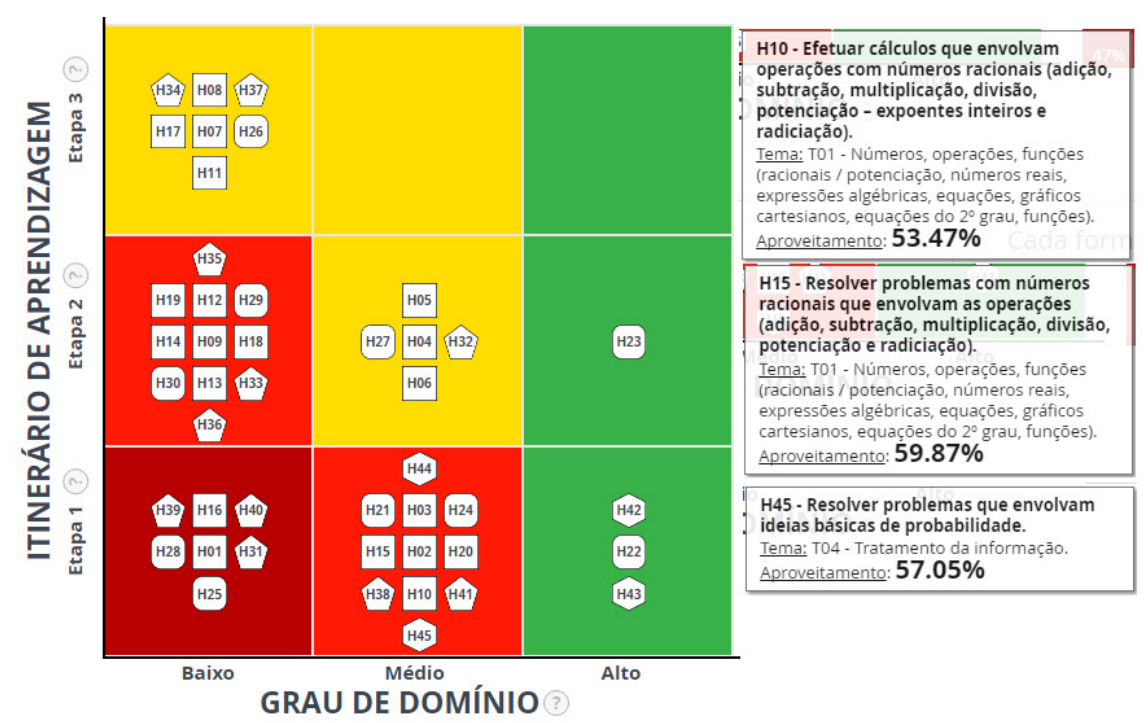

FIGURA 2. Probabilidade de acertos nas habilidades propostas ao $9^{\circ}$ ano do Ensino Fundamental

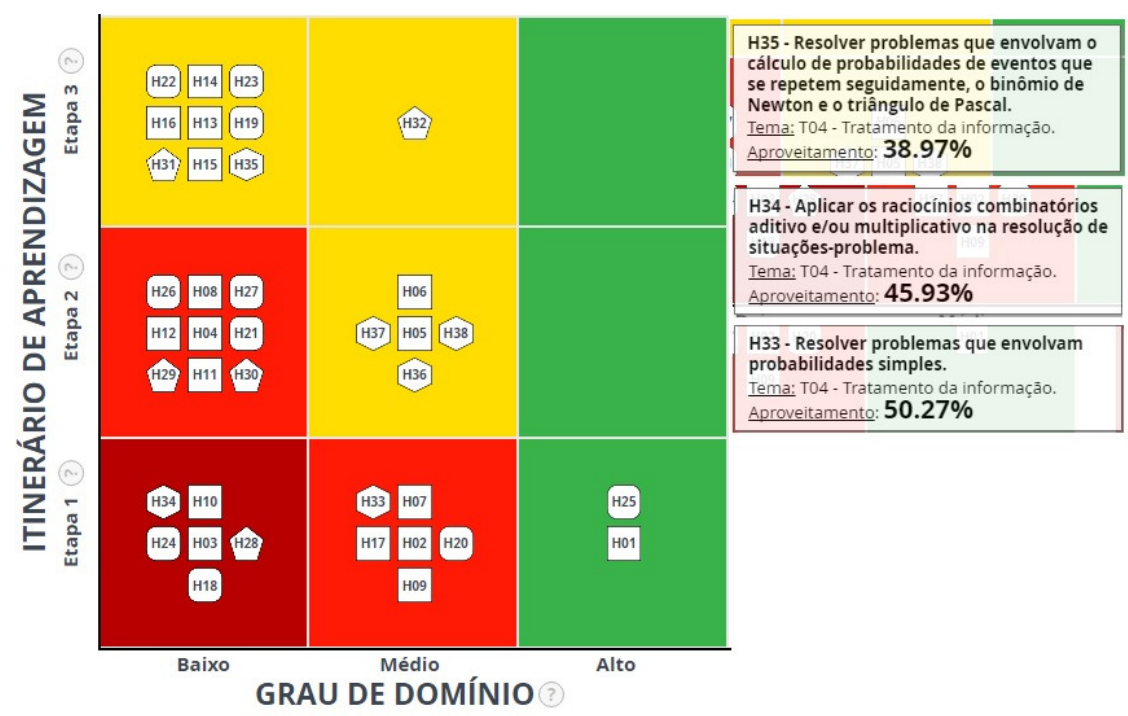

Figura 3. Probabilidade de acertos nas habilidades propostas à $3^{a}$ série do Ensino Médio

Importante ressaltar que as habilidades estão divididas em três etapas: estruturantes, de consolidação e de aprofundamento, e que elas nunca mudam de etapa.

A avaliação Saresp é aplicada apenas nos anos/séries citados, mas avaliam habilidades também de anos anteriores.

\section{Breve história da probabilidade}

Sabemos não ser de hoje, da contemporaneidade, a relação entre jogos, jogadores e a Matemática. Movidos pela curiosidade e vontade de vencer sem precisar contar com a sorte muitos jogadores e matemáticos se prontificaram à estudar melhor os números almejando vitória certa. Com problemas voltados ou não aos jogos de azar uma nova teoria foi se desenvolvendo. Exemplo 
disto é Girolamo Cardano, italiano de Pávia, nascido em 1501. Era conhecido por seu gênio e muitas vezes interpretado como perverso. Foi médico, astrônomo, físico e matemático. Seu trabalho mais evidente foi Ars Magna, tratado em latim dedicado à álgebra. Eves, 2005, relata que por se tratar de um 'jogador inveterado, Cardano escreveu um manual do jogador em que abordou algumas questões interessantes de probabilidade' denominado Liber de ludo aleae.

Neste mesmo sentido, pensando em resolver problemas voltados à divisão de apostas e outros assuntos do gênero, correspodências foram trocadas em 1654 entre Pascal e Fermat e desse material pode-se tirar os fundamentos da teoria matemática da probabilidade. O principal problema sobre divisão de apostas ficou conhecido como o problema dos pontos. Dentre as publicações de Pascal, podemos citar Traité du Triangle Aritmétique. Em relação às publicações de Fermat, evidenciamos sua colaboração aos variados ramos da Matemática de forma a ser considerado o maior matemático francês do século XVII, além de toda história envolvendo o último teorema de Fermat. Fermat, na margem de seu exemplar da Aritmética de Diofanto, anunciou que 'Dividir um cubo em dois cubos, uma quarta potência ou, em geral uma potência qualquer em duas potências da mesma denominação acima da segunda é impossível e garante ter uma prova admirável para ela, mas diz não a escrever ali mesmo devido ao fato de o espaço, segundo ele, ser demasiadamente pequeno.

O holandês Christiaan Huygens publicou em 1657 bom material relacionado as correnpondências entre Pascal e Fermat, onde também tratou de um novo conceito chamado de "esperança matemática". Entre outros trabalhos, publicou De ratiociniis in ludo aleae, contudo a maior de suas publicações foi Horolagium oscillatorium.

Em 1713, postumamente, foi publicada Ars Conjectandi do suíço Jakob Bernoulli que continha reimpresso o tratado de Christiaan Huygens e mais material desenvolvido.

O francês Abraham De Moivre (1667-1754) também contribuiu de forma significativa sobre probabilidade. Entre seus trabalhos, Doctrine of Chances contém muito sobre probabilidade.

Outros matemáticos também contribuíram direta e indiretamente sobre probabilidade. Os coeficientes binomiais de Newton, por exemplo, são ferramentas muitas vezes indispensáveis no cálculo de probabilidades.

Uma matemática aparentemente improvável de ser desenvolvida cada dia mais auxilia a humanidade.

\section{Sobre o jogo Resto Zero}

A seguir definiremos todas as características, convenções e pontuação do jogo Resto Zero, as quais entendemos ser a melhor opção para o desenvolvimento do mesmo no cotidiano escolar.

O leitor tem autonomia de fazer adaptações adequadas a realidade da sua escola e de seu público alvo sempre que estas modificações visem a melhoria da aprendizagem.

4.1. Características. Trata-se de uma jogo de cartas desenvolvido com uma baralho convencional de 52 cartas. De maneira lúdica, auxilia o aluno no desenvolvimento de seu raciocínio lógico. Competências e habilidades referentes às operações básicas, critérios de divisibilidade, análise combinatória e probabilidade podem ser desenvolvidas a partir da utilização adequada do jogo Resto Zero. Auxilia também no desenvolvimento das competências e habilidades necessárias para o domínio dos critérios de divisibilidade.

Outro aspecto importante é poder ser oferecido aos alunos de todas as séries, com ou sem adaptações, uma vez que se identifique defasagem das habilidades e competências citadas acima. Verificando domínio pleno das operações e dos critérios de divisibilidade, o professor pode utilizálo como ferramenta de aprofundamento. Pode, por exemplo, discutir com os alunos e criar uma convenção que iniba o uso de determinadas operações. Pode também motivar o uso específico de uma, a potenciação, por exemplo.

A partir do $9^{\circ}$ ano, o jogo oferece a oportunidade de se trabalhar a probabilidade e análise combinatória, adentrando assim em assuntos do ensino médio. 
Por se tratar de baralho, instrumento amplamente conhecido em nosso país, o jogo Resto Zero dispensa a confecção de material para sua aplicação.

Uma de suas principais características é a facilidade de seu uso ser facilmente adaptado ao tempo. Uma vez que os alunos tenham ciência de sua utilização, pode ser facilmente aplicado em uma aula de 50 minutos.

4.2. Convenções. Poderíamos chamar de regras o que aqui denominamos convenções, contudo corremos o risco de que, frente a um impasse ou situação inusitada, os jogadores sintam-se desestimulados. Desta forma pode-se criar convenção adequada ao momento ou mesmo à realidade local.

Estipular o que pode e o que não pode ser feito é de suma importância para o desenvolvimento do jogo e também para o desenvolvimento do jogador. Neste instante o jogador se vê obrigado a respeitar o outro, entendendo que cada um tem seu espaço e que ele próprio também pode e deve ser respeitado. Um nivelamento dos direitos e deveres dos personagens é evidenciado pelas regras e convenções. Visto isso, a socialização cria raízes e o papel humano dos jogos se estabelece. Não há problema em discutir as convenções, pois o ambiente é lúdico, desde que os alunos cheguem a um consenso.

A priori estas são as convenções iniciais:

(1) A mesa pode ser constituída de 2 a 6 jogadores;

(2) Um jogador por rodada embaralha e distribui as cartas, iniciando a distribuição pelo jogador imediatamente a sua direita;

(3) Cada jogador recebe três cartas, inclusive o jogador que as distribuiu, o que dispensa um jogador coordenador;

(4) Após os jogadores terem recebido suas cartas, três cartas entre as restantes são viradas na mesa;

(5) O próximo jogador, imediatamente a direta, deve considerar as cartas que estão em suas mãos como sendo divisores num processo de divisão e as cartas que estão expostas a mesa como sendo dividendos do mesmo processo;

(6) O jogador deve dividir uma carta da mesa por uma das cartas de sua mão ou uma combinação qualquer entre duas cartas da mesa (adição, subtração, multiplicação e divisão) por uma única carta presente em suas mãos;

(7) A divisão entre a carta (ou combinação da mesa) pela carta em posse do jogador deve ser exata, sendo assim de quociente inteiro e apresentando resto zero ${ }^{2}$;

(8) Alcançando o previsto no ítem imediatamente anterior, o jogador diz a todos a operação feita e guarda todas as cartas envolvidas no processo para serem computados pontos a seu favor ao final da rodada;

(9) Sempre que uma ou mais cartas da mesa forem utilizadas deve haver reposição, pois todos os jogadores devem ter disponíveis três cartas em sua vez de jogar;

(10) Os demais jogadores são responsáveis por verificar se os resultados estão corretos;

(11) Passa-se a vez ao próximo jogador, repetindo-se o processo até que um dos jogadores fique sem nenhuma carta em mãos, situação conhecida como 'bate', ou quando acaba o baralho da mesa;

(12) Não se pode combinar três cartas da mesa para se obter um divisor favorável;

(13) Uma vez que o jogador não consegue realizar a divisão ou a faz de maneira incorreta, deve 'comprar' uma carta das que restam ${ }^{3}$, aumentando as cartas em suas mãos e passando a vez ao próximo jogador.

\footnotetext{
${ }^{2}$ Fica a critério dos participantes poder realizar divisões cujo quociente seja um número racional qualquer.

${ }^{3}$ Cartas que não foram distribuídas aos jogadores e também não foram utilizadas na mesa. Portanto, estão agrupadas em um único monte.
} 
4.3. A pontuação. Ao fim do jogo os pontos deverão ser computados para verificar o vencedor da rodada e, caso continuem jogando, verificar de forma parcial quem está vencendo o jogo.

A forma de calcular os pontos preza um equilíbrio para que nenhum jogador possa consagrar-se campeão já nas primeiras rodadas. Neste sentido estipulamos:

(1) Para a contagem dos pontos devem ser considerados os valores absolutos de cada carta ${ }^{4}$;

(2) O somatório dos pontos referentes às cartas que ficaram na mão de um jogador após a batida assumem valores negativos enquanto que o somatório dos pontos referentes às cartas conquistadas pelos jogadores ao longo da rodada assumem valores positivos, calculando entre ambos somatórios o saldo resultante;

(3) Cada jogador verifica seu saldo, que consiste em subtrair da pontuação conquistada (positiva) a pontuação acumulada em mãos (negativa);

(4) O jogador que finalizar a rodada por meio do 'bate' ganha 10 pontos extras;

(5) Caso os membros queiram continuar jogando, anotam os pontos em uma folha para fazer uma pontuação acumulada ao final.

Os jogadores podem conferir seus próprios pontos ou trocar as cartas para que outro faça a contagem. Poderá ocorrer saldo negativo. Isso geralmente acontece quando o jogador acumula muitas cartas em suas mãos e conquista em suas jogadas cartas cujo valor é baixo. Marcar pontos negativos ou simplesmente colocar ' 0 pontos' mostrando que o jogador não alcançou pontos positivos fica a critério do professor e dos alunos. Este é um momento oportuno de se criar uma convenção. Marcar um resultado negativo inicialmente pode desestimular aquele jogador que ainda tem muitas dificuldades tanto com as operações a serem realizadas quanto com as convenções. Recomendamos que inicialmente, até que todos se familiarizem com o jogo, que se houver saldo negativo este seja substituído por ' 0 pontos'. Já estando os jogadores habituados, inicia-se a marcação de saldos negativos.

\footnotetext{
${ }^{4}$ Às, $J, Q, K$, valem 1, 11, 12 e 13 pontos, respectivamente.
} 



\section{CAPíTULO 2}

\section{Probabilidade no jogo Resto Zero}

Neste capítulo consideramos vários eventos relativamente simples associados ao jogo Resto Zero. O principal objetivo é motivar o estudo da combinatória enumerativa e da teoria de probabilidade elementar utilizando várias situações que ocorrem no jogo. Alguns dos pré-requisitos necessários são apresentados no apêndice. A maior parte deste material pode ser desenvolvido nos últimos anos do Ensino Médio uma vez que sejam revisadas as noções básicas de combinação e probabilidade.

\section{Duas questões associadas ao Resto Zero}

A primeira parte deste capítulo está direcionada ao estudo do seguinte problema,

Qual é a probabilidade de que uma carta em posse do jogador divida uma carta da mesa?

Mesmo simples, esta pergunta permite definir um espaço de probabilidade apropriado assim como alguns eventos e a notação inicial a ser utilizada. Em seguida, será considerada uma segunda questão também relacionada diretamente ao Resto Zero,

Qual é a probabilidade de que uma carta em posse do jogador divida a soma de quaisquer duas cartas da mesa?

Faremos referência a questão em $Q_{1}$ como o problema de 'Divisão simples' e a questão em $Q_{2}$ como o problema da 'Divisão composta pela soma'.

\section{Espaço amostral}

O espaço amostral ao relativo jogo do Resto Zero, do ponto de vista de um único jogador, é o conjunto $\Omega$ formado pelas amostras não ordenadas e sem reposição de 6 cartas escolhidas ao acaso de um baralho comum de 52 cartas. Embora as amostras sejam não ordenadas devemos distinguir as três cartas que estão em posse do jogador das três cartas que estão sobre a mesa. Denotamos por $\mathscr{H}$ e $\mathscr{D}$ os conjuntos formados pelas cartas do jogador e pelas cartas da mesa, respectivamente. Formalmente, o espaço amostral corresponde ao conjunto

$$
\Omega=\left\{\left(\left\{\omega_{1}, \omega_{2}, \omega_{3}\right\},\left\{\omega_{4}, \omega_{5}, \omega_{6}\right\}\right): \omega_{1}, \omega_{2}, \omega_{3} \in \mathcal{H} ; \omega_{4}, \omega_{5}, \omega_{6} \in \mathscr{D}\right\} .
$$

Utilizando o princípio fundamental da contagem é simples verificarmos que a cardinalidade de $\Omega$ é de fato

$$
\#(\Omega)=\left(\begin{array}{c}
52 \\
3
\end{array}\right)\left(\begin{array}{c}
49 \\
3
\end{array}\right)=407170400 .
$$

\section{O problema da divisão simples}

3.1. Eventos. Para respondermos a questão $Q_{1}$ tomamos a liberdade de criar um simbologia de fácil compreensão. Denotamos por $q$ o valor da carta objeto de estudo que sempre deverá ser visto como um divisor. Os losangos abertos $\diamond$ representam os valores das cartas divisíveis por $q$ mas diferentes desta última, e os círculos abertos $\circ$ representam as cartas divisíveis, inclusive aquelas com valor $q$. Finalmente, o símbolo $x$ representa o valor das cartas não divisíveis pela carta em 
estudo $q$. De acordo com a notação usual, denotamos por $\omega_{i} \mid \omega_{j}$ a situação onde o valor da carta $\omega_{i}$ divide o valor da carta $\omega_{j}$ e $\omega_{i} \nmid \omega_{j}$ quando $\omega_{i}$ não divide $\omega_{j}$. Reservamos os indices $i, j, k$ para cartas em $\mathscr{H}$ e os indices $l, m, n$ para cartas em $\mathscr{D}$. Representamos um evento qualquer formado pelas três cartas do jogador e as três cartas na mesa utilizando a notação $\omega_{i} \omega_{j} \omega_{k} \omega_{l} \omega_{m} \omega_{n}$. Para exemplificar, citaremos três eventos, explicando-os.

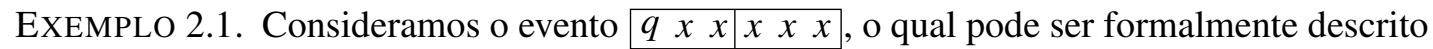
segundo a notação para os elementos do espaço amostral como $\exists i: \omega_{i} \nmid \mathscr{H} \backslash\left\{\omega_{i}\right\} ; \omega_{i} \nmid \mathscr{D}$. Ou seja, dentre as cartas em posse do jogador, existe uma carta com valor $q$, a qual não divide nenhuma outra carta da mão ou mesmo uma carta qualquer da mesa. A Figura 4 apresenta um evento elementar, ou realização, do evento \begin{tabular}{|lll|lll}
$q$ & $x$ & $x$ & $x$ & $x$ & $x$
\end{tabular} .
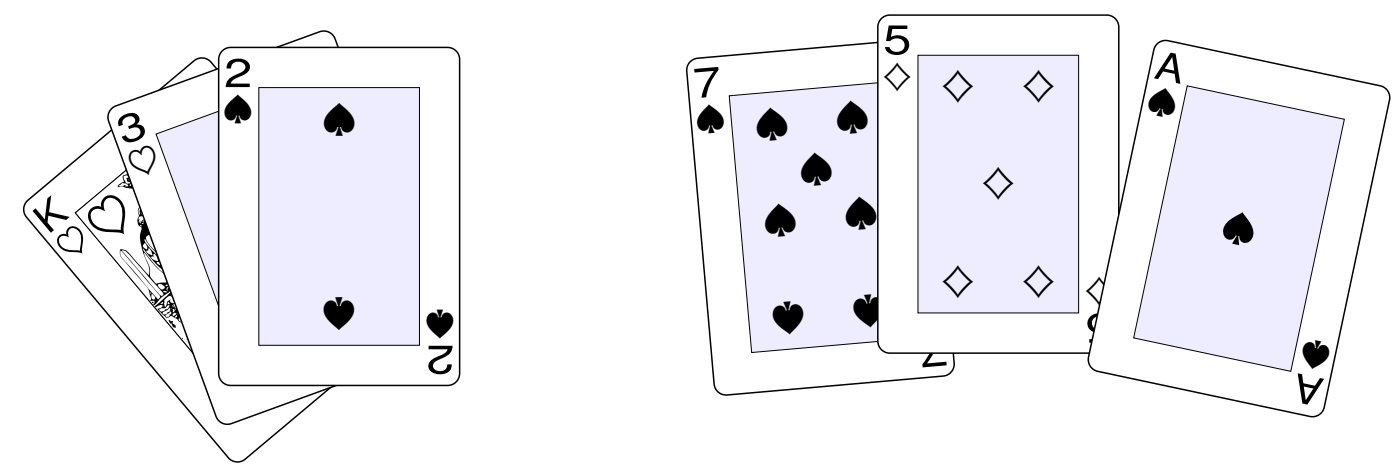

Figura 4. Uma realização do evento para o Exemplo $2.1 \operatorname{com} q=2$. As três cartas em posse do jogador são apresentadas à esquerda.

EXEMPLO 2.2. Consideramos agora o evento

$$
q \diamond x \times x \times \text {, isto é } \quad \exists i, j, k: \omega_{i} \mid \omega_{j} ; \omega_{i} \nmid \omega_{k} ; \omega_{i} \nmid \mathscr{D} \text {. }
$$

Neste caso o conjunto $\mathscr{H}$ apresenta uma carta $\diamond$ que é múltiplo da carta $q$ (também em $\mathscr{H}$ ) e uma outra carta $x$ que não é múltiplo de $q$. Por outro lado, a carta $q$ não divide nenhuma das cartas da mesa.

EXEMPLO 2.3. Seja o evento

$$
q q \diamond\left|\circ \circ x \quad \exists i, j, k, l, m, n: \omega_{i}=\omega_{j} ; \omega_{i}\right| \omega_{k} ; \omega_{i} \mid\left\{\omega_{l}, \omega_{m}\right\} ; \omega_{i} \nmid \omega_{n} .
$$

Aqui o jogador possui duas cartas com o mesmo valor $q$ e uma terceira carta cujo valor é múltiplo das duas primeiras, $\diamond$. As cartas $q$ também dividem outras duas cartas $\circ$ da mesa, porém não dividem a terceira carta da mesa $x$. Relembramos aqui que $\circ$ representa todos os múltiplos de $q$. Já $\diamond$ refere-se apenas aos múltiplos de $q$ diferentes deste. Vale ressaltar que as duas cartas em $\mathscr{D}$ citadas como múltiplas não são necessariamente iguais entre si.

Está implícito na notação definida que a ocorrência do símbolo $q$ se refere a qualquer um dos valores dentre $1,2, \ldots, 13$. Desta maneira, por exemplo,

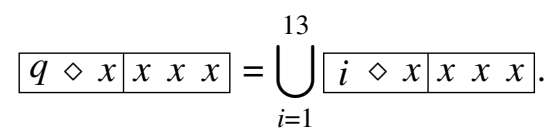


Esta observação torna-se importante aos efeitos dos cálculos de probabilidade a serem considerados adiante.

EXEMPLO 2.4. Para uma exemplificação ainda mais particular, escolhemos o evento

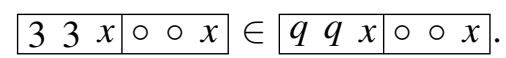

O conjunto dos múltiplos de 3 , representados por o é formado pelas cartas $3 \mathbf{p}, 3 \mathbf{\phi}, 3 \diamond, 3 \diamond, 6 \mathbf{q}$,

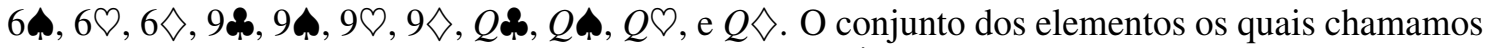
de $x$, é formado pelas demais cartas do baralho, $x \in\{$ Às, $2,4,5,7,8,10, J, K\}$, com cada valor aparecendo 4 vezes devido aos naipes. Desta maneira o evento \begin{tabular}{|c|c|c|c|}
$q q x$ & $\circ$ & $\circ$ & está constituído por
\end{tabular}

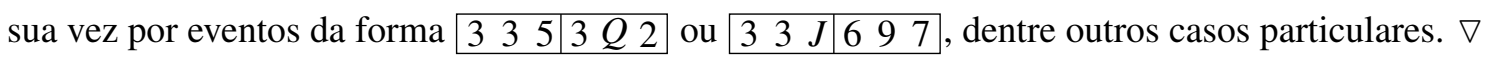

\section{Probabilidade das divisões simples}

Descrevemos, um a um, os eventos existentes levando em consideração uma divisão entre uma única carta da mesa por uma carta de posse do jogador. Temos no apêndice, parte entitulada por 'Eventos para a divisão simples' 24 destes eventos, denotados $E_{1}-E_{24}$. Mostraremos agora que a probabilidade de cada um destes eventos pode ser calculada com o auxílio de uma fórmula. Com o propósito de motivar o desenvolvimento da mesma, apresentamos primeiramente alguns exemplos.

EXEMPLO 2.5. Apresentamos primeiro o cálculo para a probabilidade de evento $E_{7}$, da forma $q \diamond x \circ \circ$ para $q=2$, isto é, quando o divisor em questão $q$ é uma carta com valor 2 . A Figura 5 apresenta um evento elementar deste tipo.
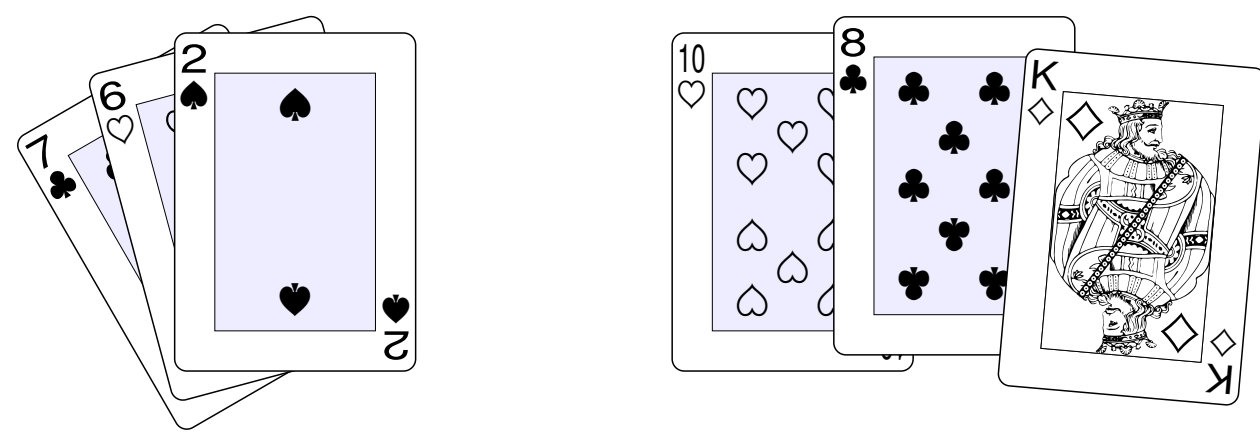

FIGURA 5. Uma realização do evento $E_{7} \operatorname{com} q=2$. A três cartas do jogador são apresentadas à esquerda.

A probabilidade do evento $2 \diamond x \mid \circ \circ x$ é

$$
\begin{aligned}
\mathbb{P}\{2 \diamond x \mid \circ \circ x\} & =\frac{\left(\begin{array}{c}
4 \\
1
\end{array}\right)\left(\begin{array}{c}
24-4 \\
1
\end{array}\right)\left(\begin{array}{c}
28 \\
1
\end{array}\right)\left(\begin{array}{c}
24-(1+1) \\
2
\end{array}\right)\left(\begin{array}{c}
28-1 \\
1
\end{array}\right)}{\left(\begin{array}{c}
52 \\
3
\end{array}\right)\left(\begin{array}{c}
49 \\
3
\end{array}\right)} \\
& =\frac{4 \cdot 20 \cdot 28 \cdot 231 \cdot 27}{407170400}=0,03431212 .
\end{aligned}
$$


A escolha da carta com valor 2 pode ser realizada de $\left(\begin{array}{l}4 \\ 1\end{array}\right)$ maneiras, pois isto envolve a escolha de um dos quatro possíveis naipes com este valor. A expressão $\left(\begin{array}{c}24-4 \\ 1\end{array}\right)$ representa o número de maneiras de escolhermos a carta $\omega_{j}$ como sendo uma carta que é múltiplo de 2, porém diferente do próprio 2 , ou seja do tipo $\diamond$. Observamos que o baralho possui 24 cartas cujo valor é múltiplo de 2 . De

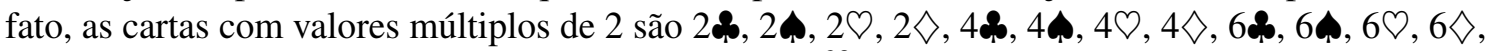
$10 \boldsymbol{\$}, 10 \boldsymbol{\wedge}, 10 \diamond, 10 \diamond$, e $Q \boldsymbol{\$}, Q \boldsymbol{\wedge}, Q \triangleright, Q \diamond$. O fator $\left(\begin{array}{c}28 \\ 1\end{array}\right)$ corresponde ao número de maneiras de escolhermos a carta $\omega_{k}$ com valor não múltiplo de 2 , isto é a escolha da carta do tipo $x$ em posse do jogador. Claramente temos 52 - $24=28$ cartas que não são múltiplos de 2 . O fator $\left(\begin{array}{c}24-(1+1) \\ 2\end{array}\right)$ corresponde ao número de maneiras de escolhermos as duas cartas, múltiplos de 2 , na mesa. Como vimos, poderíamos contar com 24 cartas de valor múltiplo de 2 , porém deste conjunto já foram retirados dois elementos em posse do jogador: a própria carta com valor 2 e a carta divisível, esta diferente de dois. $\mathrm{O}$ fator $\left(\begin{array}{c}28-1 \\ 1\end{array}\right)$ determina o número de maneiras de escolhermos a carta da mesa não múltiplo de 2: temos 28 possibilidades, porém já eliminamos uma destas ao escolher a carta do tipo $x$ em posse do jogador.

Para determinar a probabilidade do evento $E_{7}$, observamos que este é constituído pela união disjunta de eventos da forma $q \diamond x \circ \circ x$, com $q \in\{1,2, \ldots, 13\}$. Assim, da aditividade da função de probabilidade

$$
\mathbb{P}\left\{E_{7}\right\}=\mathbb{P}\left(\bigcup_{q=1}^{13} q \diamond x \circ \circ x\right)=\sum_{q=1}^{13} \mathbb{P}\left\{\begin{array}{|l|l|l|l|}
q \diamond x & \circ \circ x
\end{array}\right\}
$$

Seja $N_{q}$ o número de cartas no baralho que são múltiplos da carta com valor $q$. Os valores para $N_{q}$ em um baralho comum são apresentados na Tabela 2, sendo $N_{1}=N_{\text {ás. }}$ Observamos que estes valores contam inclusive as cartas distinguindo os seus naipes. Das fórmulas em (1) e (2) obtemos

$$
\begin{aligned}
\mathbb{P}\left\{E_{7}\right\} & =\frac{1}{\#(\Omega)} \sum_{q=1}^{13}\left(\begin{array}{l}
4 \\
1
\end{array}\right)\left(\begin{array}{c}
N_{q}-4 \\
1
\end{array}\right)\left(\begin{array}{c}
52-N_{q} \\
1
\end{array}\right)\left(\begin{array}{c}
N_{q}-2 \\
2
\end{array}\right)\left(\begin{array}{c}
52-N_{q}-1 \\
1
\end{array}\right) \\
& =\frac{102}{\#(\Omega)} \sum_{q=1}^{13}\left(52-N_{q}\right)\left(N_{q}-4\right)\left(N_{q}-3\right)\left(N_{q}-2\right)
\end{aligned}
$$

Ao substituirmos os valores para $N_{q}$ apresentados na Tabela 2 finalmente resulta

$$
\begin{array}{c|ccccccccccccc}
\multicolumn{10}{c}{\mathbb{P}\left\{E_{7}\right\}=\frac{70632}{748475} \approx 0,0943679 .} \\
q & 1 & 2 & 3 & 4 & 5 & 6 & 7 & 8 & 9 & 10 & 11 & 12 & 13 \\
N_{q} & 52 & 24 & 16 & 12 & 8 & 8 & 4 & 4 & 4 & 4 & 4 & 4 & 4 \\
& & \\
\text { TABELA } & 2 . & \text { Valores para } N_{q}
\end{array}
$$

EXEMPLO 2.6. Passamos agora para uma segunda situação onde o divisor $q$ em questão aparece em duplicidade em $\omega_{1}, \omega_{2}$ e $\omega_{3}$, e em $\omega_{4}, \omega_{5}$ e $\omega_{6}$ surgem dois múltiplos do mesmo. Trata-se do evento $E_{15}$, da forma \begin{tabular}{l}
$q q x$ \\
\hline a
\end{tabular}

na Figura 6. A probabilidade do evento $55 x \circ \circ \circ x$ é calculada de forma análoga ao descrito no exemplo anterior. Agora, o resultado é o seguinte

$$
\mathbb{P}\left\{\begin{array}{cc|c|c|c}
55 & x & \circ & \circ & x
\end{array}\right\}=\frac{\left(\begin{array}{l}
4 \\
2
\end{array}\right)\left(\begin{array}{c}
52-8 \\
1
\end{array}\right)\left(\begin{array}{c}
8-2 \\
2
\end{array}\right)\left(\begin{array}{c}
52-8-1 \\
1
\end{array}\right)}{\left(\begin{array}{c}
52 \\
3
\end{array}\right)\left(\begin{array}{c}
49 \\
3
\end{array}\right)}
$$



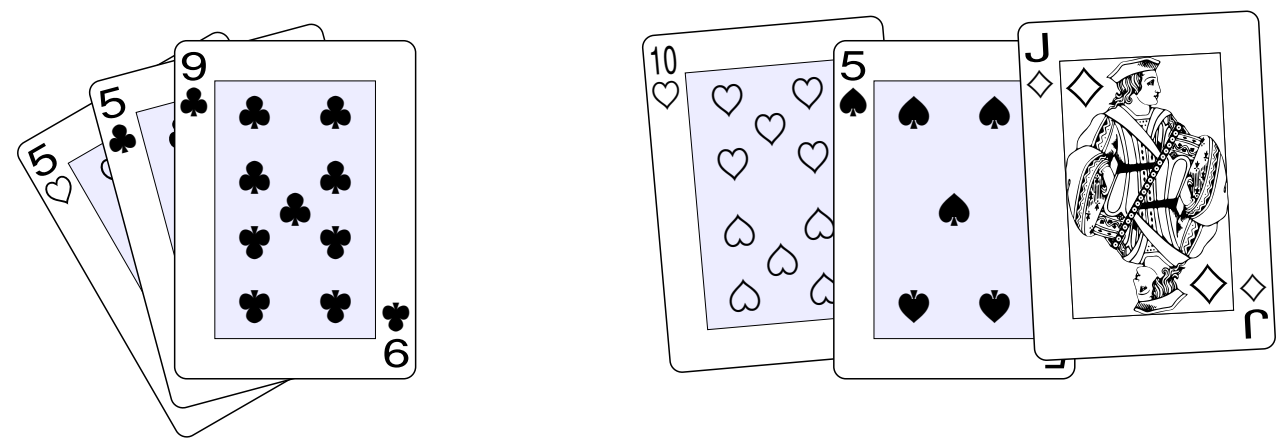

FIGURA 6. Uma realização do evento $E_{15} \operatorname{com} q=5$. As cartas em posse do jogador são apresentadas à esquerda.

$$
=\frac{6 \cdot 44 \cdot 15 \cdot 43}{407170400}=0,000418203 .
$$

O fator $\left(\begin{array}{l}4 \\ 2\end{array}\right)$ determina o número de maneiras de escolhermos dois naipes de valor 5 . $\left(\begin{array}{c}52-8 \\ 1\end{array}\right)$ corresponde ao número de maneiras de escolhermos a carta $x$ em posse do jogador. Para isto é suficiente observar que o número de cartas com valores múltiplos de $5, N_{5}$, é 8 . Estas últimas

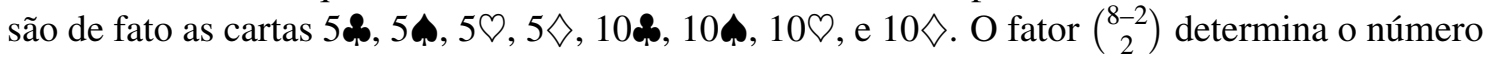
de maneiras de escolhermos as duas cartas da mesa que são múltiplos do número 5. Dentre as 8 possibilidades devemos retirar duas, correspondentes as duas cartas com valor $5 \mathrm{em}$ posse do jogador. Por último, $\left(\begin{array}{c}52-8-1 \\ 1\end{array}\right)$ determina o número de maneiras de escolhermos a última carta da mesa, com valor não múltiplo de 5 . No total temos 52-8 possíveis valores, porém é necessário retirar a carta deste tipo em posse do jogador.

Para o evento $E_{15}$ temos, portanto,

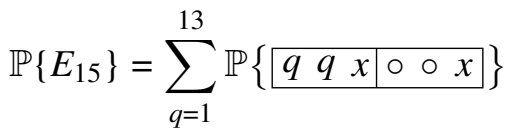

$$
\begin{aligned}
& =\frac{1}{\#(\Omega)} \sum_{q=1}^{13}\left(\begin{array}{l}
4 \\
2
\end{array}\right)\left(\begin{array}{c}
52-N_{q} \\
1
\end{array}\right)\left(\begin{array}{c}
N_{q}-2 \\
2
\end{array}\right)\left(\begin{array}{c}
52-N_{q}-1 \\
1
\end{array}\right) \\
& =\frac{3}{\#(\Omega)} \sum_{q=1}^{13}\left(52-N_{q}\right)\left(51-N_{q}\right)\left(N_{q}-3\right)\left(N_{q}-2\right)
\end{aligned}
$$

Fazendo as devidas substituições para os valores de $N_{q}$ fornecidos pela Tabela 2 obtemos

$$
\mathbb{P}\left\{E_{15}\right\}=\frac{81009}{12724075}=0,00636659 \text {. }
$$

É possível generalizarmos os cálculos descritos nos exemplos 2.5 e 2.6 para qualquer um dos eventos em $E_{1}-E_{24}$. Apresentamos a seguir uma fórmula geral para a cardinalidade de qualquer um destes eventos. Para tanto, continuaremos especificando o divisor como $q$, seus múltiplos como $\circ$, os não mútiplos como $x$. Também é importante observar que em determinados momentos, para efeito de cáculo, um número não poderá ser considerado múltiplo de si mesmo e para isto usaremos a notação $\diamond$. Desta maneira, estamos considerando todos os múltiplos descartando o divisor $q$. Isso ocorrerá sempre em $\omega_{1}, \omega_{2}$ e $\omega_{3}$, onde as cartas $q$ são as primeiras a serem especificadas. 
Assim, quando for preciso especificar as demais cartas, ou seja, os demais múltiplos, temos que não considerá-las.

Para as três cartas $\omega_{1}, \omega_{2}$ e $\omega_{3}$ que estão na mão do jogador introduzimos a seguinte notação. Seja $q$ o valor da carta $\omega_{i}$, logo sejam

$D_{\mathscr{H}}^{q}$ : quantidade de divisores do valor da carta $q$ dentre $\omega_{j}, \omega_{k}$,

$M_{\mathcal{H}}^{\diamond}$ : quantidade de múltiplos do tipo $\diamond$ dentre $\omega_{j}, \omega_{k}$,

$M_{\mathcal{H}}^{x}$ : quantidade de não múltiplos $x$ dentre $\omega_{j}, \omega_{k}$.

Para as três cartas $\omega_{4}, \omega_{5}$ e $\omega_{6}$ viradas sobre a mesa definimos de maneira análoga as seguintes quantidades. Sejam

$M_{\triangleright}^{\circ}$ : quantidade de cartas múltiplas $\circ$ dentre $\omega_{4}, \omega_{5}$ e $\omega_{6}$ incluindo o próprio divisor em estudo $q$,

$M_{D}^{x}$ : quantidade de cartas não múltiplas de $q$ dentre $\omega_{4}, \omega_{5}$ e $\omega_{6}$,

E pensando no baralho como um todo, denotado por $\mathscr{B}$, definimos

$D_{\mathscr{B}}^{q}$ : todas as cartas divisores $q$,

$M_{\mathscr{B}}^{\circ}$ : todos os múltiplos o de $q$, incluindo-os,

$M_{\mathscr{B}}^{x}$ : todos os não múltiplos $x$ de $q$.

PROPOSIÇão 2.7. Dado um valor para $q \in\{1, \ldots, 13\}$, a cardinalidade de qualquer um dos eventos em $E_{1}-E_{24}$ é dada pela expressão

$$
\left(\begin{array}{c}
D_{\mathscr{B}}^{q} \\
D_{\mathcal{H}}^{q}
\end{array}\right)\left(\begin{array}{c}
M_{\mathscr{B}}^{\circ}-D_{\mathscr{B}}^{q} \\
M_{\mathcal{H}}^{\diamond}
\end{array}\right)\left(\begin{array}{c}
M_{\mathcal{B}}^{x} \\
M_{\mathcal{H}}^{x}
\end{array}\right)\left(\begin{array}{c}
M_{\mathscr{B}}^{\circ}-\left(D_{\mathcal{H}}^{q}+M_{\mathcal{H}}^{\diamond}\right) \\
M_{\mathscr{D}}^{\circ}
\end{array}\right)\left(\begin{array}{c}
M_{\mathcal{B}}^{x}-M_{\mathcal{H}}^{x} \\
M_{\mathscr{D}}^{x}
\end{array}\right) .
$$

A Proposição 2.7 permite calcular a probabilidade do evento relativo à questão $\left(Q_{1}\right)$.

TEOREMA 2.8. $\mathbb{P}\left\{Q_{1}\right\} \geq 0,682536$.

Demonstração. Para calcularmos a probabilidade de que uma carta em posse do jogador divida pelo menos uma carta da mesa, devemos somar a probabilidade de todos os eventos em $E_{1}-E_{24}$ que apresentam pelo menos alguma carta do tipo $\circ$ em $\omega_{4}, \omega_{5}, \omega_{6}$. Existem no total 24 - $6=18$ eventos deste tipo. A probabilidade de cada um destes pode ser calculada segundo a Proposição 2.7, somando sobre todos os possíveis valores do divisor $q$ de 1 até 13. Entretanto, há outra maneira mais eficiente de calcular a probabilidade, baseada na observação de que existem somente 6 eventos com as três cartas do tipo $x$ na mesa: $E_{1}, E_{5}, E_{9}, E_{13}, E_{17}$ e $E_{21}$. Assim,

$$
\mathbb{P}\left\{Q_{1}\right\}=1-\mathbb{P}\left\{\bar{Q}_{1}\right\}=1-\mathbb{P}\left\{\bigcup_{k=0}^{5} E_{1+4 \cdot k}\right\}
$$

sendo $\bar{Q}_{1}$ o evento complementar de $Q_{1}$, ou seja $\bar{Q}_{1}$ é o evento no qual o jogador não possui carta que divida pelo menos alguma carta da mesa.

Observamos primeiro que para os três eventos $E_{9}, E_{17}$ e $E_{21}$ podemos utilizar diretamente a Proposição 2.7. Para $E_{9}$,

$$
\begin{aligned}
& \mathbb{P}\left\{E_{9}\right\}=\sum_{q=2}^{13} \mathbb{P}\left\{q \diamond \diamond \begin{array}{lll}
x & x & x
\end{array}\right\} \\
& =\frac{1}{\#(\Omega)} \sum_{q=2}^{13}\left(\begin{array}{l}
4 \\
1
\end{array}\right)\left(\begin{array}{c}
N_{q}-4 \\
2
\end{array}\right)\left(\begin{array}{c}
52-N_{q} \\
3
\end{array}\right) \\
& =\frac{1}{3 \#(\Omega)} \sum_{q=2}^{13}\left(52-N_{q}\right)\left(51-N_{q}\right)\left(50-N_{q}\right)\left(N_{q}-5\right)\left(N_{q}-4\right)
\end{aligned}
$$




$$
=\frac{27308}{1817725}=0,0150232 \text {. }
$$

Para $E_{17}$ tem-se,

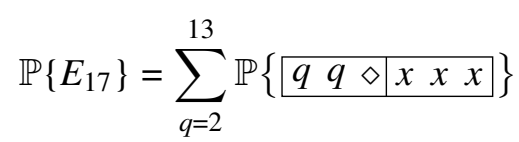

$$
\begin{aligned}
& =\frac{1}{\#(\Omega)} \sum_{q=2}^{13}\left(\begin{array}{l}
4 \\
2
\end{array}\right)\left(\begin{array}{c}
N_{q}-4 \\
1
\end{array}\right)\left(\begin{array}{c}
52-N_{q} \\
3
\end{array}\right) \\
& =\frac{1}{\#(\Omega)} \sum_{q=2}^{13}\left(52-N_{q}\right)\left(51-N_{q}\right)\left(50-N_{q}\right)\left(N_{q}-4\right) \\
& =\frac{3708}{748475}=0,00495407 \text {. }
\end{aligned}
$$

Para $E_{21}$,

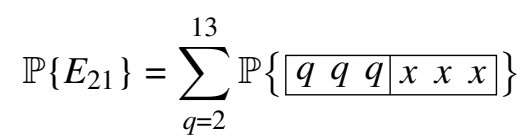

$$
\begin{aligned}
& =\frac{1}{\#(\Omega)} \sum_{q=2}^{13}\left(\begin{array}{l}
4 \\
3
\end{array}\right)\left(\begin{array}{c}
52-N_{q} \\
3
\end{array}\right) \\
& =\frac{2}{3} \frac{1}{\#(\Omega)} \sum_{q=2}^{13}\left(52-N_{q}\right)\left(51-N_{q}\right)\left(50-N_{q}\right) \\
& =\frac{1614}{978775}=0,001649 \text {. }
\end{aligned}
$$

Para calcular as probabilidades de $E_{1}, E_{5}$ e $E_{13}$ devemos proceder de maneira diferente. Para estes eventos, além da carta $q$, a mão do jogador apresenta uma ou duas cartas do tipo $x$, as quais tampouco devem ser divisoras das cartas da mesa. É necessário distinguirmos as cartas do tipo $x$ em posse do jogador daquelas na mesa. Sejam $u$ ou $v$ quaisquer duas cartas do tipo $x$ em posse do jogador que não dividem nenhuma das cartas sobre a mesa. Denotamos por $N_{u}$ e $N_{v}$ o número de cartas que são múltiplos das cartas com valor $u$ e $v$ respectivamente. Analisamos primeiro a situação para o evento $E_{5}$, isto é, para o evento da forma $q \diamond u \mid x \times x$. Neste caso tem-se

$$
\begin{aligned}
\mathbb{P}\left\{E_{5}\right\} & =\sum_{q=2}^{13} \sum_{\substack{u=2 \\
u: q \nmid u}}^{13} \mathbb{P}\{|q \diamond u| x x \quad x\} \\
& =\frac{1}{\#(\Omega)} \sum_{q=2}^{13}\left(\begin{array}{l}
4 \\
1
\end{array}\right)\left(\begin{array}{c}
N_{q}-4 \\
1
\end{array}\right)\left(\begin{array}{c}
4 \\
1
\end{array}\right) \sum_{\substack{u=2 \\
u: q \nmid u}}^{13}\left(\begin{array}{c}
52-N_{q}-N_{u} \\
3
\end{array}\right) \\
& =\frac{8}{3} \frac{1}{\#(\Omega)} \sum_{q=2}^{13}\left(N_{q}-4\right) \sum_{\substack{u=2 \\
u: q \nmid u}}^{13}\left(52-N_{q}-N_{u}\right)\left(51-N_{q}-N_{u}\right)\left(50-N_{q}-N_{u}\right) \\
& =\frac{9088}{149695}=0,0607101 .
\end{aligned}
$$

Observamos que não é necessário retirarmos os múltiplos de $\diamond, N_{\diamond}$, dentre os possíveis valores para $x$ na mesa, pois $\diamond$ é múltiplo de $q$. Este fato, mesmo sendo elementar, é mostrado no Lema 3.1 do 
apêndice. O número $52-N_{q}$ inclui, portanto, aquelas cartas que não são múltiplos de ambos os valores $q$ e $\diamond$.

Para o evento $E_{13}$ procedemos da seguinte maneira.

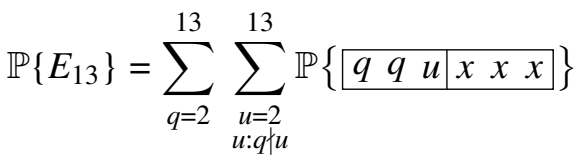

$$
\begin{aligned}
& =\frac{1}{\#(\Omega)} \sum_{q=2}^{13}\left(\begin{array}{l}
4 \\
2
\end{array}\right)\left(\begin{array}{l}
4 \\
1
\end{array}\right) \sum_{\substack{u=2 \\
u: q \nmid u}}^{13}\left(\begin{array}{c}
52-N_{q}-N_{u} \\
3
\end{array}\right)
\end{aligned}
$$

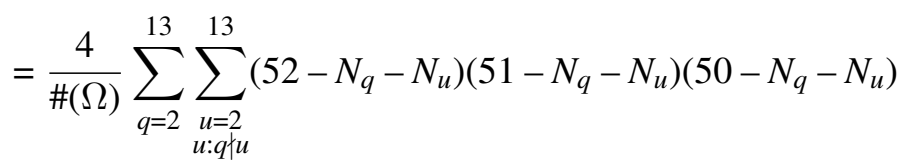

$$
\begin{aligned}
& =\frac{774756}{12724075} \approx 0,0608890 .
\end{aligned}
$$

Para o evento $E_{1}$, da forma \begin{tabular}{|lllll}
$q u$ & $v$ & $x$ & $x$ & $x$
\end{tabular} , devemos considerar dois casos $u \neq v$ e $u=v$, ou seja

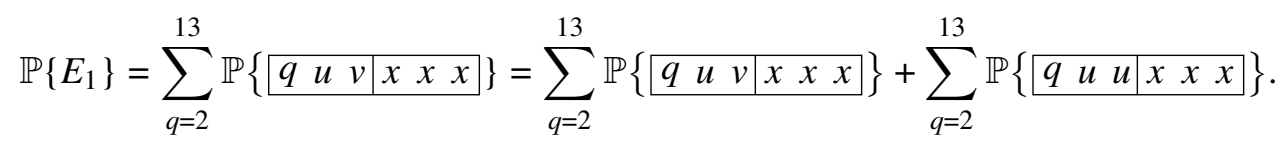

Analisamos separadamente cada caso. Primeiro,

$$
\begin{aligned}
& \sum_{q=2}^{13} \mathbb{P}\left\{\begin{array}{lll|lll}
q & u & u & x & x & x
\end{array}\right\}=\frac{1}{\#(\Omega)} \sum_{q=2}^{13} \sum_{\substack{u=2 \\
u: q \nmid u}}^{13}\left(\begin{array}{l}
4 \\
1
\end{array}\right)\left(\begin{array}{l}
4 \\
2
\end{array}\right)\left(\begin{array}{c}
52-N_{q}-N_{u} \\
3
\end{array}\right) \\
& =\frac{4}{\#(\Omega)} \sum_{q=2}^{13} \sum_{\substack{u=2 \\
u: q \nmid u}}^{13}\left(52-N_{q}-N_{u}\right)\left(51-N_{q}-N_{u}\right)\left(50-N_{q}-N_{u}\right) \\
& =\frac{774756}{12724075}=0,060889 \text {. }
\end{aligned}
$$

Para o caso $u \neq v$, definimos $N_{q, u, v}=N_{q}+N_{u}+N_{v}$, logo

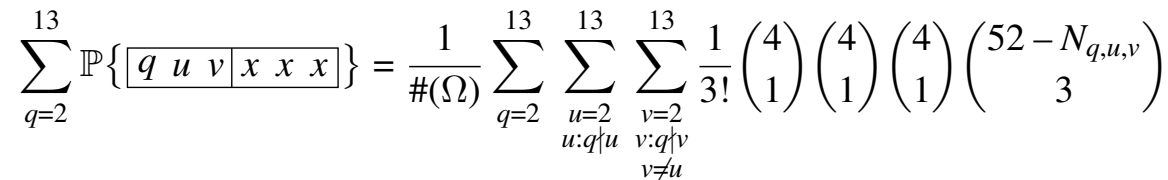

$$
\begin{aligned}
& =\frac{16}{9} \frac{1}{\#(\Omega)} \sum_{q=2}^{13} \sum_{\substack{u=2 \\
u: q \nmid u}}^{13} \sum_{\substack{v=2 \\
v q \nmid \downarrow \\
v \neq u}}^{13}\left(52-N_{q, u, v}\right)\left(51-N_{q, u, v}\right)\left(50-N_{q, u, v}\right) \\
& =\frac{110944}{978775} \approx 0,11335 \text {. }
\end{aligned}
$$

Deduzimos destes valores que probabilidade do evento $E_{1}$ é 0,174239 .

Para concluirmos a demonstração utilizamos a desigualdade de Boole, veja por exemplo Ross (2010), para a união em (4), isto é,

$$
\mathbb{P}\left\{\bigcup_{k=0}^{5} E_{1+4 \cdot k}\right\} \leq \sum_{k=0}^{5} \mathbb{P}\left\{E_{1+4 \cdot k}\right\} .
$$


Desse último concluímos que

$$
\mathbb{P}\left\{Q_{1}\right\} \geq 1-\sum_{k=0}^{5} \mathbb{P}\left\{E_{1+4 \cdot k}\right\} .
$$

A necessidade da desigualdade de Boole é justificada ao observarmos que nem todos os eventos em (4) são disjuntos. As interseções dependem da escolha da carta com valor $q$ em $\mathcal{H}$. Além dos eventos já considerados, é possível escolher qualquer uma das cartas do tipo $\diamond \in \mathscr{H}$ como o divisor. Esta troca induz as seguintes identidades entre $E_{17}$ e $E_{5}$,

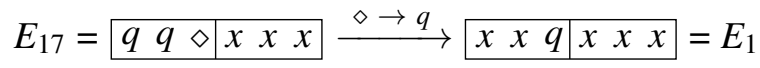

$$
\begin{aligned}
& E_{5}=\begin{array}{llllll}
q & \diamond & x & x & x & x \\
\hline
\end{array} \stackrel{\diamond \rightarrow q}{\longrightarrow} \begin{array}{lll|lll}
x & q & x & x & x & x
\end{array}=E_{1} .
\end{aligned}
$$

Para $E_{9}$, com duas cartas do tipo $\diamond$, devemos considerar os seguintes casos. Se as duas cartas do tipo $\diamond$ possuem o mesmo valor, temos

$$
E_{9}=q \diamond \diamond x \times x \stackrel{\diamond \rightarrow q}{\longrightarrow} \times q q q \times x \times x=E_{13},
$$

e se estas apresentam valor diferentes $u \neq v$,

$$
\begin{aligned}
& E_{9}=\begin{array}{lll|lllll}
q & u & v & x & x & x & \stackrel{u}{\longrightarrow} q \\
\longrightarrow & x & q & x & x & x & x
\end{array}=E_{1}
\end{aligned}
$$

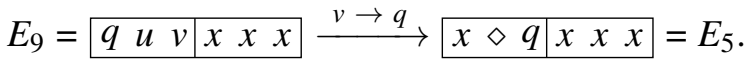

Temos portanto os seguintes eventos

$$
E_{17} \cap E_{1}, \quad E_{5} \cap E_{1}, \quad E_{9} \cap E_{13}, \quad E_{9} \cap E_{1}, \quad \text { e } \quad E_{9} \cap E_{5}
$$

constituídos por interseções não vazias.

OBSERVAÇÃo 2.9. O cálculo das probabilidades para eventos em (5), junto ao princípio de inclusão/exclusão permite determinar a probilidade exata de $Q_{1}$. Não consideramos isso aqui e deixamos em aberto para análise futura.

\section{O problema da divisão composta pela soma}

Passamos agora à análise da divisão do valor da soma de duas cartas da mesa por uma carta com valor $q$ em posse do jogador. Com o objetivo de mostrar algumas das dificuldades inerentes à esta questão e motivar os desenvolvimentos desta seção apresentamos a seguir um exemplo simples.

EXEMPlo 2.10. Suponhamos que o aluno se depare com a situação exposta na Figura 7. Temos nesta figura um evento elementar onde o divisor $q=3$ é determinado pela carta $3 \boldsymbol{\beta}$ e as outras duas cartas em posse do jogador, $K \odot$ e $K \boldsymbol{Q}$, compõem soma não divisível por $q$.

Seguindo as convenções, (e uma delas deixa claro não poder somar as três cartas da mesa) o jogador pode somar duas cartas de $\mathscr{D}$ na tentativa de conseguir um múltiplo de uma das cartas em $\mathscr{H}$. Note que $K \odot$ e $K$ não dividem nenhuma carta de $\mathscr{D}$ e nenhuma das 3 somas que podem ser feitas entre elas. Contudo, $3 \boldsymbol{\phi}$ tanto divide $10 \varnothing+5 \boldsymbol{\$}$ como $10 \varnothing+J \diamond$, também temos uma soma não divisível por 3ధ, a saber $5 \boldsymbol{\phi}+J \diamond$.

Para efeito do cálculo de probabilidades, os eventos ligados a esta nova operação exigem mais cautela em suas composições.

Mudando as cartas da mesa, outras situações de soma podem surgir. Umas podem conter duas cartas múltiplas de uma das cartas de $\omega_{1}, \omega_{2}$ e $\omega_{3}$, outras somas podem inclusive conter uma carta igual a uma das cartas da mesa. Podem aparecer também somas cujos resultados não são favoráveis à divisão mesmo que um dos valores das cartas seja múltiplo do valor de uma das cartas da mesa. Importante ressaltar que podemos ter somas de cartas na mesa que não são múltiplas de uma das cartas de $\omega_{1}, \omega_{2}$ e $\omega_{3}$ e mesmo assim fornecem um resultado favorável à divisão. 

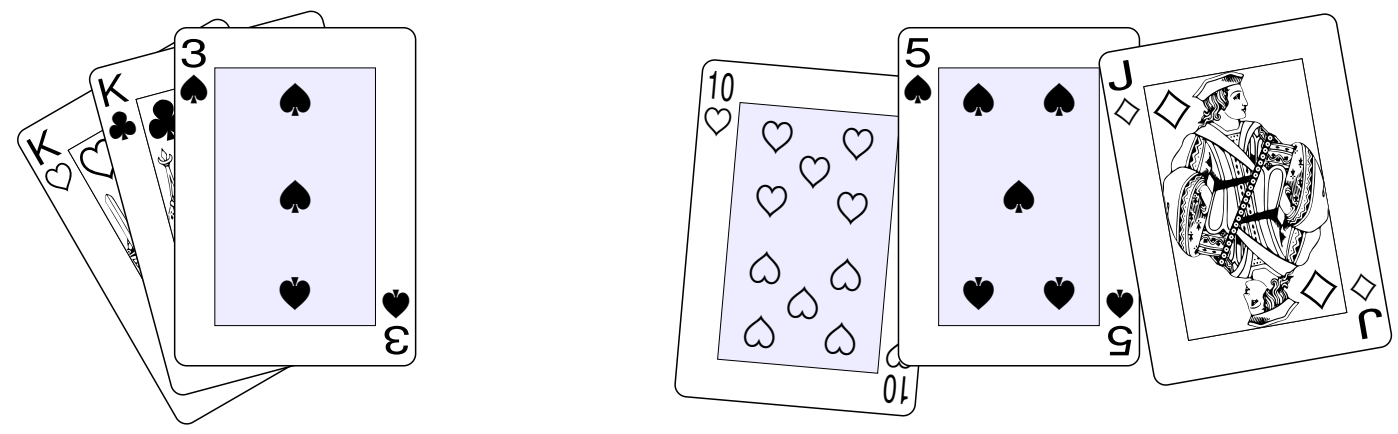

FIGURA 7. Exemplo de um evento favorável à divisão da soma de duas cartas em $\omega_{4}, \omega_{5}$ e $\omega_{6}$. As cartas em posse do jogador são mostradas à esquerda.

5.1. Principais eventos. Como fizemos anteriormente, elencaremos alguns símbolos para explicar a composição dos eventos a serem considerados.

DEFINIÇÃo 2.11. Sejam $\omega_{a}$ e $\omega_{b}$ duas cartas quaisquer em $\mathscr{H}$ ou $\mathscr{D}$. Dado $q \in\{1, \ldots, 13\}$ sejam

$$
S=\left\{\left\{\omega_{a}, \omega_{b}\right\}: q \nmid\left(\omega_{a}+\omega_{b}\right)\right\}, \quad \Sigma=\left\{\left\{\omega_{a}, \omega_{b}\right\}: q \mid\left(\omega_{a}+\omega_{b}\right)\right\}, \quad \text { e } \quad \mathbb{S}=S \cup \Sigma .
$$

O conjunto $S$ é constituído por pares de cartas cuja soma não é divisível por $q$, e $\Sigma$ é o conjunto formado por aqueles pares cuja soma é divisível por $q$. Desta maneira, chamamos qualquer elemento de $S$ de soma não favorável e qualquer um de $\Sigma$ de soma favorável.

De maneira análoga ao considerado para o problema da divisão simples, utilizamos a notação $q \mathbb{S}_{\mathcal{H}} \mid \mathbb{S}_{\mathscr{D}} \omega_{n}$ para denotarmos um evento no qual o jogador possui uma carta com valor $q$ e outras duas cartas quaisquer, cuja soma $\mathbb{S}_{\mathcal{H}}$ deve ser analisada. Neste evento, a mesa apresenta duas cartas cuja soma $\mathbb{S}_{\not \supset}$ também deve ser analisada, e uma terceira carta $\omega_{n}$ a qual pode ser de qualquer um dos tipos $q, \diamond$ ou $x$. Pensando em todos os casos de somas entre duas cartas quaisquer do baralho, favoráveis ou não, notamos que os conjuntos $S$ e $\Sigma$ são amplos e precisam ser organizados em subconjuntos. A seguir, vamos caracterizar os subconjuntos de somas favoráveis e de somas não favoráveis.

5.1.1. Somas não favoráveis. O conjunto $S$ das somas não favoráveis pode ser particionado nos subconjuntos $S_{\circ}$ e $S_{x}$. $S_{\circ}$ é uma soma entre duas cartas, respectivamente com valores $x$ e $y$, tal que $q \nmid S_{\circ}$ e $q=x$ ou $q=y$, mas nunca $q=x=y$. Isso quer dizer que o jogador pode se deparar com o fato de que, entre duas cartas de $\omega_{4}, \omega_{5}$ e $\omega_{6}$, uma delas é igual a carta $q$, de $\omega_{1}$, $\omega_{2}$ e $\omega_{3}$, e a outra não ser divisível por $q$. O par de cartas de $S_{\circ}$ será do tipo $\{q, x\}$ e $q$ não divide esta soma. O conjunto $S_{x}$ está constituído por pares de cartas cuja soma $x+y$ é tal que $q \nmid(x+y)$ e $q \neq x, y$. Nenhuma das duas cartas é igual a $q$, mas uma delas pode ou não ser múltipla de $q$ e a outra necessariamente ser não múltipla $x$. Estamos pensando em pares do tipo $\{\diamond, x\},\{x, x\}$. Formalmente consideramos a seguinte definição para os conjuntos $S_{\circ}$ e $S_{x}$.

DEFINIÇÃo 2.12. Sejam $\omega_{a}$ e $\omega_{b}$ duas cartas quaisquer em $\mathscr{H}$ ou $\mathscr{D}$ e $q \in\{1, \ldots, 13\}$, e sejam $S_{\circ}$ e $S_{x}$ definidos por

$$
\begin{aligned}
& S_{\circ}=\left\{\left\{\omega_{a}, \omega_{b}\right\}: q \nmid\left(\omega_{a}+\omega_{b}\right) ; \omega_{a}=q \text { ou } \omega_{b}=q\right\}, \\
& S_{x}=\left\{\left\{\omega_{a}, \omega_{b}\right\}: q \nmid\left(\omega_{a}+\omega_{b}\right) ; \omega_{a} \neq q \text { e } \omega_{b} \neq q\right\} .
\end{aligned}
$$


O conectivo 'ou' na definição de $S_{\circ}$ tem caráter de exclusão, por exemplo, se $\omega_{a}=q$ então $\omega_{b} \neq q$, e vice-versa.

O evento $S_{x}$ é consituído por pares de cartas com soma $x+y$ tal que $q \nmid(x+y)$ e $q \neq x, q \neq y$. Contudo, os pares podem ter, ou não, múltiplos de $q$ em seus termos. Desta forma, realizamos a separação nos casos $S_{S}^{\prime}$, $S_{x}^{\prime \prime}$ e $S_{x}^{\prime \prime \prime}$ definidos da seguinte maneira.

$$
\begin{aligned}
S_{x}^{\prime}(q) & =\left\{\left\{\omega_{a}, \omega_{b}\right\} \in S_{x}: q \mid \omega_{a}, q \nmid \omega_{b}, \omega_{a} \neq q\right\}, \\
S_{x}^{\prime \prime}(q) & =\left\{\left\{\omega_{a}, \omega_{b}\right\} \in S_{x}: q \nmid \omega_{a}, q \nmid \omega_{b}, \omega_{a} \neq \omega_{b}\right\} . \\
S_{x}^{\prime \prime \prime}(q) & =\left\{\left\{\omega_{a}, \omega_{b}\right\} \in S_{x}: q \nmid \omega_{a}, q \nmid \omega_{b}, \omega_{a}=\omega_{b}\right\} .
\end{aligned}
$$

É importante ressaltar que existem somas entre duas cartas cujos valores não são múltiplos de $q$, ambas do mesmo valor, que resultam em soma favorável. Os pares considerados em $S_{x}^{\prime \prime}$ incluem apenas as somas entre dois não múltiplos com resultados não favoráveis.

5.1.2. Somas favoráveis. As somas favoráveis podem ser divididas em dois casos definidos da seguinte maneira.

Definição 2.13. Sejam $\omega_{a}$ e $\omega_{b}$ duas cartas quaisquer em $\mathscr{H}$ ou em $\mathscr{D}$. Dado $q \in\{1, \ldots, 13\}$ sejam

$$
\begin{aligned}
& \Sigma_{\circ}=\left\{\left\{\omega_{a}, \omega_{b}\right\}: q \mid\left(\omega_{a}+\omega_{b}\right) ; \omega_{a}=q \text { ou } \omega_{b}=q \text { ou } \omega_{a}=\omega_{b}=q\right\}, \\
& \Sigma_{x}=\left\{\left\{\omega_{a}, \omega_{b}\right\}: q \mid\left(\omega_{a}+\omega_{b}\right) ; \omega_{a} \neq q \text { e } \omega_{b} \neq q\right\},
\end{aligned}
$$

O conectivo 'ou' em $\Sigma_{\circ}$ tem caráter de exclusão, proporcionando três situações diferentes,

O evento $\Sigma_{\circ}$ é um subconjunto que engloba as todas somas entre duas cartas com valores $x$ e $y$ tais que $q \mid(x+y)$ e $q=x$ ou $q=y$ ou mesmo $q=x=y$. Isto quer dizer que pelo menos uma das cartas $\omega_{a}$ ou $\omega_{b}$, cuja soma está sendo considerada, possui o mesmo valor da carta com valor $q$. Para que o par seja divisível por $q$, a segunda carta que constituirá a soma deve necessariamente atender a seguinte condição: ser divisível pela primeira. Desta forma, a segunda carta pode ser igual a primeira ou múltipla desta. Consideramos portanto os seguintes subconjuntos de $\Sigma_{\circ}$.

$$
\begin{aligned}
& \Sigma_{\circ}^{\prime}(q)=\left\{\left\{\omega_{a}, \omega_{b}\right\} \in \Sigma_{\circ}: \omega_{a}=\omega_{b}=q\right\}, \\
& \Sigma_{\circ}^{\prime \prime}(q)=\left\{\left\{\omega_{a}, \omega_{b}\right\} \in \Sigma_{\circ}: \omega_{a}=q, \omega_{b}=\diamond\right\} .
\end{aligned}
$$

No último evento $\Sigma_{\circ}^{\prime \prime}(q)$, o par $\omega_{a}, \omega_{b}$, além de conter uma carta com valor igual a $q$, contém uma carta múltipla de $q$, mas diferente desse.

O evento $\Sigma_{x}$ é constituído pelos pares de cartas com soma $x+y$ tal que $q \mid(x+y)$ e $q \neq x, q \neq y$. Os pares $\{x, y\}$ podem ser constituídos a partir de quatro configurações diferentes, a saber:

$$
\begin{aligned}
\Sigma_{x}^{\prime}(q) & =\left\{\left\{\omega_{a}, \omega_{b}\right\} \in \Sigma_{x}: q\left|\omega_{a}, q\right| \omega_{b}, \omega_{a} \neq q, \omega_{b} \neq q, \omega_{a} \neq \omega_{b}\right\} \\
\Sigma_{x}^{\prime \prime}(q) & =\left\{\left\{\omega_{a}, \omega_{b}\right\} \in \Sigma_{x}: q \nmid \omega_{a}, q \nmid \omega_{b}, \omega_{a} \neq \omega_{b}\right\} . \\
\Sigma_{x}^{\prime \prime \prime}(q) & =\left\{\left\{\omega_{a}, \omega_{b}\right\} \in \Sigma_{\circ}: q\left|\omega_{a}, q\right| \omega_{b}, \omega_{a}=\omega_{b}, \omega_{a} \neq q\right\}, \\
\Sigma_{x}^{i v}(q) & =\left\{\left\{\omega_{a}, \omega_{b}\right\} \in \Sigma_{\circ}: q \nmid \omega_{a}, q \nmid \omega_{b}, \omega_{a}=\omega_{b}\right\}
\end{aligned}
$$

A cardinalidade dos subconjuntos definidos nesta seção é apresentada na Tabela 3. Os números fornecidos por esta tabela serão utilizados para calcular as probabilidades relativas ao problema definido pela questão $Q_{2}$.

A Tabela 4 apresenta todos os possíveis eventos da forma $q \mathbb{S}_{\mathcal{H}} \mid \mathbb{S}_{\mathcal{D}} \omega_{n}$, onde $\mathbb{S}$ pode ser qualquer um dos conjuntos $S_{\circ}, S_{x}, \Sigma_{\circ}$ ou $\Sigma_{x}$, e a carta $\omega_{b}$ pode assumir qualquer uma das formas $\diamond$, $x$ ou $q$.

O exemplo seguinte tem como objetivo ilustrar a notação definida nesta seção. 


\begin{tabular}{c|ccccccc}
$q$ & $\Sigma_{x}^{\prime}(q)$ & $\Sigma_{x}^{\prime \prime}(q)$ & $\Sigma_{x}^{\prime \prime \prime}(q)$ & $\Sigma_{x}^{i v}(q)$ & $S_{x}^{\prime}(q)$ & $S_{x}^{\prime \prime}(q)$ & $S_{x}^{\prime \prime \prime}(q)$ \\
\hline$A$ & 66 & 0 & 12 & 0 & 0 & 0 & 0 \\
2 & 10 & 21 & 5 & 7 & 36 & 0 & 0 \\
3 & 3 & 20 & 3 & 0 & 27 & 16 & 9 \\
4 & 1 & 15 & 2 & 3 & 20 & 31 & 7 \\
5 & 0 & 15 & 1 & 0 & 11 & 41 & 11 \\
6 & 0 & 11 & 1 & 2 & 11 & 44 & 9 \\
7 & 0 & 12 & 0 & 0 & 0 & 55 & 12 \\
8 & 0 & 9 & 0 & 2 & 0 & 57 & 10 \\
9 & 0 & 8 & 0 & 0 & 0 & 58 & 12 \\
10 & 0 & 7 & 0 & 1 & 0 & 59 & 11 \\
$J$ & 0 & 7 & 0 & 0 & 0 & 64 & 12 \\
$Q$ & 0 & 6 & 0 & 1 & 0 & 60 & 11 \\
$K$ & 0 & 6 & 0 & 0 & 0 & 60 & 12
\end{tabular}

TABELA 3. Cardinalidade de alguns subconjuntos relativos ao problema da divisão composta pela soma.

EXEMPLO 2.14. Voltando à situação proposta pela figura $7 \operatorname{com} q=3$, temos os subconjuntos constituídos da seguinte forma: ${ }^{1}$

$$
\begin{aligned}
& \Sigma(3)=\{(A, 2) ;(A, 5) ;(A, 8) ;(A, J) ;(2,4) ;(2,7) ;(2,10) ;(2, K) ;(3,3) ;(3,6) ;(3,9) ;(3, Q) ; \\
& (4,5) ;(4,8) ;(4, J) ;(5,7) ;(5,10) ;(5, K) ;(6,6) ;(6,9) ;(6, Q) ;(7,8) ;(7, J) ;(8,10) \text {; } \\
& (8, K) ;(9,9) ;(9, Q) ;(10, J) ;(J, K) ;(Q, Q)\}, \\
& \Sigma_{\circ}(3)=\{(3,3) ;(3,6) ;(3,9) ;(3, Q)\} \text {, } \\
& \Sigma_{\circ}^{\prime}(3)=\{(3,3)\} \text {, } \\
& \Sigma_{\circ}^{\prime \prime}(3)=\{(3,6) ;(3,9) ;(3, Q)\} \text {, } \\
& \Sigma_{x}(3)=\{(A, 2) ;(A, 5) ;(A, 8) ;(A, J) ;(2,4) ;(2,7) ;(2,10) ;(2, K) ;(4,5) ;(4,8) ;(4, J) ;(5,7) \text {; } \\
& (5,10) ;(5, K) ;(6,6) ;(6,9) ;(6, Q) ;(7,8) ;(7, J) ;(8,10) ;(8, K) ;(9,9) ;(9, Q) ;(10, J) \text {; } \\
& (J, K) ;(Q, Q)\} \\
& \Sigma_{x}^{\prime}(3)=\{(6,9) ;(6, Q) ;(9, Q) ;\} \\
& \Sigma_{x}^{\prime \prime}(3)=\{(A, 2) ;(A, 5) ;(A, 8) ;(A, J) ;(2,4) ;(2,7) ;(2,10) ;(2, K) ;(4,5) ;(4,8) ;(4, J) ;(5,7) ; \\
& (5,10) ;(5, K) ;(7,8) ;(7, J) ;(8,10) ;(8, K) ;(10, J) ;(J, K) ;\} \\
& \Sigma_{x}^{\prime \prime \prime}(3)=\{(6,6) ;(9,9) ;(Q, Q)\} \\
& \Sigma_{x}^{i v}(3)=\emptyset \\
& S_{\circ}(3)=\{(3, A) ;(3,2) ;(3,4) ;(3,5) ;(3,7) ;(3,8) ;(3,10) ;(3, J) ;(3, K)\} \text {, } \\
& S_{x}(3)=\{(A, A) ;(A, 4) ;(A, 6) ;(A, 9) ;(A, 10) ;(A, Q) ;(A, K) ;(2,2) ;(2,5) ;(2,6) ;(2,8) ;(2,9) \text {; } \\
& (2, J) ;(2, Q) ;(4,4) ;(4,6) ;(4,10) ;(4, Q) ;(4, K) ;(5,5) ;(5,6) ;(5,8) ;(5,9) ;(5, J) \text {; } \\
& (5, Q) ;(6,7) ;(6,8) ;(6,10) ;(6, J) ;(6, K) ;(7,7) ;(7,9) ;(7,10) ;(7, Q) ;(7, K) ;(8,8) \text {; } \\
& (8,9) ;(8, J) ;(8, Q) ;(9,10) ;(9, J) ;(9, K) ;(10,10) ;(10, Q) ;(10, K) ;(J, J) ;(J, Q) ;(Q, K) \text {; } \\
& (K, K)\} \text {, }
\end{aligned}
$$

\footnotetext{
${ }^{1}$ Note que não estão sendo considerados os naipes das cartas.
} 


$$
\begin{aligned}
& S_{x}^{\prime}(3)=\{(A, 6) ;(A, 9) ;(A, Q) ;(2,6) ;(2,9) ;(2, Q) ;(4,6) ;(4,9) ;(4, Q) ;(5,6) ;(5,9) ;(5, Q) ; \\
&(6,7) ;(6,8) ;(6,10) ;(6, J) ;(6, K) ;(7,9) ;(7, Q) ;(8,9) ;(8, Q) ;(9,10) ;(9, J) ;(9, K) ; \\
&(10, Q) ;(J, Q) ;(Q, K)\}, \\
& S_{x}^{\prime \prime}(3)=\{(A, 4) ;(A, 7) ;(A, 10) ;(A, K),(2,5) ;(2,8) ;(2, J) ;(4,7) ;(4,10) ;(4, K) ;(5,8) ;(5, J) ; \\
&(7,10) ;(7, K) ;(8, J) ;(10, K) ;\}, \\
& S_{x}^{\prime \prime \prime}(3)=\{(A, A) ;(2,2) ;(4,4) ;(5,5) ;(7,7) ;(8,8) ;(10,10) ;(J, J) ;(K, K)\}
\end{aligned}
$$

\section{Probabilidade da divisão composta pela soma}

Dentre os 48 eventos apresentados na Tabela 4, unicamente são relevantes aqueles que apresentam uma soma favorável, ou seja, aqueles denotados pelos símbolos $\Sigma_{\circ}$ ou $\Sigma_{x}$ nas cartas em D. A lista inicial de 48 eventos é, portanto, reduzida a uma lista de 24 eventos, os quais, por sua vez, podem ser agrupados em 8 conjuntos, de acordo as seguintes equações definidas para cada $q \in\{1, \ldots, 13\}$,

$$
\begin{aligned}
& G_{1}(q)=\begin{array}{|l|l|l|l|l|l|l|l|l|l|l|}
q & q S_{x} & \Sigma_{x} x \\
\hline
\end{array} \\
& G_{2}(q)=\begin{array}{|l|l|l|l|l|l|l|l|l|l|l|}
q S_{x} & \Sigma_{\circ} x \\
\hline q S_{x} & \Sigma_{\circ} \diamond \\
\hline
\end{array} \\
& G_{3}(q)=\begin{array}{|l|l|l|l|l|l|l|l|l|l|l|l|}
\hline q S_{\circ} & \Sigma_{x} x \\
\hline q S_{\circ} & \Sigma_{x} \diamond & \Sigma_{x} q \\
\hline
\end{array} \\
& G_{4}(q)=\begin{array}{|l|l|l|l|l|l|l|l|l|}
q S_{\circ} & \Sigma_{\circ} x \\
\hline q S_{\circ} & \Sigma_{\circ} \diamond & q S_{\circ} & \Sigma_{\circ} q \\
\hline
\end{array} \\
& G_{5}(q)=q \Sigma_{x} \Sigma_{x} x \cup\left|q \Sigma_{x}\right| \Sigma_{x} \diamond \bigcup \begin{array}{|l|l|l|}
q \Sigma_{x} & \Sigma_{x} q \\
\hline
\end{array} \\
& G_{6}(q)=q \Sigma_{x}\left|\Sigma_{\circ} x \cup q \Sigma_{x} \Sigma_{\circ} \diamond \bigcup q \Sigma_{x}\right| \Sigma_{\circ} q \\
& G_{7}(q)=q \Sigma_{\circ}\left|\Sigma_{x} x \cup\right| q \Sigma_{\circ}\left|\Sigma_{x} \diamond \bigcup q \Sigma_{\circ}\right| \Sigma_{x} q \\
& G_{8}(q)=q \Sigma_{\circ} \mid \Sigma_{\circ} x \cup \begin{array}{|l|l|l|l|l|l|}
q & q \Sigma_{\circ} & \Sigma_{\circ} \diamond \\
\hline
\end{array}
\end{aligned}
$$

Estes últimos eventos são determinados ao se unirem as três possibilidades para a carta $\omega_{n} \in \mathscr{D}$ em \begin{tabular}{l|l|l}
$q \mathbb{S}_{\mathcal{H}}$ & $\mathbb{S}_{\mathscr{D}} \omega_{n}$
\end{tabular} . Finalmente definimos

$$
G_{i}=\bigcup_{q=1}^{13} G_{i}(q), \quad i=1, \ldots, 8 .
$$

Estes últimos eventos são, em princípo, úteis para respondermos a questão $Q_{2}$. As probabilidades dos eventos $G_{1}$ a $G_{8}$ são dadas pelos seguintes Lemas.

LEMA 2.15. A probabilidade do evento $G_{1}$ é 0,481292 .

LEMA 2.16. A probabilidade do evento $G_{2}$ é 0,060579 .

LEMA 2.17. A probabilidade do evento $G_{3}$ é 0,066798 .

LEMA 2.18. A probabilidade do evento $G_{4}$ é 0,00267061 .

Lema 2.19. A probabilidade do evento $G_{5}$ é 0,903747.

Lema 2.20. A probabilidade do evento $G_{6}$ é 0,103954 .

LEMA 2.21. A probabilidade do evento $G_{7} e ́$ 0,0527602.

LEMA 2.22. A probabilidade do evento $G_{8}$ é 0,004055078 . 


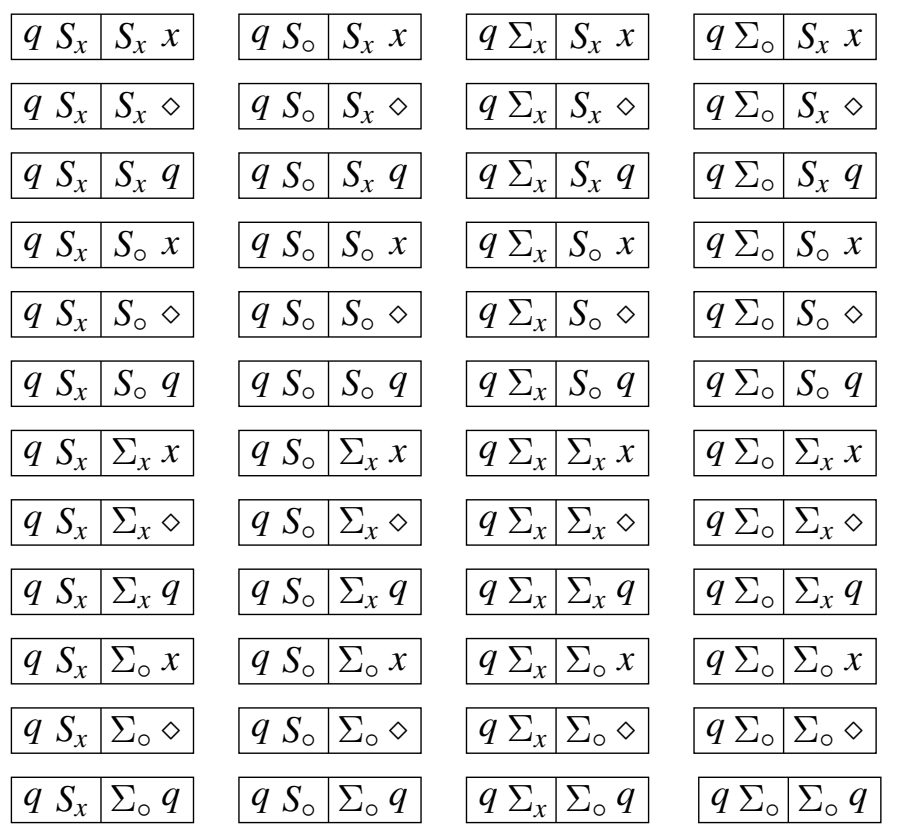

TABELA 4. Eventos do problema da divisão composta pela soma

A demostração destes Lemas é relativamente simples, porém longa e por isso as descrevemos no Apêndice 3. Os eventos $G_{i}, i=1, \ldots, 8$ não são em geral eventos disjuntos, pois dependem da escolha da carta em $\mathscr{H}$ que é identificada como o divisor. $\mathrm{O}$ seguinte exemplo fornece uma situação simples que ilustra essa afirmação.

EXEMPLO 2.23. Vamos considerar a situação exposta na figura 8. Temos nesta figura um evento elementar onde o divisor $q \in \mathcal{H}$ pode assumir qualquer um dos valores $q=2, q=5$ ou $q=11$ determinados respectivamente pelas cartas $2 \varnothing, 5 \boldsymbol{\phi}$ e $J \boldsymbol{h}$. As cartas $K \boldsymbol{\phi}, Q \odot$ e $J \boldsymbol{\phi}$ compõem a mesa. Observamos a seguir que a cada $q$ escolhido é contemplado um caso diferente de $G_{i}(q)$. De fato para $q=2$, o evento elementar em questão corresponde a um elemento do evento

$$
\begin{array}{|l|l|}
\hline q \Sigma_{x}^{\prime \prime} & \Sigma_{x}^{\prime \prime} \diamond, \\
\hline
\end{array}
$$

e portanto pertence ao grupo $G_{5}(2)$. Por outro lado, para $q=5$, o mesmo evento elementar pertence também ao evento

$$
\begin{array}{|l|l|}
\hline q S_{x}^{\prime \prime} & \Sigma_{x}^{\prime \prime} x \\
\hline
\end{array}
$$

e assim, também ao grupo $G_{1}(5)$.

Poderíamos explorar ainda mais este ou outros exemplos, mas já está claro que uma mesma sequência de cartas pode estar relacionada a mais de uma situação. O exemplo mostra que os eventos $G_{i}, i=1, \ldots, 8$ não são disjuntos. Mesmo assim, é possível utilizarmos os eventos $G_{i}$ para respondermos $Q_{2}$. Segundo o princípio de inclusão-exclusão, veja por exemplo Carvalho et al. (2006), a probabilidade de que uma carta em posse do jogador divida uma soma das cartas na mesa é

$$
\mathbb{P}\left\{Q_{2}\right\}=\sum_{i=1}^{8} \mathbb{P}\left\{G_{i}\right\}-\sum_{i<j} \mathbb{P}\left\{G_{i} \cap G_{j}\right\}+\sum_{i<j<k} \mathbb{P}\left\{G_{i} \cap G_{j} \cap G_{k}\right\}-\ldots-\mathbb{P}\left\{\bigcap_{i=1}^{8} G_{i}\right\} .
$$

Devemos portanto determinar todas as situações de interseções entre os grupos $G_{i}$. 

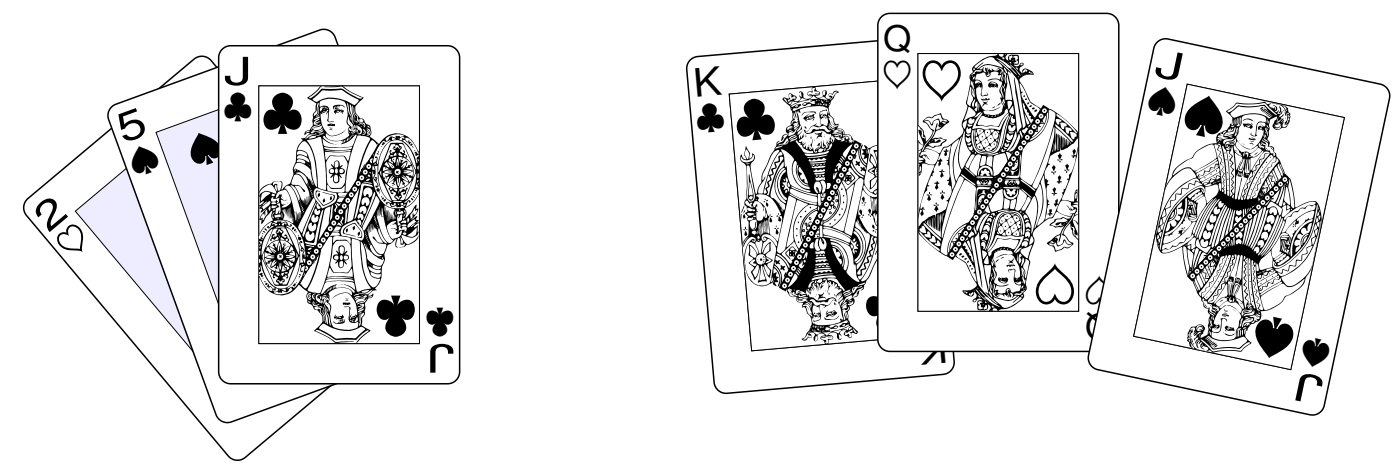

FIGURA 8. Exemplo que mostra as possíveis interseções entre os casos $G_{i}(q)$.

OBSERVAÇÃo 2.24. Neste trabalho nós não analisamos tais interseções e, assim, deixamos a questão $Q_{2}$ em aberto para análise futura. 



\section{CAPíTULO 3}

\section{Apêndice}

\section{Eventos para a divisão simples}

Apresentamos nesta seção a descrição por extenso de cada um dos eventos envolvidos no problema da divisão simples. Os símbolos $\mathcal{H}$ e $\mathscr{D}$ representam o conjunto das cartas em posse do jogador e na mesa, respectivamente. Reservamos os sub-índices $i, j, k$ para cartas em $\mathscr{H} \mathrm{e}$ $n, m, l$ para aquelas em $\mathscr{D}$. Um evento elementar em $\Omega$ é determinado assim pela sequência $\left(\left\{\omega_{i}, \omega_{j}, \omega_{k}\right\},\left\{\omega_{l}, \omega_{m}, \omega_{n}\right\}\right)$.

Explicitamos o significado de alguns caracteres para uma compreensão plena da descrição dos eventos. Temos então: ( I ) divide; $(\nmid)$ não divide; $(\backslash)$ menos; $($ : ) tal que.

Com o intuito de motivar a leitura e análise de todos os eventos, descrevemos aqui o $E_{1}$ : existe $i$, tal que $\omega_{i}$ não divide as cartas da mão, com excessão de $\omega_{i}$ (ou menos $\omega_{i}$ ); $\omega_{i}$ não divide os elementos da mesa.

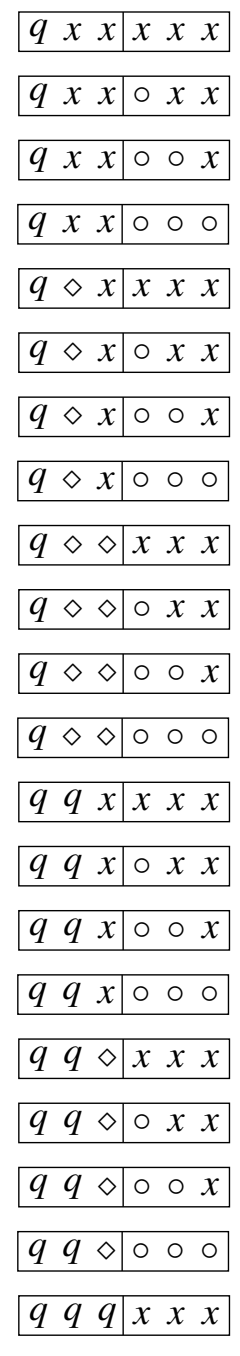

$$
\begin{aligned}
& \exists i: \omega_{i} \nmid \mathscr{H} \backslash\left\{\omega_{i}\right\} ; \omega_{i} \nmid \mathscr{D} \quad\left(E_{1}\right) \\
& \exists i, l: \omega_{i} \nmid \mathscr{H} \backslash\left\{\omega_{i}\right\} ; \omega_{i} \mid \omega_{l} ; \omega_{i} \nmid \mathscr{D} \backslash\left\{\omega_{l}\right\} \quad\left(E_{2}\right) \\
& \exists i, l, m, n: \omega_{i} \nmid \mathscr{H} \backslash\left\{\omega_{i}\right\} ; \omega_{i} \mid\left\{\omega_{l}, \omega_{m}\right\} ; \omega_{i} \nmid \omega_{n} ; \quad\left(E_{3}\right) \\
& \exists i: \omega_{i} \nmid \mathscr{H} \backslash\left\{\omega_{i}\right\} ; \omega_{i} \mid \mathscr{D} ; \quad \text { (E } \\
& \exists i, j, k: \omega_{i} \mid \omega_{j} ; \omega_{i} \nmid \omega_{k} ; \omega_{i} \nmid \mathscr{D} \\
& \exists i, j, k, l: \omega_{i}\left|\omega_{j} ; \omega_{i} \nmid \omega_{k} ; \omega_{i}\right| \omega_{l} ; \omega_{i} \nmid \mathscr{D} \backslash\left\{\omega_{l}\right\} \quad\left(E_{6}\right) \\
& \exists i, j, k: \omega_{i}\left|\mathcal{H} \backslash\left\{\omega_{k}\right\} ; c\right| \mathscr{D} \backslash\left\{\omega_{n}\right\} \quad\left(E_{7}\right) \\
& \exists i, j, k: \omega_{i}\left|\mathcal{H} \backslash\left\{\omega_{k}\right\} ; c\right| \mathscr{D} \\
& \exists i, j, k: \omega_{i} \mid \mathscr{H} ; c \nmid \mathscr{D} \quad \text { (E9) } \\
& \exists i, j, k: \omega_{i} \mid \mathcal{H} ; c \nmid \mathscr{D} \backslash\left\{\omega_{l}\right\} \quad\left(E_{10}\right) \\
& \left.\exists i, j, k: \omega_{i}|\mathscr{H} ; c| \mathscr{D} \backslash\left\{\omega_{n}\right\} \quad \text { (E } E_{11}\right) \\
& \exists i: \omega_{i}\left|\mathcal{H} \backslash\left\{\omega_{i}\right\} ; \omega_{i}\right| \mathscr{D} \quad\left(E_{12}\right) \\
& \exists i, j, k: \omega_{i}=\omega_{j} \mid \mathscr{H} \backslash\left\{\omega_{k}\right\} ; c \nmid \mathscr{D} \quad \text { (E } \\
& \exists i, j, k: \omega_{i}=\omega_{j} \mid \mathcal{H} \backslash\left\{\omega_{k}\right\} ; c \nmid \mathscr{D} \backslash\left\{\omega_{l}\right\} \quad \text { (E } \\
& \exists i, j, k: \omega_{i}=\omega_{j}\left|\mathscr{H} \backslash\left\{\omega_{k}\right\} ; c\right| D \backslash\left\{\omega_{n}\right\} \quad\left(E_{15}\right) \\
& \exists i, j, k: \omega_{i}=\omega_{j}\left|\mathcal{H} \backslash\left\{\omega_{k}\right\} ; c\right| \mathscr{D} \quad\left(E_{16}\right) \\
& \exists i, j, k, l: \omega_{i}=\omega_{j} ; \omega_{i} \mid \omega_{k} ; \omega_{i} \nmid \mathscr{D} \quad\left(E_{17}\right) \\
& \exists i, j, k, l: \omega_{i}=\omega_{j} ; \omega_{i}\left|\omega_{k} ; \omega_{i}\right| \omega_{l} ; \omega_{i} \nmid \mathscr{D} \backslash\left\{\omega_{l}\right\} \quad\left(E_{18}\right) \\
& \exists i, j, k, l, m, n: \omega_{i}=\omega_{j} ; \omega_{i}\left|\omega_{k} ; \omega_{i}\right|\left\{\omega_{l}, \omega_{n}\right\} ; \omega_{i} \nmid \omega_{n} \\
& \exists i, j, k: \omega_{i}=\omega_{j} ; \omega_{i}\left|\omega_{k} ; \omega_{i}\right| \mathscr{D} \\
& \omega_{i}=\omega_{j}=\omega_{k} ; \omega_{i} \nmid \mathscr{D}
\end{aligned}
$$




\begin{tabular}{|ll|}
\hline$q q q \mid$ & $\circ \times x$ \\
\hline$q q q \mid$ & $\exists i, l: \omega_{i}=\omega_{j}=\omega_{k} ; \omega_{i} \mid \omega_{l} ; \omega_{i} \nmid \mathscr{D} \backslash\left\{\omega_{l}\right\}$ \\
\hline$q q q$ & $\exists i, l, m, n: \omega_{i}=\omega_{j}=\omega_{k} ; \omega_{i} \mid\left\{\omega_{l}, \omega_{m}\right\} ; \omega_{i} \nmid \omega_{n}$ \\
\hline
\end{tabular}

\section{Eventos para a divisão composta pela soma}

Reservamos os sub-índices $i, j, k$ exclusivamente para as cartas em $\mathscr{H}$ e os sub-índices $l, m, n$ para as cartas em $\mathscr{D}$.

\begin{tabular}{|c|c|c|c|}
\hline \begin{tabular}{l|l|}
$q S_{x}$ & $\Sigma_{x} x$ \\
\end{tabular} & $\exists i, j, k:$ & $\begin{array}{l}\omega_{i} \neq\left(\omega_{j}, \omega_{k}, \omega_{l}, \omega_{m}, \omega_{n}\right), \\
\omega_{i} \nmid \omega_{j}+\omega_{k}, \omega_{i} \mid \omega_{l}+\omega_{m}, \omega_{i} \nmid \omega_{n} ;\end{array}$ & $\left(E_{1 s}\right)$ \\
\hline \begin{tabular}{l|l|}
$q S_{x}$ & $\Sigma_{x} \circ$ \\
\end{tabular} & $\exists i, j, k$ & $\left\{\begin{array}{l}\omega_{i} \neq\left(\omega_{j}, \omega_{k}, \omega_{l}, \omega_{m}, \omega_{n}\right), \\
\omega_{i} \nmid \omega_{j}+\omega_{k}, \omega_{i}\left|\omega_{l}+\omega_{m}, \omega_{i}\right| \omega_{n} ;\end{array}\right.$ & $\left(E_{2 s}\right)$ \\
\hline \begin{tabular}{l|l|}
$q S_{x}$ & $\Sigma_{x} q$ \\
\end{tabular} & $\exists i, j, k$ & $\left\{\begin{array}{l}\omega_{i} \neq\left(\omega_{j}, \omega_{k}, \omega_{l}, \omega_{m}, \omega_{n}\right) \backslash \omega_{l}, \\
\omega_{i} \nmid \omega_{j}+\omega_{k}, \omega_{i}\left|\omega_{l}+\omega_{m}, \omega_{i}\right| \omega_{n} ;\end{array}\right.$ & $\left(E_{3 s}\right)$ \\
\hline \begin{tabular}{l|l|}
$q S_{x}$ & $\Sigma_{\circ} x$ \\
\end{tabular} & $\exists i, j, k$ & $\left\{\begin{array}{l}\omega_{i} \neq\left(\omega_{j}, \omega_{k}, \omega_{l}, \omega_{m}, \omega_{n}\right) \backslash \omega_{l}, \\
\omega_{i} \nmid \omega_{j}+\omega_{k}, \omega_{i} \mid \omega_{l}+\omega_{m}, \omega_{i} \nmid \omega_{n} ;\end{array}\right.$ & $\left(E_{4 s}\right)$ \\
\hline \begin{tabular}{|l|l|}
$q S_{x}$ & $\Sigma_{\circ} \circ$ \\
\end{tabular} & $\exists i, j, k$ & $\left\{\begin{array}{l}\omega_{i} \neq\left(\omega_{j}, \omega_{k}, \omega_{l}, \omega_{m}, \omega_{n}\right) \backslash \omega_{l}, \\
\omega_{i} \nmid \omega_{j}+\omega_{k}, \omega_{i}\left|\omega_{l}+\omega_{m}, \omega_{i}\right| \omega_{n} ;\end{array}\right.$ & $\left(E_{5 s}\right)$ \\
\hline \begin{tabular}{l|l|}
$q S_{x}$ & $\Sigma_{\circ} q$ \\
\end{tabular} & $\exists i, j, k:$ & $\begin{array}{l}\omega_{i} \neq\left(\omega_{j}, \omega_{k}, \omega_{l}, \omega_{m}, \omega_{n}\right) \backslash\left(\omega_{m}, \omega_{n}\right), \\
\omega_{i} \nmid \omega_{j}+\omega_{k}, \omega_{i}\left|\omega_{l}+\omega_{m}, \omega_{i}\right| \omega_{n} ;\end{array}$ & $\left(E_{6 s}\right)$ \\
\hline \begin{tabular}{l|l|}
$q S_{\circ}$ & $\Sigma_{x} x$ \\
\end{tabular} & $\exists i, j, k$ & $\left\{\begin{array}{l}\omega_{i} \neq\left(\omega_{j}, \omega_{k}, \omega_{l}, \omega_{m}, \omega_{n}\right) \backslash \omega_{j}, \\
\omega_{i} \nmid \omega_{j}+\omega_{k}, \omega_{i} \mid \omega_{l}+\omega_{m}, \omega_{i} \nmid \omega_{n} ;\end{array}\right.$ & $\left(E_{7 s}\right)$ \\
\hline \begin{tabular}{l|l|}
$q S_{\circ}$ & $\Sigma_{x} \circ$ \\
\end{tabular} & $\exists i, j, k$ & $\begin{array}{l}\omega_{i} \neq\left(\omega_{j}, \omega_{k}, \omega_{l}, \omega_{m}, \omega_{n}\right) \backslash \omega_{j}, \\
\omega_{i} \nmid \omega_{j}+\omega_{k}, \omega_{i}\left|\omega_{l}+\omega_{m}, \omega_{i}\right| \omega_{n} ;\end{array}$ & $\left(E_{8 s}\right)$ \\
\hline \begin{tabular}{l|l|}
$q S_{\circ}$ & $\Sigma_{x} q$ \\
\end{tabular} & $\exists i, j, k$ & $\left\{\begin{array}{l}\omega_{i} \neq\left(\omega_{j}, \omega_{k}, \omega_{l}, \omega_{m}, \omega_{n}\right) \backslash\left(\omega_{j}, \omega_{n}\right), \\
\omega_{i} \nmid \omega_{j}+\omega_{k}, \omega_{i}\left|\omega_{l}+\omega_{m}, \omega_{i}\right| \omega_{n} ;\end{array}\right.$ & $\left(E_{9_{s}}\right)$ \\
\hline \begin{tabular}{l|l|}
$q S_{\circ}$ & $\Sigma_{\circ} x$ \\
\end{tabular} & $\exists i, j, k:$ & $\left\{\begin{array}{l}\omega_{i} \neq\left(\omega_{j}, \omega_{k}, \omega_{l}, \omega_{m}, \omega_{n}\right) \backslash\left(\omega_{j}, \omega_{l}\right), \\
\omega_{i} \nmid \omega_{j}+\omega_{k}, \omega_{i} \mid \omega_{l}+\omega_{m}, \omega_{i} \nmid \omega_{n} ;\end{array}\right.$ & $\left(E_{10 s}\right)$ \\
\hline \begin{tabular}{l|l|}
$q S_{\circ}$ & $\Sigma_{\circ} \circ$ \\
\end{tabular} & $\exists i, j, k:$ & $\left\{\begin{array}{l}\omega_{i} \neq\left(\omega_{j}, \omega_{k}, \omega_{l}, \omega_{m}, \omega_{n}\right) \backslash\left(\omega_{j}, \omega_{l}\right) \\
\omega_{i} \nmid \omega_{j}+\omega_{k}, \omega_{i}\left|\omega_{l}+\omega_{m}, \omega_{i}\right| \omega_{n}\end{array}\right.$ & $\left(E_{11 s}\right)$ \\
\hline \begin{tabular}{l|l|}
$q S_{\circ}$ & $\Sigma_{\circ} q$ \\
\end{tabular} & $\exists i, j, k:$ & $\left\{\begin{array}{l}\omega_{i} \neq\left(\omega_{j}, \omega_{k}, \omega_{l}, \omega_{m}, \omega_{n}\right) \backslash\left(\omega_{j}, \omega_{l}, \omega_{n}\right), \\
\omega_{i} \nmid \omega_{j}+\omega_{k}, \omega_{i}\left|\omega_{l}+\omega_{m}, \omega_{i}\right| \omega_{n} ;\end{array}\right.$ & $\left(E_{12 s}\right)$ \\
\hline \begin{tabular}{|l|l|}
$q \Sigma_{x}$ & $\Sigma_{x} x$ \\
\end{tabular} & $\exists i, j, k$ & $\left\{\begin{array}{l}\omega_{i} \neq\left(\omega_{j}, \omega_{k}, \omega_{l}, \omega_{m}, \omega_{n}\right), \\
\omega_{i}\left|\omega_{j}+\omega_{k}, \omega_{i}\right| \omega_{l}+\omega_{m}, \omega_{i} \nmid \omega_{n} ;\end{array}\right.$ & $\left(E_{13 s}\right)$ \\
\hline
\end{tabular}




$\exists i, j, k:\left\{\begin{array}{l}\omega_{i} \neq\left(\omega_{j}, \omega_{k}, \omega_{l}, \omega_{m}, \omega_{n}\right), \\ \omega_{i}\left|\omega_{j}+\omega_{k}, \omega_{i}\right| \omega_{l}+\omega_{m}, \omega_{i} \mid \omega_{n} ;\end{array}\right.$
$\exists i, j, k:\left\{\begin{array}{l}\omega_{i} \neq\left(\omega_{j}, \omega_{k}, \omega_{l}, \omega_{m}, \omega_{n}\right) \backslash \omega_{n}, \\ \omega_{i}\left|\omega_{j}+\omega_{k}, \omega_{i}\right| \omega_{l}+\omega_{m}, \omega_{i} \mid \omega_{n} ;\end{array}\right.$
$\exists i, j, k:\left\{\begin{array}{l}\omega_{i} \neq\left(\omega_{j}, \omega_{k}, \omega_{l}, \omega_{m}, \omega_{n}\right) \backslash \omega_{l}, \\ \omega_{i}\left|\omega_{j}+\omega_{k}, \omega_{i}\right| \omega_{l}+\omega_{m}, \omega_{i} \nmid \omega_{n} ;\end{array}\right.$
$\exists i \Sigma_{x} \mid \Sigma_{x} q$
$\exists i \Sigma_{x} \mid \Sigma_{\circ} x$
$\exists i, j, k:\left\{\begin{array}{l}\omega_{i} \neq\left(\omega_{j}, \omega_{k}, \omega_{l}, \omega_{m}, \omega_{n}\right) \backslash \omega_{l}, \\ \omega_{i}\left|\omega_{j}+\omega_{k}, \omega_{i}\right| \omega_{l}+\omega_{m}, \omega_{i} \mid \omega_{n} ; \\ \omega_{i}\left|\omega_{j}+\omega_{k}, \omega_{i}\right| \omega_{l}+\omega_{m}, \omega_{i} \mid \omega_{n} ;\end{array}\right.$
$\exists i, j, k:\left\{\begin{array}{l}\omega_{i} \neq\left(\omega_{j}, \omega_{k}, \omega_{l}, \omega_{m}, \omega_{n}\right) \backslash \omega_{j}, \\ \omega_{i}\left|\omega_{j}+\omega_{k}, \omega_{i}\right| \omega_{l}+\omega_{m}, \omega_{i} \nmid \omega_{n} ;\end{array}\right.$
$\exists i \Sigma_{x} \mid \Sigma_{\circ} q$

\section{Demonstração dos Lemas relativos ao problema da divisão composta pela soma}

Apresentamos a seguir a demonstração dos Lemas 2.15-2.22. Em linhas gerais, todos os Lemas são demonstrados utilizando os mesmos argumentos. Desta maneira, decidimos incluir a descrição por extenso de unicamente dois dos Lemas, a saber a do Lema 2.15 e a do Lema 2.18. Embora arbitrária, esta escolha inclui a análise de um caso simples e outro com maior desenvolvimento.

DemonstraÇão Do Lema 2.15. O evento $G_{1}(q)$ refere-se ao caso onde o jogador tem em $\mathcal{H}$ (em suas mãos) um divisor com valor $q$ e outras duas cartas, que somadas, resultam em uma soma não favorável. Então, $\mathcal{H}$ está constituído por uma carta com valor $q$ e outras duas cartas do tipo $S_{x}$. Passamos a análise das cartas em $\mathscr{D}$ (na mesa). Duas das cartas em $\mathscr{D}$ formam uma soma favorável do tipo $\Sigma_{x}$. Além das duas cartas da mesa que compõem a referida soma, ainda resta uma carta em $\mathscr{D}$ que pode ser $x, \diamond$ ou $q$. Desta forma, estamos nos referindo à seguinte união

$$
G_{1}(q)=\begin{array}{|l|l|l|l|l|l|}
q S_{x} & \Sigma_{x} x \\
\hline q S_{x} & \Sigma_{x} \diamond \\
\hline q S_{x} & \Sigma_{x} q \\
\hline
\end{array}
$$


Calcularemos as cardinalidades de $q, S_{x}$ e $\Sigma_{x}$ para finalmente calcular o número de maneiras para escolhermos o valor da última carta em $\mathscr{D}$. Seja $q \in\{1, \ldots, 13\}$. A cardinalidade do evento $G_{1}(q)$ é

$$
\begin{aligned}
& \left(\begin{array}{l}
4 \\
1
\end{array}\right)\left[\left(\begin{array}{l}
4 \\
1
\end{array}\right)\left(\begin{array}{l}
4 \\
1
\end{array}\right) S_{x}^{\prime}(q)\left(\begin{array}{l}
3 \\
1
\end{array}\right)\left(N_{q}-4-4\right)+\left(\begin{array}{l}
4 \\
1
\end{array}\right)\left(\begin{array}{l}
4 \\
1
\end{array}\right) S_{x}^{\prime}(q)\left(\begin{array}{l}
4 \\
1
\end{array}\right)\left(\begin{array}{l}
4 \\
1
\end{array}\right) \Sigma_{x}^{\prime}(q)\right] \\
& \cdot\left[\left(\begin{array}{c}
52-N_{q}-1 \\
1
\end{array}\right)+\left(\begin{array}{c}
N_{q}-4-3 \\
1
\end{array}\right)+\left(\begin{array}{l}
3 \\
1
\end{array}\right)\right] \\
& +\left(\begin{array}{l}
4 \\
1
\end{array}\right)\left[\left(\begin{array}{l}
4 \\
1
\end{array}\right)\left(\begin{array}{l}
4 \\
1
\end{array}\right) \Sigma_{x}^{\prime \prime}(q)\left(\begin{array}{l}
3 \\
1
\end{array}\right)\left(N_{q}-4\right)+\left(\begin{array}{l}
4 \\
1
\end{array}\right)\left(\begin{array}{l}
4 \\
1
\end{array}\right) \Sigma_{x}^{\prime \prime}(q)\left(\begin{array}{c}
52-N_{q}-4-4 \\
1
\end{array}\right)\left(\begin{array}{c}
N_{q}-4 \\
1
\end{array}\right)\right] \\
& \cdot\left[\left(\begin{array}{c}
52-N_{q}-3 \\
1
\end{array}\right)+\left(\begin{array}{c}
N_{q}-4-1 \\
1
\end{array}\right)+\left(\begin{array}{l}
3 \\
1
\end{array}\right)\right] \\
& +\left(\begin{array}{l}
4 \\
1
\end{array}\right)\left[\left(\begin{array}{l}
4 \\
1
\end{array}\right)\left(\begin{array}{l}
4 \\
1
\end{array}\right) S_{x}^{\prime}(q)\left(\begin{array}{c}
4-1 \\
2
\end{array}\right)+\left(\begin{array}{l}
4 \\
2
\end{array}\right) \Sigma_{x}^{\prime \prime \prime}(q)\left(N_{q}-4-4\right)\left(52-N_{q}\right)\right]\left[\left(\begin{array}{c}
52-N_{q}-1 \\
1
\end{array}\right)\right. \\
& \left.+\left(\begin{array}{c}
N_{q}-4-3 \\
1
\end{array}\right)+\left(\begin{array}{l}
3 \\
1
\end{array}\right)\right] \\
& +\left(\begin{array}{l}
4 \\
1
\end{array}\right)\left[\left(\begin{array}{l}
4 \\
1
\end{array}\right)\left(\begin{array}{l}
4 \\
1
\end{array}\right) S_{x}^{\prime}(q)\left(\begin{array}{c}
4-1 \\
2
\end{array}\right)+\left(\begin{array}{l}
4 \\
2
\end{array}\right) \Sigma_{x}^{i v}(q)\left(N_{q}-4\right)\left(52-N_{q}-4\right)\right]\left[\left(\begin{array}{c}
52-N_{q}-3 \\
1
\end{array}\right)\right. \\
& \left.+\left(\begin{array}{c}
N_{q}-4-1 \\
1
\end{array}\right)+\left(\begin{array}{l}
3 \\
1
\end{array}\right)\right] \\
& +\left(\begin{array}{l}
4 \\
1
\end{array}\right)\left(\begin{array}{l}
4 \\
1
\end{array}\right)\left(\begin{array}{l}
4 \\
1
\end{array}\right) S_{x}^{\prime \prime}(q)\left(\begin{array}{l}
4 \\
1
\end{array}\right)\left(\begin{array}{l}
4 \\
1
\end{array}\right) \Sigma_{x}^{\prime}(q)\left[\left(\begin{array}{c}
52-N_{q}-2 \\
1
\end{array}\right)+\left(\begin{array}{c}
N_{q}-4-2 \\
1
\end{array}\right)+\left(\begin{array}{l}
3 \\
1
\end{array}\right)\right] \\
& +\left(\begin{array}{l}
4 \\
1
\end{array}\right)\left[\left(52-N_{q}-4-4\right)\left(\begin{array}{l}
3 \\
1
\end{array}\right)\left(\begin{array}{l}
4 \\
1
\end{array}\right)\left(\begin{array}{l}
4 \\
1
\end{array}\right)+H_{q}\right]\left[\left(\begin{array}{c}
52-N_{q}-4 \\
1
\end{array}\right)+\left(\begin{array}{c}
N_{q}-4 \\
1
\end{array}\right)+\left(\begin{array}{l}
3 \\
1
\end{array}\right)\right] \\
& +\left(\begin{array}{l}
4 \\
1
\end{array}\right)\left(\begin{array}{l}
4 \\
1
\end{array}\right)\left(\begin{array}{l}
4 \\
1
\end{array}\right) S_{x}^{\prime \prime}(q)\left(\begin{array}{l}
4 \\
1
\end{array}\right)\left(\begin{array}{l}
4 \\
1
\end{array}\right) \Sigma_{x}^{\prime \prime \prime}(q)\left[\left(\begin{array}{c}
52-N_{q}-2 \\
1
\end{array}\right)+\left(\begin{array}{c}
N_{q}-4-2 \\
1
\end{array}\right)+\left(\begin{array}{l}
3 \\
1
\end{array}\right)\right] \\
& +\left(\begin{array}{l}
4 \\
1
\end{array}\right)\left[\left(\begin{array}{l}
4 \\
1
\end{array}\right)\left(\begin{array}{l}
4 \\
1
\end{array}\right) S_{x}^{\prime \prime}(q)\left(\begin{array}{l}
3 \\
2
\end{array}\right)+\left(\begin{array}{l}
4 \\
1
\end{array}\right)\left(\begin{array}{l}
4 \\
1
\end{array}\right) S_{x}^{\prime \prime}(q)\left(\begin{array}{l}
4 \\
2
\end{array}\right) \Sigma_{x}^{i v}(q)\right] \\
& \cdot\left[\left(\begin{array}{c}
52-N_{q}-4 \\
1
\end{array}\right)+\left(\begin{array}{c}
N_{q}-4 \\
1
\end{array}\right)+\left(\begin{array}{l}
3 \\
1
\end{array}\right)\right] \\
& +\left(\begin{array}{l}
4 \\
1
\end{array}\right)\left(\begin{array}{l}
4 \\
2
\end{array}\right) S_{x}^{\prime \prime \prime}(q)\left(\begin{array}{l}
4 \\
1
\end{array}\right)\left(\begin{array}{l}
4 \\
1
\end{array}\right) \Sigma_{x}^{\prime}(q)\left[\left(\begin{array}{c}
52-N_{q}-2 \\
1
\end{array}\right)+\left(\begin{array}{c}
N_{q}-4-2 \\
1
\end{array}\right)+\left(\begin{array}{l}
3 \\
1
\end{array}\right)\right] \\
& +\left(\begin{array}{l}
4 \\
1
\end{array}\right)\left[\left(\begin{array}{l}
3 \\
2
\end{array}\right)\left(\begin{array}{l}
4 \\
1
\end{array}\right)\left(\begin{array}{l}
4 \\
1
\end{array}\right) \Sigma_{x}^{\prime \prime}(q)+\left(\begin{array}{l}
4 \\
2
\end{array}\right) S_{x}^{\prime \prime \prime}(q)\left(\begin{array}{l}
4 \\
1
\end{array}\right)\left(\begin{array}{l}
4 \\
1
\end{array}\right) \Sigma_{x}^{\prime \prime}(q)\right] \\
& \cdot\left[\left(\begin{array}{c}
52-N_{q}-4 \\
1
\end{array}\right)+\left(\begin{array}{c}
N_{q}-4 \\
1
\end{array}\right)+\left(\begin{array}{l}
3 \\
1
\end{array}\right)\right] \\
& +\left(\begin{array}{l}
4 \\
1
\end{array}\right)\left(\begin{array}{l}
4 \\
2
\end{array}\right) S_{x}^{\prime \prime \prime}(q)\left(\begin{array}{l}
4 \\
2
\end{array}\right) \Sigma_{x}^{\prime \prime \prime}(q)\left[\left(\begin{array}{c}
52-N_{q}-2 \\
1
\end{array}\right)+\left(\begin{array}{c}
N_{q}-4-2 \\
1
\end{array}\right)+\left(\begin{array}{l}
3 \\
1
\end{array}\right)\right] \\
& +\left(\begin{array}{l}
4 \\
1
\end{array}\right)\left[\left(\begin{array}{l}
4 \\
2
\end{array}\right) S_{x}^{\prime \prime \prime}(q)\left(\begin{array}{l}
4 \\
2
\end{array}\right) \Sigma_{x}^{i v}\right]\left[\left(\begin{array}{c}
52-N_{q}-4 \\
1
\end{array}\right)+\left(\begin{array}{c}
N_{q}-4 \\
1
\end{array}\right)+\left(\begin{array}{l}
3 \\
1
\end{array}\right)\right]
\end{aligned}
$$

Para justificar esta expressão, observamos primeiro que o conjunto $S_{x}$ é composto pelo subconjuntos $S_{x}^{\prime}(q), S_{x}^{\prime \prime}(q)$ e $S_{x}^{\prime \prime \prime}(q)$ e que o conjunto $\Sigma_{x}$ é composto pelos subconjuntos $\Sigma_{x}^{\prime}(q), \Sigma_{x}^{\prime \prime}(q), \Sigma_{x}^{\prime \prime \prime}(q)$ e $\sum_{x}^{i v}(q)$. Portanto, temos 1 situação referente à carta $q, 3$ situações referentes ao conjunto $S_{x}, 4$ situações referentes ao conjunto $\Sigma_{x}$ e 3 situações referentes à última carta $(x, \diamond$ ou $q)$. Pelo princípio 
multiplicativo temos $1 \cdot 3 \cdot 4 \cdot 3=36$ partes a serem escritas e somadas de tal maneira que nenhuma combinação dessas deixe de ser calculada. Poderá observar que escrevemos apenas 12 partes. Isso se justifica pela fatoração que foi possível fazer considerando a última carta e que explicaremos a seguir. Apresentaremos agora as 36 situações do grupo $G_{1}(q)$ para se ter uma visão geral.

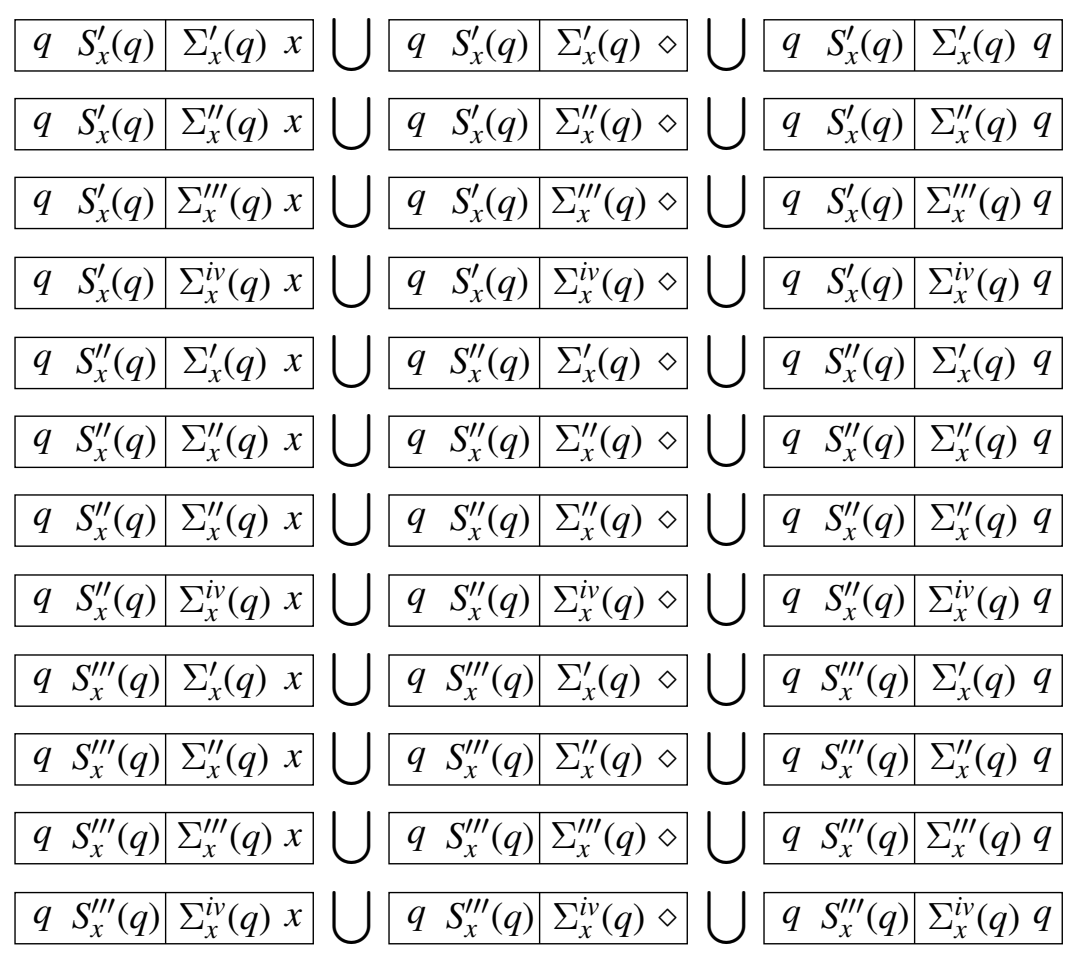

Os três primeiros casos abordados em $G_{1}(q)$,

$$
\begin{array}{|ll|l|l|l|l|l|l|l|l|l|l|l|l|l|l|l|l|l|}
\hline q & S_{x}^{\prime}(q) & \Sigma_{x}^{\prime}(q) & S_{x}^{\prime}(q) & \Sigma_{x}^{\prime}(q) \diamond & \Sigma_{x}^{\prime}(q) & q \\
\hline
\end{array}
$$

podem ser contados pela linha

$$
\begin{gathered}
\left(\begin{array}{l}
4 \\
1
\end{array}\right)\left[\left(\begin{array}{l}
4 \\
1
\end{array}\right)\left(\begin{array}{l}
4 \\
1
\end{array}\right) S_{x}^{\prime}(q)\left(\begin{array}{l}
3 \\
1
\end{array}\right)\left(N_{q}-4-4\right)+\left(\begin{array}{l}
4 \\
1
\end{array}\right)\left(\begin{array}{l}
4 \\
1
\end{array}\right) S_{x}^{\prime}(q)\left(\begin{array}{l}
4 \\
1
\end{array}\right)\left(\begin{array}{l}
4 \\
1
\end{array}\right) \Sigma_{x}^{\prime}(q)\right] \\
{\left[\left(\begin{array}{c}
52-N_{q}-1 \\
1
\end{array}\right)+\left(\begin{array}{c}
N_{q}-4-3 \\
1
\end{array}\right)+\left(\begin{array}{l}
3 \\
1
\end{array}\right)\right]}
\end{gathered}
$$

onde o primeiro binômio $\left(\begin{array}{l}4 \\ 1\end{array}\right)$ representa a escolha dos naipes de $q$, sendo possível escolher um naipe em quatro opções.

Sabemos que $S_{x}^{\prime}(q)$ são pares de cartas com um múltiplo de $q$, representado por $\diamond$, e um não múltiplo $x$. $\Sigma_{x}^{\prime}(q)$ são pares de cartas com dois não múltiplos $x$. Para explicar o conteúdo presente em

$$
\left[\left(\begin{array}{l}
4 \\
1
\end{array}\right)\left(\begin{array}{l}
4 \\
1
\end{array}\right) S_{x}^{\prime}(q)\left(\begin{array}{l}
3 \\
1
\end{array}\right)\left(N_{q}-4-4\right)+\left(\begin{array}{l}
4 \\
1
\end{array}\right)\left(\begin{array}{l}
4 \\
1
\end{array}\right) S_{x}^{\prime}(q)\left(\begin{array}{l}
4 \\
1
\end{array}\right)\left(\begin{array}{l}
4 \\
1
\end{array}\right) \Sigma_{x}^{\prime}(q)\right]
$$

temos que considerar dois casos particulares:

- O múltiplo de $q$ presente em $S_{x}^{\prime}(q)$ é igual a um dos múltiplos de $q$ presentes em $\Sigma_{x}^{\prime}(q)$. Neste caso, temos que calcular os naipes das duas cartas de $S_{x}^{\prime}(q)$ por $\left(\begin{array}{l}4 \\ 1\end{array}\right)\left(\begin{array}{l}4 \\ 1\end{array}\right)$ e a quatidade desses pares por $S_{x}^{\prime}(q)$. Como o múltiplo se repete, restam três para serem contados em $\Sigma_{x}^{\prime}(q)$ e por isso o binômio $\left(\begin{array}{l}3 \\ 1\end{array}\right)$. Em seguida, para contarmos o último múltiplo de $q$, devemos considerar todos seus múltiplos, dados por $N_{q}$. Contudo devemos desconsiderar quatro deles, os próprios $q$ e o outro múltiplo que acabou de ser citado (considerado 4 
vezes devido aos naipes), o que justifica não ser utilizado novamente. Desta forma temos $\left(N_{q}-4-4\right)$.

Ressaltamos que $N_{q}$ abrange todos os múltiplos incluindo os diferentes naipes e por isso não há a necessidade de contar naipes quando citamos $N_{q}$.

- O múltiplo de $q$ presente em $S_{x}^{\prime}(q)$ é diferente dos múltiplos de $q$ presentes em $\Sigma_{x}^{\prime}(q)$. Contamos os naipes por $\left(\begin{array}{l}4 \\ 1\end{array}\right)\left(\begin{array}{l}4 \\ 1\end{array}\right)$ e a quantidade destes pares por $S_{x}^{\prime}(q)$ e os naipes $\left(\begin{array}{l}4 \\ 1\end{array}\right)\left(\begin{array}{l}4 \\ 1\end{array}\right)$ dos pares $\Sigma_{x}^{\prime}(q)$.

Cada um dos binômios presentes em

$$
\left[\left(\begin{array}{c}
52-N_{q}-1 \\
1
\end{array}\right)+\left(\begin{array}{c}
N_{q}-4-3 \\
1
\end{array}\right)+\left(\begin{array}{l}
3 \\
1
\end{array}\right)\right]
$$

representam, respectivamente a escolha de uma das cartas $x, \diamond \mathrm{e} q$ na última posição. Contamos $x$ por $\left(\begin{array}{c}52-N_{q}-1 \\ 1\end{array}\right)$ dado que são 52 cartas no baralho e destas devemos retirar todas que são múltiplas de $q, N_{q}$, e uma não múltipla que já foi utilizada. A parte $\left(\begin{array}{c}N_{q}-4-3 \\ 1\end{array}\right)$ representa a escolha de um múltiplo de $N_{q}$, dado que não podemos utilizar $q$ (contados como 4 devidos aos naipes) e os três múltiplos já foram utilizados. Como a primeira carta da sequência é um $q$, restaram apenas três delas para se escolher uma que será colocada na última posição, o que justifica a escolha $\left(\begin{array}{l}3 \\ 1\end{array}\right)$.

Descrevemos a seguir a contagem dos casos

$$
\begin{array}{|ll|l|l|l|l|l|l|l|l|l|l|l|l|l|l|l|}
\hline q & S_{x}^{\prime}(q) & \Sigma_{x}^{\prime \prime}(q) x & S_{x}^{\prime}(q) & \Sigma_{x}^{\prime \prime}(q) \diamond & \Sigma_{x}^{\prime \prime}(q) q \\
\hline
\end{array}
$$

calculados por

$$
\begin{gathered}
\left(\begin{array}{l}
4 \\
1
\end{array}\right)\left[\left(\begin{array}{l}
4 \\
1
\end{array}\right)\left(\begin{array}{l}
4 \\
1
\end{array}\right) \Sigma_{x}^{\prime \prime}(q)\left(\begin{array}{l}
3 \\
1
\end{array}\right)\left(N_{q}-4\right)+\left(\begin{array}{l}
4 \\
1
\end{array}\right)\left(\begin{array}{l}
4 \\
1
\end{array}\right) \Sigma_{x}^{\prime \prime}(q)\left(\begin{array}{c}
52-N_{q}-4-4 \\
1
\end{array}\right)\left(\begin{array}{c}
N_{q}-4 \\
1
\end{array}\right)\right] \\
{\left[\left(\begin{array}{c}
52-N_{q}-3 \\
1
\end{array}\right)+\left(\begin{array}{c}
N_{q}-4-1 \\
1
\end{array}\right)+\left(\begin{array}{l}
3 \\
1
\end{array}\right)\right]}
\end{gathered}
$$

Estamos querendo resolver $S_{x}^{\prime} \cdot \Sigma_{x}^{\prime \prime}$, considerando suas cardinalidades, e por se tratar de produto, realizaremos $\Sigma_{x}^{\prime \prime} \cdot S_{x}^{\prime}$, nesta ordem.

Podemos escolher o naipe de $q$ de quatro maneira e para representar esta escolha utilizamos $\left(\begin{array}{l}4 \\ 1\end{array}\right)$. Note que $S_{x}^{\prime}(q)$ é composto por um $x$ e um $\diamond$ e que $\Sigma_{x}^{\prime \prime}(q)$ é composto por dois $x$ diferentes entre si. Visto isso, há duas situações que devem ser consideradas para explicar a composição de

$$
\left[\left(\begin{array}{l}
4 \\
1
\end{array}\right)\left(\begin{array}{l}
4 \\
1
\end{array}\right) \Sigma_{x}^{\prime \prime}(q)\left(\begin{array}{l}
3 \\
1
\end{array}\right)\left(N_{q}-4\right)+\left(\begin{array}{l}
4 \\
1
\end{array}\right)\left(\begin{array}{l}
4 \\
1
\end{array}\right) \Sigma_{x}^{\prime \prime}(q)\left(\begin{array}{c}
52-N_{q}-4-4 \\
1
\end{array}\right)\left(\begin{array}{c}
N_{q}-4 \\
1
\end{array}\right)\right] .
$$

- O não múltiplo $x$ presente em $S_{x}^{\prime}(q)$ é igual a um dos não múltiplos presentes em $\Sigma_{x}^{\prime \prime}(q)$. Iniciamos calculando a cardinalidade de $\Sigma_{x}^{\prime \prime}(q)$ considerando os naipes das duas diferentes cartas por $\left(\begin{array}{l}4 \\ 1\end{array}\right)\left(\begin{array}{l}4 \\ 1\end{array}\right) \Sigma_{x}^{\prime \prime}(q)$. A próxima carta é igual a uma já escolhida. Então devemos a escolher entre três cartas possíveis, logo $\left(\begin{array}{l}3 \\ 1\end{array}\right)$. A carta $\diamond$ é múltipla e, por isso, devemos recorrer a todas as cartas múltiplas descontando os própios $q$. Assim, escolhemos $\diamond$ por $\left(N_{q}-4\right)$.

- Neste caso, todas as cartas são todas diferentes entre si. Iniciamos calculando a cardinalidade de $\Sigma_{x}^{\prime \prime}(q)$ considerando os naipes das duas diferentes cartas por $\left(\begin{array}{l}4 \\ 1\end{array}\right)\left(\begin{array}{l}4 \\ 1\end{array}\right) \Sigma_{x}^{\prime \prime}(q)$. A próxima carta, além de ser do tipo $x$, não pode ser igual a nenhuma das duas primeiras. De todas as $\mathbf{5 2}$ cartas devemos tirar as que são múltiplas, $N_{q}$, e as cartas já utilizadas. Isso explica $\left(\begin{array}{c}52-N_{q}-4-4 \\ 1\end{array}\right)$. A escolha da última carta é análoga ao caso anterior.

Cada um dos binômios presentes em

$$
\left[\left(\begin{array}{c}
52-N_{q}-3 \\
1
\end{array}\right)+\left(\begin{array}{c}
N_{q}-4-1 \\
1
\end{array}\right)+\left(\begin{array}{l}
3 \\
1
\end{array}\right)\right]
$$


representam, respectivamente a escolha de uma das cartas $x, \diamond \mathrm{e} q$ na última posição. Contamos $x$ por $\left(\begin{array}{c}52-N_{q}-3 \\ 1\end{array}\right)$, dado que são 52 cartas no baralho e destas devemos retirar todas que são múltiplas, $N_{q}$, e três não múltiplas que já foram utilizadas. A parte $\left(\begin{array}{c}N_{q}-4-1 \\ 1\end{array}\right)$ representa a escolha de um múltiplo de $N_{q}$, dado que não podemos utilizar nenhum dos quatro $q$ e o múltiplo $\diamond$ que já foi utilizado. Como a primeira carta da sequência é um $q$, restaram apenas três delas para se escolher uma que será colocada na última posição, o que justifica a escolha $\left(\begin{array}{l}3 \\ 1\end{array}\right)$.

Descrevemos a seguir a contagem dos casos

$$
\begin{array}{|ll|l|l|l|l|l|l|l|l|l|l|l|l|l|l|}
\hline q & S_{x}^{\prime}(q) & \Sigma_{x}^{\prime \prime \prime}(q) x & S_{x}^{\prime}(q) & \Sigma_{x}^{\prime \prime \prime}(q) \diamond & \Sigma_{x}^{\prime \prime \prime}(q) q \\
\hline
\end{array}
$$

calculados por

$$
\begin{gathered}
\left(\begin{array}{l}
4 \\
1
\end{array}\right)\left[\left(\begin{array}{l}
4 \\
1
\end{array}\right)\left(\begin{array}{l}
4 \\
1
\end{array}\right) S_{x}^{\prime}(q)\left(\begin{array}{c}
4-1 \\
2
\end{array}\right)+\left(\begin{array}{l}
4 \\
2
\end{array}\right) \Sigma_{x}^{\prime \prime \prime}(q)\left(N_{q}-4-4\right)\left(52-N_{q}\right)\right]\left[\left(\begin{array}{c}
52-N_{q}-1 \\
1
\end{array}\right)\right. \\
\left.+\left(\begin{array}{c}
N_{q}-4-3 \\
1
\end{array}\right)+\left(\begin{array}{l}
3 \\
1
\end{array}\right)\right]
\end{gathered}
$$

O primeiro binômio $\left(\begin{array}{l}4 \\ 1\end{array}\right)$ representa a escolha dos naipes de $q$, sendo possível escolher um naipe em quatro opções.

Sabemos que $S_{x}^{\prime}(q)$ são pares de cartas com um múltiplo de $q$,, e um não múltiplo $x$. $\Sigma_{x}^{\prime \prime \prime}(q)$ são pares de cartas com dois múltiplos de $q, \diamond$, iguais. Para explicar o conteúdo presente em

$$
\left[\left(\begin{array}{l}
4 \\
1
\end{array}\right)\left(\begin{array}{l}
4 \\
1
\end{array}\right) S_{x}^{\prime}(q)\left(\begin{array}{c}
4-1 \\
2
\end{array}\right)+\left(\begin{array}{l}
4 \\
2
\end{array}\right) \Sigma_{x}^{\prime \prime \prime}(q)\left(N_{q}-4-4\right)\left(52-N_{q}\right)\right]
$$

temos que considerar duas particularidades, a saber

- O múltiplo de $q$ presente em $S_{x}^{\prime}(q)$ é igual aos múltiplos de $q$ presentes em $\Sigma_{x}^{\prime \prime \prime}(q)$. Escolhemos os naipes dos pares $S_{x}^{\prime}(q)$ por $\left(\begin{array}{l}4 \\ 1\end{array}\right)\left(\begin{array}{l}4 \\ 1\end{array}\right)$, justificando a parte $\left(\begin{array}{l}4 \\ 1\end{array}\right)\left(\begin{array}{l}4 \\ 1\end{array}\right) S_{x}^{\prime}(q)$. Como as cartas de $\Sigma_{x}^{\prime \prime \prime}(q)$ são iguais a uma carta já escolhida, precisamos escolher duas em três que é o mesmo que $\left(\begin{array}{c}4-1 \\ 1\end{array}\right)$.

- O múltiplo de $q$ presente em $S_{x}^{\prime}(q)$ é diferente dos múltiplos de $q$ presentes em $\Sigma_{x}^{\prime \prime \prime}(q)$. Calculamos primeiro os pares de $\Sigma_{x}^{\prime \prime \prime}(q)$ por $\left(\begin{array}{l}4 \\ 2\end{array}\right) \Sigma_{x}^{\prime \prime \prime}(q)$ considerando que são cartas iguais e por isso escolhemos 2 em 4 opções. Essas opções não poderão ser escolhidas em $S_{x}^{\prime}(q)$ e, por isso, as tiramos de todos os possíveis múltiplos $N_{q}$ e também os próprios $q$, ficando $\left(N_{q}-4-4\right)$. A esolha do não múltiplo de $q$ se dá retirando das 52 cartas do baralho as cartas $N_{q}$ que são múltiplas, ficando assim $\left(52-N_{q}\right)$.

Cada um dos binômios presentes em

$$
\left[\left(\begin{array}{c}
52-N_{q}-1 \\
1
\end{array}\right)+\left(\begin{array}{c}
N_{q}-4-3 \\
1
\end{array}\right)+\left(\begin{array}{l}
3 \\
1
\end{array}\right)\right]
$$

representam, respectivamente a escolha de uma das cartas $x, \diamond \mathrm{e} q$ na última posição. Contamos $x$ por $\left(\begin{array}{c}52-N_{q}-1 \\ 1\end{array}\right)$ dado que são 52 cartas no baralho e destas devemos retirar todas que são múltiplas, $N_{q}$, e uma não múltipla que já foi utilizada. A parte $\left(\begin{array}{c}N_{q}-4-3 \\ 1\end{array}\right)$ representa a escolha de um múltiplo de $N_{q}$, dado que não podemos utilizar nenhum dos quatro $q$ e três múltiplos $\diamond$ que já foram utilizados. Como a primeira carta da sequência é um $q$, restaram apenas três delas para se escolher uma que será colocada na última posição, o que justifica a escolha $\left(\begin{array}{l}3 \\ 1\end{array}\right)$.

Descrevemos a seguir a contagem dos casos

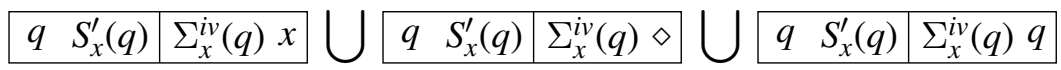

calculados por

$$
\left(\begin{array}{l}
4 \\
1
\end{array}\right)\left[\left(\begin{array}{l}
4 \\
1
\end{array}\right)\left(\begin{array}{l}
4 \\
1
\end{array}\right) S_{x}^{\prime}(q)\left(\begin{array}{c}
4-1 \\
2
\end{array}\right)+\left(\begin{array}{l}
4 \\
2
\end{array}\right) \Sigma_{x}^{i v}(q)\left(N_{q}-4\right)\left(52-N_{q}-4\right)\right]
$$




$$
\left[\left(\begin{array}{c}
52-N_{q}-3 \\
1
\end{array}\right)+\left(\begin{array}{c}
N_{q}-4-1 \\
1
\end{array}\right)+\left(\begin{array}{l}
3 \\
1
\end{array}\right)\right]
$$

O primeiro binômio $\left(\begin{array}{l}4 \\ 1\end{array}\right)$ representa a escolha dos naipes de $q$, sendo possível escolher um naipe em quatro opções.

Sabemos que $S_{x}^{\prime}(q)$ são pares de cartas com um múltiplo de $q, \diamond$, e um não múltiplo $x$. $\Sigma_{x}^{i v}(q)$ são pares de cartas com dois não múltiplos de $q, x$, iguais. Para explicar o conteúdo presente em

$$
\left[\left(\begin{array}{l}
4 \\
1
\end{array}\right)\left(\begin{array}{l}
4 \\
1
\end{array}\right) S_{x}^{\prime}(q)\left(\begin{array}{c}
4-1 \\
2
\end{array}\right)+\left(\begin{array}{l}
4 \\
2
\end{array}\right) \Sigma_{x}^{i v}(q)\left(N_{q}-4\right)\left(52-N_{q}-4\right)\right]
$$

temos que considerar duas particularidades, a saber:

- O não múltiplo $x$ presente em $S_{x}^{\prime}(q)$ é igual aos dois não múltiplos em $\Sigma_{x}^{i v}(q)$. Calculamos os naipes dos pares e a quantidade de pares que estão nas mãos do jogador por $\left(\begin{array}{l}4 \\ 1\end{array}\right)\left(\begin{array}{l}4 \\ 1\end{array}\right) S_{x}^{\prime}(q)$. Como as cartas que compõem o par da mesa são iguais a uma já escolhida, escolheremos duas em três, ou seja, $\left(\begin{array}{c}4-1 \\ 2\end{array}\right)$.

- O não múltiplo $x$ presente em $S_{x}^{\prime}(q)$ é diferente aos dois não múltiplos pesentes em $\Sigma_{x}^{i v}(q)$. Calculamos primeiro os pares de cartas $x$, iguais entre si, que estão na mesa considerando os naipes de cada uma e sua característica por $\left(\begin{array}{l}4 \\ 2\end{array}\right) \sum_{x}^{i v}(q)$. Voltamos nossa atenção para as mãos do jogador onde o par que queremos contar é composto de um $\diamond$, múltiplo de $q$ e de um $x$, não múltiplo de $q$. Para calcular $\diamond$, temos apenas que descontar de todos os múltiplos $N_{q}$ os quatro $q$, ficando $\left(N_{q}-4\right)$. Para escolher o não múltiplo $x$ que falta de todas as 52 cartas do baralho, descontamos todas que são múltiplas e ainda aquelas que iguais as que foram utilizadas na mesa, portanto $\left(52-N_{q}-4\right)$.

Cada um dos binômios presentes em

$$
\left[\left(\begin{array}{c}
52-N_{q}-3 \\
1
\end{array}\right)+\left(\begin{array}{c}
N_{q}-4-1 \\
1
\end{array}\right)+\left(\begin{array}{l}
3 \\
1
\end{array}\right)\right]
$$

representam, respectivamente a escolha de uma das cartas $x, \diamond \mathrm{e} q$ na última posição. Contamos $x$ por $\left(\begin{array}{c}52-N_{q}-3 \\ 1\end{array}\right)$ dado que são 52 cartas no baralho e destas devemos retirar todas que são múltiplas, $N_{q}$, e três não múltiplas que já foram utilizadas. A parte $\left(\begin{array}{c}N_{q}-4-1 \\ 1\end{array}\right)$ representa a escolha de um múltiplo de $N_{q}$, dado que não podemos utilizar nenhum dos quatro $q$ e um múltiplo $\diamond$ que já foi utilizado. Como a primeira carta da sequência é um $q$, restaram apenas três delas para se escolher uma que será colocada na última posição, o que justifica a escolha $\left(\begin{array}{l}3 \\ 1\end{array}\right)$.

Descrevemos a seguir a contagem dos casos

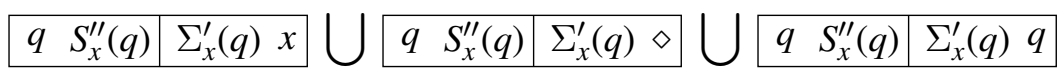

calculados por

$$
\left(\begin{array}{l}
4 \\
1
\end{array}\right)\left(\begin{array}{l}
4 \\
1
\end{array}\right)\left(\begin{array}{l}
4 \\
1
\end{array}\right) S_{x}^{\prime \prime}(q)\left(\begin{array}{l}
4 \\
1
\end{array}\right)\left(\begin{array}{l}
4 \\
1
\end{array}\right) \Sigma_{x}^{\prime}(q)\left[\left(\begin{array}{c}
52-N_{q}-2 \\
1
\end{array}\right)+\left(\begin{array}{c}
N_{q}-4-2 \\
1
\end{array}\right)+\left(\begin{array}{l}
3 \\
1
\end{array}\right)\right] .
$$

Não há nenhum tipo de interseção entre os subconjuntos $S_{x}^{\prime \prime}(q)$ e $\Sigma_{x}^{\prime}(q)$, pois o primeiro é composto apenas de não múltiplos de $q$, diferentes entre si e o segundo subconjunto é composto de dois múltiplos de $q$, também diferentes entre si.

Analisando a parte

$$
\left(\begin{array}{l}
4 \\
1
\end{array}\right)\left(\begin{array}{l}
4 \\
1
\end{array}\right)\left(\begin{array}{l}
4 \\
1
\end{array}\right) S_{x}^{\prime \prime}(q)\left(\begin{array}{l}
4 \\
1
\end{array}\right)\left(\begin{array}{l}
4 \\
1
\end{array}\right) \Sigma_{x}^{\prime}(q)
$$

temos que o primeiro binômio $\left(\begin{array}{l}4 \\ 1\end{array}\right)$ representa a escolha da primeira carta que é o próprio divisor $q$. A sequência $\left(\begin{array}{l}4 \\ 1\end{array}\right)\left(\begin{array}{l}4 \\ 1\end{array}\right) S_{x}^{\prime \prime}(q)$ está ligada a quantidade de pares $S_{x}^{\prime \prime}(q)$ e os naipes de cada uma das cartas que formam este tipo de par. De forma similiar ocorre com a sequência $\left(\begin{array}{l}4 \\ 1\end{array}\right)\left(\begin{array}{l}4 \\ 1\end{array}\right) \Sigma_{x}^{\prime}(q)$, onde são contados os naipes de cada par do subconjunto $\Sigma_{x}^{\prime}(q)$. 
Cada um dos binômios presentes em

$$
\left[\left(\begin{array}{c}
52-N_{q}-2 \\
1
\end{array}\right)+\left(\begin{array}{c}
N_{q}-4-2 \\
1
\end{array}\right)+\left(\begin{array}{l}
3 \\
1
\end{array}\right)\right]
$$

representam, respectivamente a escolha de uma das cartas $x, \diamond \mathrm{e} q$ na última posição. Contamos $x$ por $\left(\begin{array}{c}52-N_{q}-2 \\ 1\end{array}\right)$ dado que são 52 cartas no baralho e destas devemos retirar todas que são múltiplas, $N_{q}$, e duas não múltiplas que já foram utilizadas. A parte $\left(\begin{array}{c}N_{q}-4-2 \\ 1\end{array}\right)$ representa a escolha de um múltiplo de $N_{q}$, dado que não podemos utilizar nenhum dos quatro $q$ e dois múltiplos $\diamond$ que já foram utilizados. Como a primeira carta da sequência é um $q$, restaram apenas três delas para se escolher uma que será colocada na última posição, o que justifica a escolha $\left(\begin{array}{l}3 \\ 1\end{array}\right)$.

Descrevemos a seguir a contagem dos casos

$$
\begin{array}{|l|l|l|l|l|l|l|l|l|l|l|l|l|l|l|l|l|l|l|}
\hline q & S_{x}^{\prime \prime}(q) & \Sigma_{x}^{\prime \prime}(q) x & S_{x}^{\prime \prime}(q) & \Sigma_{x}^{\prime \prime}(q) & \Sigma_{x}^{\prime \prime}(q) \diamond \\
\hline
\end{array}
$$

calculados por

$$
\begin{gathered}
\left(\begin{array}{l}
4 \\
1
\end{array}\right)\left[\left(52-N_{q}-4-4\right)\left(\begin{array}{l}
3 \\
1
\end{array}\right)\left(\begin{array}{l}
4 \\
1
\end{array}\right)\left(\begin{array}{l}
4 \\
1
\end{array}\right) S_{x}^{\prime \prime}(q)+H_{q}\right] \\
{\left[\left(\begin{array}{c}
52-N_{q}-4 \\
1
\end{array}\right)+\left(\begin{array}{c}
N_{q}-4 \\
1
\end{array}\right)+\left(\begin{array}{l}
3 \\
1
\end{array}\right)\right]}
\end{gathered}
$$

O primeiro binômio $\left(\begin{array}{l}4 \\ 1\end{array}\right)$ representa a escolha dos naipes de $q$, sendo possível escolher um naipe em quatro opções.

Sabemos que $S_{x}^{\prime \prime}(q)$ são pares de cartas não múltiplas de $q, x$, e diferentes entre si. $\Sigma_{x}^{\prime \prime}(q)$ são pares de cartas com dois não múltiplos de $q, x$, também diferentes entre si. A constituição de $S_{x}^{\prime \prime}(q)$ e $\Sigma_{x}^{\prime \prime}(q)$ é a mesma, contudo a soma das cartas do primeiro subconjunto não é divisível por $q$ ao contrário do que ocorre em $\Sigma_{x}^{\prime \prime}(q)$.

Para explicar o conteúdo presente em

$$
\left[\left(52-N_{q}-4-4\right)\left(\begin{array}{l}
3 \\
1
\end{array}\right)\left(\begin{array}{l}
4 \\
1
\end{array}\right)\left(\begin{array}{l}
4 \\
1
\end{array}\right) S_{x}^{\prime \prime}(q)+H_{q}\right]
$$

temos que considerar duas particularidades, a saber:

- Os pares $S_{x}^{\prime \prime}(q)$ e $\Sigma_{x}^{\prime \prime}(q)$ possuem uma carta em comum. Observe que, mesmo sendo as quatro cartas não múltiplas $x$, nesta situação elas não podem ser todas iguais, pois a natureza dos pares são diferentes. Todas cartas iguais levam a pares iguais, o que seria um absurdo visto que um par é divisível por $q$ e o outro não. Inicialmente, $\left(\begin{array}{l}4 \\ 1\end{array}\right)\left(\begin{array}{l}4 \\ 1\end{array}\right) S_{x}^{\prime \prime}(q)$ calcula quantos são os pares do tipo $\Sigma_{x}^{\prime \prime}(q)$ e os naipes de cada carta do par. A carta de $S_{x}^{\prime \prime}(q)$ que é igual a uma das cartas de $\Sigma_{x}^{\prime \prime}(q)$ pode ser escolhida entre apenas três, visto que uma já foi utilizada e, por isso, contada por $\left(\begin{array}{l}3 \\ 1\end{array}\right)$. Até o momento, de todos os valores não múltiplos de $q, 52-N_{q}$, utilizamos dois. Então, para contar a última carta $x$ que falta, fazemos $\left(52-N_{q}-4-4\right)$. Quando não podemos utilizar um valor, em se tratando de baralho, devemos retirá-lo 4 vezes, pois um valor é representado por quatro cartas que se diferenciam pelos naipes. Por isso $-4-4$.

- Todas as quatro cartas presentes nos dois pares são diferentes. Neste caso não foi possível fazer uma generalização. Para solucionar este caso, contamos separadamente quantas possibilidades existem a partir de cada $q$ e colocamos os valor encontrado na Tabela 5. O código $H_{q}$ é uma variável com $q$ variando de 1 a 13, no âmbito dos números inteiros, com valores pré definidos.

Cada um dos binômios presentes em

$$
\left[\left(\begin{array}{c}
52-N_{q}-4 \\
1
\end{array}\right)+\left(\begin{array}{c}
N_{q}-4 \\
1
\end{array}\right)+\left(\begin{array}{l}
3 \\
1
\end{array}\right)\right]
$$


representam, respectivamente a escolha de uma das cartas $x$, $\diamond$ e $q$ na última posição. Contamos $x$ por $\left(\begin{array}{c}52-N_{q}-4 \\ 1\end{array}\right)$ dado que são 52 cartas no baralho e destas devemos retirar todas que são múltiplas, $N_{q}$, e quatro não múltiplas que já foram utilizadas. A parte $\left(\begin{array}{c}N_{q}-4 \\ 1\end{array}\right)$ representa a escolha de um múltiplo de $N_{q}$, dado que não podemos utilizar nenhum dos quatro $q$ e nenhum outro foi utilizado. Como a primeira carta da sequência é um $q$, restaram apenas três delas para se escolher uma que será colocada na última posição, o que justifica a escolha $\left(\begin{array}{l}3 \\ 1\end{array}\right)$.

Descrevemos a seguir a contagem dos casos

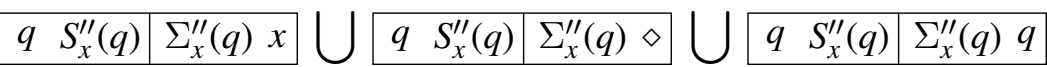

calculados por

$$
\left(\begin{array}{l}
4 \\
1
\end{array}\right)\left(\begin{array}{l}
4 \\
1
\end{array}\right)\left(\begin{array}{l}
4 \\
1
\end{array}\right) S_{x}^{\prime \prime \prime}(q)\left(\begin{array}{l}
4 \\
1
\end{array}\right)\left(\begin{array}{l}
4 \\
1
\end{array}\right) \Sigma_{x}^{\prime \prime \prime}(q)\left[\left(\begin{array}{c}
52-N_{q}-2 \\
1
\end{array}\right)+\left(\begin{array}{c}
N_{q}-4-2 \\
1
\end{array}\right)+\left(\begin{array}{l}
3 \\
1
\end{array}\right)\right]
$$

Não há nenhum tipo de interseção entre os subconjuntos $S_{x}^{\prime \prime}(q)$ e $\Sigma_{x}^{\prime \prime \prime}(q)$, pois o primeiro é composto apenas de não múltiplos de $q$, diferentes entre si e o segundo subconjunto é composto de dois múltiplos de $q$, iguais entre si.

Analisando a parte

$$
\left(\begin{array}{l}
4 \\
1
\end{array}\right)\left(\begin{array}{l}
4 \\
1
\end{array}\right)\left(\begin{array}{l}
4 \\
1
\end{array}\right) S_{x}^{\prime \prime}(q)\left(\begin{array}{l}
4 \\
2
\end{array}\right) \Sigma_{x}^{\prime \prime \prime}(q)
$$

temos que o primeiro binômio $\left(\begin{array}{l}4 \\ 1\end{array}\right)$ representa a escolha da primeira carta que é o próprio divisor $q$. A sequência $\left(\begin{array}{l}4 \\ 1\end{array}\right)\left(\begin{array}{l}4 \\ 1\end{array}\right) S_{x}^{\prime \prime}(q)$ está ligada a quantidade de pares $S_{x}^{\prime \prime}(q)$ e os naipes de cada uma das cartas que formam este tipo de par. De forma similiar ocorre com a sequência $\left(\begin{array}{l}4 \\ 2\end{array}\right) \Sigma_{x}^{\prime \prime \prime}(q)$, onde são contados os naipes de cada par do subconjunto $\Sigma_{x}^{\prime}(q)$. Neste caso escolhemos 2 em 4 quartas devido ao fato de serem numericamente iguais, visando, assim, a escolha do naipe.

Cada um dos binômios presentes em

$$
\left[\left(\begin{array}{c}
52-N_{q}-2 \\
1
\end{array}\right)+\left(\begin{array}{c}
N_{q}-4-2 \\
1
\end{array}\right)+\left(\begin{array}{l}
3 \\
1
\end{array}\right)\right]
$$

representam, respectivamente a escolha de uma das cartas $x, \diamond$ e $q$ na última posição. Contamos $x$ por $\left(\begin{array}{c}52-N_{q}-2 \\ 1\end{array}\right)$ dado que são 52 cartas no baralho e destas devemos retirar todas que são múltiplas, $N_{q}$, e duas não múltiplas que já foram utilizadas. A parte $\left(\begin{array}{c}N_{q}-4-2 \\ 1\end{array}\right)$ representa a escolha de um múltiplo de $N_{q}$, dado que não podemos utilizar nenhum dos quatro $q$ e dois múltiplos $\diamond$ que já foram utilizados. Como a primeira carta da sequência é um $q$, restaram apenas três delas para se escolher uma que será colocada na última posição, o que justifica a escolha $\left(\begin{array}{l}3 \\ 1\end{array}\right)$.

Descrevemos a seguir a contagem dos casos

$$
\begin{array}{|l|l|l|l|l|l|l|l|l|l|l|l|l|l|}
\hline q & S_{x}^{\prime \prime}(q) & \sum_{x}^{i v}(q) x & S_{x}^{\prime \prime}(q) & \sum_{x}^{i v}(q) \diamond & \sum_{x}^{i v}(q) q \\
\hline
\end{array}
$$

calculados por

$$
\left(\begin{array}{l}
4 \\
1
\end{array}\right)\left[\left(\begin{array}{l}
4 \\
1
\end{array}\right)\left(\begin{array}{l}
4 \\
1
\end{array}\right) S_{x}^{\prime \prime}(q)\left(\begin{array}{l}
3 \\
2
\end{array}\right)+\left(\begin{array}{l}
4 \\
1
\end{array}\right)\left(\begin{array}{l}
4 \\
1
\end{array}\right) S_{x}^{\prime \prime}(q)\left(\begin{array}{l}
4 \\
2
\end{array}\right) \Sigma_{x}^{i v}(q)\right]\left[\left(\begin{array}{c}
52-N_{q}-4 \\
1
\end{array}\right)+\left(\begin{array}{c}
N_{q}-4 \\
1
\end{array}\right)+\left(\begin{array}{l}
3 \\
1
\end{array}\right)\right]
$$

O primeiro binômio $\left(\begin{array}{l}4 \\ 1\end{array}\right)$ representa a escolha dos naipes de $q$, sendo possível escolher um naipe em quatro opções.

Sabemos que $S_{x}^{\prime \prime}(q)$ são pares de cartas não múltiplas de $q, x$, e diferentes entre si. $\Sigma_{x}^{i v}(q)$ são pares de cartas com dois não múltiplos de $q, x$, porém iguais entre si. 
Para explicar o conteúdo presente em

$$
\left[\left(\begin{array}{l}
4 \\
1
\end{array}\right)\left(\begin{array}{l}
4 \\
1
\end{array}\right) S_{x}^{\prime \prime}(q)\left(\begin{array}{l}
3 \\
2
\end{array}\right)+\left(\begin{array}{l}
4 \\
1
\end{array}\right)\left(\begin{array}{l}
4 \\
1
\end{array}\right) S_{x}^{\prime \prime}(q)\left(\begin{array}{l}
4 \\
2
\end{array}\right) \Sigma_{x}^{i v}(q)\right]
$$

temos que considerar duas particularidades, a saber:

- Uma das cartas de $S_{x}^{\prime \prime}(q)$ é igual as cartas de $\sum_{x}^{i v}(q)$. Escolhemos a quantidade dos pares de $S_{x}^{\prime \prime}(q)$ e seus respectivos naipes por $\left(\begin{array}{l}4 \\ 1\end{array}\right)\left(\begin{array}{l}4 \\ 1\end{array}\right) S_{x}^{\prime \prime}(q)$. As cartas da mesa, além de serem iguais entre si, são também iguais a uma das cartas já escolhida, logo temos que escolher duas em três opções e o fazemos por $\left(\begin{array}{l}3 \\ 2\end{array}\right)$.

- As cartas de $S_{x}^{\prime \prime}(q)$ são diferentes das cartas de $\Sigma_{x}^{i v}(q)$. Os pares são totalmente independentes. Calculamos os pares $S_{x}^{\prime \prime}(q)$ e seus respectivos naipes por $\left(\begin{array}{l}4 \\ 1\end{array}\right)\left(\begin{array}{l}4 \\ 1\end{array}\right) S_{x}^{\prime \prime}(q)$. Os pares $\Sigma_{x}^{i v}(q)$, por ser compostos de cartas iguais, se faz necessário escolher dois em quatro naipes por $\left(\begin{array}{l}4 \\ 2\end{array}\right) \Sigma_{x}^{i v}(q)$.

Cada um dos binômios presentes em

$$
\left[\left(\begin{array}{c}
52-N_{q}-4 \\
1
\end{array}\right)+\left(\begin{array}{c}
N_{q}-4 \\
1
\end{array}\right)+\left(\begin{array}{l}
3 \\
1
\end{array}\right)\right]
$$

representam, respectivamente a escolha de uma das cartas $x, \diamond \mathrm{e} q$ na última posição. Contamos $x$ por $\left(\begin{array}{c}52-N_{q}-4 \\ 1\end{array}\right)$ dado que são 52 cartas no baralho e destas devemos retirar todas que são múltiplas, $N_{q}$, e quatro não múltiplas que já foram utilizadas. A parte $\left(\begin{array}{c}N_{q}-4 \\ 1\end{array}\right)$ representa a escolha de um múltiplo de $N_{q}$, dado que não podemos utilizar nenhum dos quatro $q$ e nenhum outro foi utilizado. Como a primeira carta da sequência é um $q$, restaram apenas três delas para se escolher uma que será colocada na última posição, o que justifica a escolha $\left(\begin{array}{l}3 \\ 1\end{array}\right)$. Descrevemos a seguir a contagem dos casos

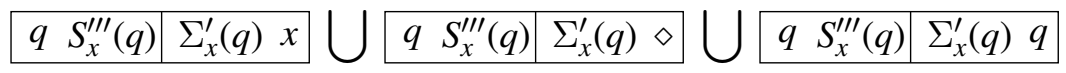

calculados por

$$
\left(\begin{array}{l}
4 \\
1
\end{array}\right)\left(\begin{array}{l}
4 \\
2
\end{array}\right) S_{x}^{\prime \prime \prime}(q)\left(\begin{array}{l}
4 \\
1
\end{array}\right)\left(\begin{array}{l}
4 \\
1
\end{array}\right) \Sigma_{x}^{\prime}(q)\left[\left(\begin{array}{c}
52-N_{q}-2 \\
1
\end{array}\right)+\left(\begin{array}{c}
N_{q}-4-2 \\
1
\end{array}\right)+\left(\begin{array}{l}
3 \\
1
\end{array}\right)\right]
$$

Não há nenhum tipo de interseção entre os subconjuntos $S_{x}^{\prime \prime \prime}(q)$ e $\Sigma_{x}^{\prime}(q)$, pois o primeiro é composto apenas de não múltiplos de $q$, iguais entre si e o segundo subconjunto é composto de dois múltiplos de $q$, diferentes entre si.

Analisando a parte

$$
\left(\begin{array}{l}
4 \\
1
\end{array}\right)\left(\begin{array}{l}
4 \\
2
\end{array}\right) S_{x}^{\prime \prime \prime}(q)\left(\begin{array}{l}
4 \\
1
\end{array}\right)\left(\begin{array}{l}
4 \\
1
\end{array}\right) \Sigma_{x}^{\prime}(q)
$$

temos que o primeiro binômio $\left(\begin{array}{l}4 \\ 1\end{array}\right)$ representa a escolha da primeira carta que é o próprio divisor $q$. A sequência $\left(\begin{array}{l}4 \\ 1\end{array}\right) S_{x}^{\prime \prime \prime}(q)$ está ligada a quantidade de pares $S_{x}^{\prime \prime}(q)$ e os naipes das cartas que formam este tipo de par, como as cartas são de mesmo valor escolhemos dois naipes em quatro possibilidade. De forma similiar ocorre com a sequência $\left(\begin{array}{l}4 \\ 1\end{array}\right)\left(\begin{array}{l}4 \\ 1\end{array}\right) \Sigma_{x}^{\prime}(q)$, onde são contados os naipes de cada carta dos pares do subconjunto $\Sigma_{x}^{\prime}(q)$.

Cada um dos binômios presentes em

$$
\left[\left(\begin{array}{c}
52-N_{q}-2 \\
1
\end{array}\right)+\left(\begin{array}{c}
N_{q}-4-2 \\
1
\end{array}\right)+\left(\begin{array}{l}
3 \\
1
\end{array}\right)\right]
$$

representam, respectivamente a escolha de uma das cartas $x, \diamond \mathrm{e} q$ na última posição. Contamos $x$ por $\left(\begin{array}{c}52-N_{q}-2 \\ 1\end{array}\right)$ dado que são 52 cartas no baralho e destas devemos retirar todas que são múltiplas, $N_{q}$, e duas não múltiplas que já foram utilizadas. A parte $\left(\begin{array}{c}N_{q}-4-2 \\ 1\end{array}\right)$ representa a escolha de um 
múltiplo de $N_{q}$, dado que não podemos utilizar nenhum dos quatro $q$ e dois múltiplos $\diamond$ que já foram utilizados. Como a primeira carta da sequência é um $q$, restaram apenas três delas para se escolher uma que será colocada na última posição, o que justifica a escolha $\left(\begin{array}{l}3 \\ 1\end{array}\right)$.

Descrevemos agora a contagem dos casos

$$
\begin{array}{|l|l|l|l|l|l|l|l|l|l|l|l|l|l|}
\hline q S_{x}^{\prime \prime \prime}(q) & \Sigma_{x}^{\prime \prime}(q) x & q S_{x}^{\prime \prime \prime}(q) & \Sigma_{x}^{\prime \prime}(q) \diamond & \Sigma_{x}^{\prime \prime}(q) q \\
\hline
\end{array}
$$

calculados por

$$
\left(\begin{array}{l}
4 \\
1
\end{array}\right)\left[\left(\begin{array}{l}
3 \\
2
\end{array}\right)\left(\begin{array}{l}
4 \\
1
\end{array}\right)\left(\begin{array}{l}
4 \\
1
\end{array}\right) \Sigma_{x}^{\prime \prime}(q)+\left(\begin{array}{l}
4 \\
2
\end{array}\right) S_{x}^{\prime \prime \prime}(q)\left(\begin{array}{l}
4 \\
1
\end{array}\right)\left(\begin{array}{l}
4 \\
1
\end{array}\right) \Sigma_{x}^{\prime \prime}(q)\right]\left[\left(\begin{array}{c}
52-N_{q}-4 \\
1
\end{array}\right)+\left(\begin{array}{c}
N_{q}-4 \\
1
\end{array}\right)+\left(\begin{array}{l}
3 \\
1
\end{array}\right)\right]
$$

O primeiro binômio $\left(\begin{array}{l}4 \\ 1\end{array}\right)$ representa a escolha dos naipes de $q$, sendo possível escolher um naipe em quatro opções.

Sabemos que $S_{x}^{\prime \prime \prime}(q)$ são pares de cartas não múltiplas de $q, x$, e iguais entre si. $\Sigma_{x}^{\prime \prime}(q)$ são pares de cartas com dois não múltiplos de $q, x$, porém diferentes entre si. Para explicar o conteúdo presente em

$$
\left[\left(\begin{array}{l}
3 \\
2
\end{array}\right)\left(\begin{array}{l}
4 \\
1
\end{array}\right)\left(\begin{array}{l}
4 \\
1
\end{array}\right) \Sigma_{x}^{\prime \prime}(q)+\left(\begin{array}{l}
4 \\
2
\end{array}\right) S_{x}^{\prime \prime \prime}(q)\left(\begin{array}{l}
4 \\
1
\end{array}\right)\left(\begin{array}{l}
4 \\
1
\end{array}\right) \Sigma_{x}^{\prime \prime}(q)\right]
$$

temos que considerar duas particularidades, a saber

- Uma das cartas de $\Sigma_{x}^{\prime \prime}(q)$ é igual as cartas de $S_{x}^{\prime \prime \prime}(q)$. Contamos primeiro os pares $\Sigma_{x}^{\prime \prime}(q)$ e os naipes de cada uma das duas cartas dos pares por $\left(\begin{array}{l}4 \\ 1\end{array}\right)\left(\begin{array}{l}4 \\ 1\end{array}\right) \Sigma_{x}^{\prime \prime}(q)$. Como necessariamente as cartas de $S_{x}^{\prime \prime \prime}(q)$ devem ser iguais a uma carta já utilizada, temos apenas duas possibilidades em três, $\left(\begin{array}{l}3 \\ 2\end{array}\right)$.

- Ambas cartas de $\Sigma_{x}^{\prime \prime}(q)$ são diferentes das cartas de $S_{x}^{\prime \prime \prime}(q)$. Por não existir interseção entre os subconjuntos, podemos calculá-los sem restrição. Assim, calculamos os pares $S_{x}^{\prime \prime \prime}(q)$ e os naipes das cartas iguais por $\left(\begin{array}{l}4 \\ 2\end{array}\right) S_{x}^{\prime \prime \prime}(q)$ e os pares $\Sigma_{x}^{\prime \prime}(q)$ com os respectivos naipes por $\left(\begin{array}{l}4 \\ 1\end{array}\right)\left(\begin{array}{l}4 \\ 1\end{array}\right) \Sigma_{x}^{\prime \prime}(q)$.

Cada um dos binômios presentes em

$$
\left[\left(\begin{array}{c}
52-N_{q}-4 \\
1
\end{array}\right)+\left(\begin{array}{c}
N_{q}-4 \\
1
\end{array}\right)+\left(\begin{array}{l}
3 \\
1
\end{array}\right)\right]
$$

representam, respectivamente a escolha de uma das cartas $x$, $\diamond \mathrm{e} q$ na última posição. Contamos $x$ por $\left(\begin{array}{c}52-N_{q}-4 \\ 1\end{array}\right)$ dado que são 52 cartas no baralho e destas devemos retirar todas que são múltiplas, $N_{q}$, e quatro não múltiplas que já foram utilizadas. A parte $\left(\begin{array}{c}N_{q}-4 \\ 1\end{array}\right)$ representa a escolha de um múltiplo de $N_{q}$, dado que não podemos utilizar nenhum dos quatro $q$ e nenhum outro foi utilizado. Como a primeira carta da sequência é um $q$, restaram apenas três delas para se escolher uma que será colocada na última posição, o que justifica a escolha $\left(\begin{array}{l}3 \\ 1\end{array}\right)$.

Descrevemos a continuação a contagem dos casos

$$
\begin{array}{|l|l|l|l|l|l|l|l|l|l|l|l|l|}
\hline q S_{x}^{\prime \prime \prime}(q) & \Sigma_{x}^{\prime \prime \prime}(q) x & q S_{x}^{\prime \prime \prime}(q) & \Sigma_{x}^{\prime \prime \prime}(q) \diamond & \Sigma_{x}^{\prime \prime \prime}(q) q \\
\hline
\end{array}
$$

calculados por

$$
+\left(\begin{array}{l}
4 \\
1
\end{array}\right)\left(\begin{array}{l}
4 \\
2
\end{array}\right) S_{x}^{\prime \prime \prime}(q)\left(\begin{array}{l}
4 \\
2
\end{array}\right) \Sigma_{x}^{\prime \prime \prime}(q)\left[\left(\begin{array}{c}
52-N_{q}-2 \\
1
\end{array}\right)+\left(\begin{array}{c}
N_{q}-4-2 \\
1
\end{array}\right)+\left(\begin{array}{l}
3 \\
1
\end{array}\right)\right]
$$

Não há nenhum tipo de interseção entre os subconjuntos $S_{x}^{\prime \prime \prime}(q)$ e $\Sigma_{x}^{\prime}(q)$, pois o primeiro é composto apenas de não múltiplos de $q$, iguais entre si e o segundo subconjunto é composto de dois múltiplos de $q$, também iguais entre si. 
Analisando a parte

$$
\left(\begin{array}{l}
4 \\
1
\end{array}\right)\left(\begin{array}{l}
4 \\
2
\end{array}\right) S_{x}^{\prime \prime \prime}(q)\left(\begin{array}{l}
4 \\
2
\end{array}\right) \Sigma_{x}^{\prime \prime \prime}(q)
$$

temos que o primeiro binômio $\left(\begin{array}{l}4 \\ 1\end{array}\right)$ representa a escolha da primeira carta que é o próprio divisor $q$. A sequência $\left(\begin{array}{l}4 \\ 2\end{array}\right) S_{x}^{\prime \prime \prime}(q)$ está ligada a quantidade de pares $S_{x}^{\prime \prime \prime}(q)$ e os naipes das cartas que formam este tipo de par, como as cartas são de mesmo valor, escolhemos dois naipes em quatro possibilidade. De forma similiar ocorre com a sequência $\left(\begin{array}{l}4 \\ 2\end{array}\right) \Sigma_{x}^{\prime \prime \prime}(q)$, onde são contados os naipes das duas cartas iguais, dentre quatro possibilidades, do subconjunto $\Sigma_{x}^{\prime \prime \prime}(q)$.

Cada um dos binômios presentes em

$$
\left[\left(\begin{array}{c}
52-N_{q}-2 \\
1
\end{array}\right)+\left(\begin{array}{c}
N_{q}-4-2 \\
1
\end{array}\right)+\left(\begin{array}{l}
3 \\
1
\end{array}\right)\right]
$$

representam, respectivamente a escolha de uma das cartas $x, \diamond \mathrm{e} q$ na última posição. Contamos $x$ por $\left(\begin{array}{c}52-N_{q}-2 \\ 1\end{array}\right)$ dado que são 52 cartas no baralho e destas devemos retirar todas que são múltiplas, $N_{q}$, e duas não múltiplas que já foram utilizadas. A parte $\left(\begin{array}{c}N_{q}-4-2 \\ 1\end{array}\right)$ representa a escolha de um múltiplo de $N_{q}$, dado que não podemos utilizar nenhum dos quatro $q$ e dois múltiplos $\diamond$ que já foram utilizados. Como a primeira carta da sequência é um $q$, restaram apenas três delas para se escolher uma que será colocada na última posição, o que justifica a escolha $\left(\begin{array}{l}3 \\ 1\end{array}\right)$.

Descrevemos a seguir a contagem dos casos

$$
\begin{array}{|l|l|l|l|l|l|l|l|l|l|l|l|l|l|}
\hline q S_{x}^{\prime \prime \prime}(q) & \sum_{x}^{i v}(q) x & q S_{x}^{\prime \prime \prime}(q) & \sum_{x}^{i v}(q) \diamond & \sum_{x}^{i v}(q) q \\
\hline
\end{array}
$$

calculados por

$$
\left(\begin{array}{l}
4 \\
1
\end{array}\right)\left[\left(\begin{array}{l}
4 \\
2
\end{array}\right) S_{x}^{\prime \prime \prime}(q)\left(\begin{array}{l}
4 \\
2
\end{array}\right) \Sigma_{x}^{i v}(q)\right]\left[\left(\begin{array}{c}
52-N_{q}-4 \\
1
\end{array}\right)+\left(\begin{array}{c}
N_{q}-4 \\
1
\end{array}\right)+\left(\begin{array}{l}
3 \\
1
\end{array}\right)\right]
$$

O primeiro binômio $\left(\begin{array}{l}4 \\ 1\end{array}\right)$ representa a escolha dos naipes de $q$, sendo possível escolher um naipe em quatro opções.

Sabemos que $S_{x}^{\prime \prime \prime}(q)$ são pares de cartas não múltiplas de $q$, $x$, e iguais entre si. $\Sigma_{x}^{i v}(q)$ são pares de cartas com dois não múltiplos de $q, x$, porém iguais entre si. Para explicar o conteúdo presente em

$$
\left[\left(\begin{array}{l}
4 \\
2
\end{array}\right) S_{x}^{\prime \prime \prime}(q)\left(\begin{array}{l}
4 \\
2
\end{array}\right) \Sigma_{x}^{i v}(q)\right]
$$

temos que considerar duas particularidades, a saber,

- As cartas de $S_{x}^{\prime \prime \prime}(q)$ e $\Sigma_{x}^{i v}(q)$ são todas iguais o que não pode ser possível. Se $q$ não divide $S_{x}^{\prime \prime \prime}(q)$ e divide $\sum_{x}^{i v}(q)$, ambos conjuntos devem necessariamente ser diferentes. Portanto, esta parte do caso não existe e, para tanto, não pode ser calculada.

- As cartas de $S_{x}^{\prime \prime \prime}(q)$ e $\sum_{x}^{i v}(q)$ são iguais apenas dentro de cada conjunto, mas não entre conjuntos. Calculamos cada parte separadamente. Como as cartas de $S_{x}^{\prime \prime \prime}(q)$ são iguais, devemos escolher duas de quatro possibilidades de naipes e ainda quantos pares fazem parte do subconjunto, $\left(\begin{array}{l}4 \\ 2\end{array}\right) S_{x}^{\prime \prime \prime}(q)$. De forma análoga, utilizamos o mesmo raciocínio para o subconjunto $\Sigma_{x}^{i v}(q)$, calculando assim $\left(\begin{array}{l}4 \\ 2\end{array}\right) \sum_{x}^{i v}(q)$.

Cada um dos binômios presentes em

$$
\left[\left(\begin{array}{c}
52-N_{q}-4 \\
1
\end{array}\right)+\left(\begin{array}{c}
N_{q}-4 \\
1
\end{array}\right)+\left(\begin{array}{l}
3 \\
1
\end{array}\right)\right]
$$

representam, respectivamente a escolha de uma das cartas $x, \diamond \mathrm{e} q$ na última posição. Contamos $x$ por $\left(\begin{array}{c}52-N_{q}-4 \\ 1\end{array}\right)$ dado que são 52 cartas no baralho e destas devemos retirar todas que são múltiplas, $N_{q}$, e quatro não múltiplas que já foram utilizadas. A parte $\left(\begin{array}{c}N_{q}-4 \\ 1\end{array}\right)$ representa a escolha de um múltiplo de $N_{q}$, dado que não podemos utilizar nenhum dos quatro $q$ e nenhum outro foi utilizado. 
Como a primeira carta da sequência é um $q$, restaram apenas três delas para se escolher uma que será colocada na última posição, o que justifica a escolha $\left(\begin{array}{l}3 \\ 1\end{array}\right)$.

Desenvolvendo os coeficientes binomiais que aparecem na expressão para a cardinalidade de $G_{1(q)}$ e simplificando obtem-se

$$
\begin{aligned}
& 188\left(H_{q}-N_{q}^{2}\left(16 \Sigma_{x}^{\prime \prime}(q)+\Sigma_{x}^{\prime \prime \prime}(q)+6 \Sigma_{x}^{i v}(q)\right)+12 N_{q}\left(-4+4 S_{x}^{\prime}(q)+68 \Sigma_{x}^{\prime \prime}(q)+5 \Sigma_{x}^{\prime \prime \prime}(q)\right.\right. \\
& \left.+26 \Sigma_{x}^{i v}(q)\right)+2\left(1059+16 S_{x}^{\prime}(q)\left(8 \Sigma_{x}^{\prime}(q)-9\right)-1480 \Sigma_{x}^{\prime \prime}(q)-208 \Sigma_{x}^{\prime \prime \prime}(q)-576 \Sigma_{x}^{i v}(q)\right. \\
& \left.+8 S_{x}^{\prime \prime}(q)\left(3+16 \Sigma_{x}^{\prime}(q)+16 \Sigma_{x}^{\prime \prime \prime}(q)+6 \Sigma_{x}^{i v}(q)\right)+6 S_{x}^{\prime \prime \prime}(q)\left(8 \Sigma_{x}^{\prime}(q)+8 \Sigma_{x}^{\prime \prime}(q)+3\left(\Sigma_{x}^{\prime \prime \prime}(q)+\Sigma_{x}^{i v}(q)\right)\right)\right)
\end{aligned}
$$

Somando esta última expressão em $q$ de 1 até 13 e utilizando as Tabelas 2,3 e 5 obtemos $\#\left(G_{1}\right)=$ 195967816, portanto

$$
\mathbb{P}\left\{G_{1}\right\}=\frac{195967816}{407170400} \approx 0,481292 .
$$

DemonstraÇão do Lema 2.16. Seja $q \in\{1, \ldots, 13\}$. A cardinalidade do evento $G_{2}(q)$ é

$$
\begin{aligned}
& \left(\begin{array}{l}
4 \\
1
\end{array}\right)\left(\begin{array}{l}
4 \\
1
\end{array}\right)\left(\begin{array}{l}
4 \\
1
\end{array}\right) S_{x}^{\prime}(q)\left(\begin{array}{l}
3 \\
2
\end{array}\right)\left[\left(\begin{array}{c}
52-N_{q}-1 \\
1
\end{array}\right)+\left(\begin{array}{c}
N_{q}-4-1 \\
1
\end{array}\right)+\left(\begin{array}{l}
1 \\
1
\end{array}\right)\right] \\
& +\left(\begin{array}{l}
4 \\
1
\end{array}\right)\left[\left(\begin{array}{c}
52-N_{q} \\
1
\end{array}\right)\left(\begin{array}{c}
N_{q}-4 \\
1
\end{array}\right)\left(\begin{array}{l}
3 \\
1
\end{array}\right)\left(\begin{array}{l}
3 \\
1
\end{array}\right)+\left(\begin{array}{c}
52-N_{q} \\
1
\end{array}\right)\left(\begin{array}{c}
N_{q}-4 \\
1
\end{array}\right)\left(\begin{array}{c}
N_{q}-4-4 \\
1
\end{array}\right)\left(\begin{array}{l}
3 \\
1
\end{array}\right)\right] \\
& {\left[\left(\begin{array}{c}
52-N_{q}-1 \\
1
\end{array}\right)+\left(\begin{array}{c}
N_{q}-4-2 \\
1
\end{array}\right)+\left(\begin{array}{l}
2 \\
1
\end{array}\right)\right]} \\
& +\left(\begin{array}{l}
4 \\
1
\end{array}\right)\left(\begin{array}{l}
4 \\
1
\end{array}\right)\left(\begin{array}{l}
4 \\
1
\end{array}\right) S_{x}^{\prime \prime}(q)\left(\begin{array}{l}
3 \\
2
\end{array}\right)\left[\left(\begin{array}{c}
52-N_{q}-2 \\
1
\end{array}\right)+\left(\begin{array}{c}
N_{q}-4 \\
1
\end{array}\right)+\left(\begin{array}{l}
1 \\
1
\end{array}\right)\right] \\
& +\left(\begin{array}{l}
4 \\
1
\end{array}\right)\left(\begin{array}{l}
4 \\
1
\end{array}\right)\left(\begin{array}{l}
4 \\
1
\end{array}\right) S_{x}^{\prime \prime}(q)\left(\begin{array}{l}
3 \\
1
\end{array}\right)\left(\begin{array}{c}
N_{q}-4 \\
1
\end{array}\right)\left[\left(\begin{array}{c}
52-N_{q}-2 \\
1
\end{array}\right)+\left(\begin{array}{c}
N_{q}-4-1 \\
1
\end{array}\right)+\left(\begin{array}{l}
2 \\
1
\end{array}\right)\right] \\
& +\left(\begin{array}{l}
4 \\
1
\end{array}\right)\left(\begin{array}{l}
4 \\
2
\end{array}\right) S_{x}^{\prime \prime \prime}(q)\left(\begin{array}{l}
3 \\
2
\end{array}\right)\left[\left(\begin{array}{c}
52-N_{q}-2 \\
1
\end{array}\right)+\left(\begin{array}{c}
N_{q}-4 \\
1
\end{array}\right)+\left(\begin{array}{c}
1 \\
1
\end{array}\right)\right] \\
& +\left(\begin{array}{l}
4 \\
1
\end{array}\right)\left(\begin{array}{l}
4 \\
2
\end{array}\right) S_{x}^{\prime \prime \prime}(q)\left(\begin{array}{l}
3 \\
1
\end{array}\right)\left(\begin{array}{c}
N_{q}-4 \\
1
\end{array}\right)\left[\left(\begin{array}{c}
52-N_{q}-2 \\
1
\end{array}\right)+\left(\begin{array}{c}
N_{q}-4-1 \\
1
\end{array}\right)+\left(\begin{array}{l}
2 \\
1
\end{array}\right)\right]
\end{aligned}
$$

Desenvolvendo a expressão anterior obtem-se

$$
\begin{aligned}
\#\left(G_{2}(q)\right)= & -564\left(N_{q}\left(\left(N_{q}-61\right) N_{q}-16 S_{x}^{\prime \prime}(q)-6 S_{x}^{\prime \prime \prime}(q)+488\right)\right. \\
& \left.-16\left(S_{x}^{\prime}(q)-3 S_{x}^{\prime \prime}(q)+65\right)+18 S_{x}^{\prime \prime \prime}(q)\right)
\end{aligned}
$$

Somando esta última expressão em $q$ de 1 até 13 e utilizando as Tabelas 2 e 3 obtemos $\#\left(G_{2}\right)=24665976$. Assim finalmente resulta que

$$
\mathbb{P}\left\{G_{2}\right\}=\frac{24665976}{407170400} \approx 0,060579 .
$$

DemonstraÇÃo do Lema 2.17. Seja $q \in\{1, \ldots, 13\}$. A cardinalidade do evento $G_{3}(q)$ é

$$
\begin{aligned}
& \left(\begin{array}{l}
4 \\
2
\end{array}\right)\left(\begin{array}{c}
52-N_{q} \\
1
\end{array}\right)\left(\begin{array}{l}
4 \\
2
\end{array}\right) \Sigma_{x}^{\prime \prime \prime}(q)\left[\left(\begin{array}{c}
52-N_{q}-1 \\
1
\end{array}\right)+\left(\begin{array}{c}
N_{q}-4-2 \\
1
\end{array}\right)+\left(\begin{array}{l}
2 \\
1
\end{array}\right)\right] \\
& +\left(\begin{array}{l}
4 \\
2
\end{array}\right)\left[\left(\begin{array}{l}
4 \\
2
\end{array}\right) \Sigma_{x}^{i v}(q)\left(\begin{array}{l}
2 \\
1
\end{array}\right)+\left(\begin{array}{l}
4 \\
2
\end{array}\right) \Sigma_{x}^{i v}(q)\right]\left[\left(\begin{array}{c}
52-N_{q}-3 \\
1
\end{array}\right)+\left(\begin{array}{c}
N_{q}-4 \\
1
\end{array}\right)+\left(\begin{array}{l}
2 \\
1
\end{array}\right)\right] \\
& +\left(\begin{array}{l}
4 \\
2
\end{array}\right)\left(\begin{array}{c}
52-N_{q} \\
1
\end{array}\right)\left(\begin{array}{l}
4 \\
1
\end{array}\right)\left(\begin{array}{l}
4 \\
1
\end{array}\right) \Sigma_{x}^{\prime}(q)\left[\left(\begin{array}{c}
52-N_{q}-1 \\
1
\end{array}\right)+\left(\begin{array}{c}
N_{q}-4-2 \\
1
\end{array}\right)+\left(\begin{array}{l}
2 \\
1
\end{array}\right)\right]
\end{aligned}
$$




$$
\begin{gathered}
+\left(\begin{array}{l}
4 \\
2
\end{array}\right)\left[\left(\begin{array}{l}
3 \\
1
\end{array}\right)\left(\begin{array}{l}
2 \\
1
\end{array}\right)\left(\begin{array}{l}
4 \\
1
\end{array}\right)\left(\begin{array}{l}
4 \\
1
\end{array}\right) \Sigma_{x}^{\prime \prime}(q)+\left(\begin{array}{c}
52-N_{q}-4-4 \\
1
\end{array}\right)\left(\begin{array}{l}
4 \\
1
\end{array}\right)\left(\begin{array}{l}
4 \\
1
\end{array}\right) \Sigma_{x}^{\prime \prime}(q)\right] \\
{\left[\left(\begin{array}{c}
52-N_{q}-3 \\
1
\end{array}\right)+\left(\begin{array}{c}
N_{q}-4 \\
1
\end{array}\right)+\left(\begin{array}{l}
2 \\
1
\end{array}\right)\right] .}
\end{gathered}
$$

Desenvolvendo obtemos

$$
\#\left(G_{3}(q)\right)=564\left(8\left(N_{q}-52\right) \Sigma_{x}^{\prime}(q)+8\left(N_{q}-50\right) \Sigma_{x}^{\prime \prime}(q)+3\left(N_{q}-52\right) \Sigma_{x}^{\prime \prime \prime}(q)+9 \Sigma_{x}^{i v}(q) .\right)
$$

Somando em $q$ e utilizando as Tabelas 2 e 3 obtemos \# $\left(G_{3}\right)=27162240$. A probabilidade de $G_{3}$ é portanto

$$
\mathbb{P}\left\{G_{3}\right\}=\frac{27162240}{407170400} \approx 0.0667098 .
$$

DEMONSTRAÇÃO DO LEMA 2.18. O evento $G_{4}(q)$ refere-se ao caso onde o jogador apresenta em $\mathcal{H}$ uma carta com valor $q$ e outras duas cartas, que são o divisor $q$ e um não múltiplo $x$, que somadas resultam em uma soma não favorável. Então, em $\mathcal{H}$ temos $q, q$ e $x$. Voltamos nossa atenção para as cartas em $\mathscr{D}$. Neste caso, duas das cartas em $\mathscr{D}$ formam uma soma favorável do tipo $\Sigma_{\circ}$. Esse subconjunto é composto por duas cartas múltiplas de $q$ onde, necessariamente, pelo menos uma delas é o próprio $q$. Desta maneira, pode ser $q$ e $q$ ou $q$ e $\diamond$. Além das duas cartas da mesa que compõem a referida soma, ainda resta uma carta em $\omega_{4}, \omega_{5}$ e $\omega_{6}$ que pode ser $x, \diamond$ ou $q$. Desta forma, estamos nos referindo à seguinte união

$$
G_{4}(q)=\begin{array}{|l|l|l|l|l|l|l|l|l|l|l|l|}
q S_{\circ} & \Sigma_{\circ} x & q S_{\circ} & \Sigma_{\circ} \diamond & \Sigma_{\circ} q \\
\hline
\end{array}
$$

Calcularemos as cardinalidades de $q, S_{x}$ e $\Sigma_{x}$ sempre nesta ordem para finalmente calcular o valor da última carta. Seja $q \in\{1, \ldots, 13\}$. A cardinalidade do evento $G_{4}(q)$ é determinada pela expressão

$$
\begin{aligned}
\#\left(G_{4}(q)\right)= & \left(\begin{array}{l}
4 \\
2
\end{array}\right)\left(\begin{array}{c}
52-N_{q} \\
1
\end{array}\right)\left(\begin{array}{l}
2 \\
1
\end{array}\right)\left(\begin{array}{c}
N_{q}-4 \\
1
\end{array}\right)\left[\left(\begin{array}{c}
52-N_{q}-1 \\
1
\end{array}\right)+\left(\begin{array}{c}
N_{q}-4-1 \\
1
\end{array}\right)+\left(\begin{array}{l}
1 \\
1
\end{array}\right)\right] \\
& +\left(\begin{array}{l}
4 \\
2
\end{array}\right)\left(\begin{array}{c}
52-N_{q} \\
1
\end{array}\right)\left(\begin{array}{l}
2 \\
2
\end{array}\right)\left[\left(\begin{array}{c}
52-N_{q}-1 \\
1
\end{array}\right)+\left(\begin{array}{c}
N_{q}-4 \\
1
\end{array}\right)\right] .
\end{aligned}
$$

Com o objetivo de justificarmos esta expressão, observamos primeiro que conjunto $S_{\circ}$ não precisou de ser particionado em subconjuntos. Existe apenas uma situação de um par de cartas, sendo uma delas necessariamente um $q$, cuja soma de seus valores resultam em um valor não divisível por $q$ : ser um $q$ somado com um $x$. O conjunto $\Sigma_{\circ}$ precisou ser decomposto em dois subconjuntos $\Sigma_{\circ}^{\prime}(q)$, (composto de $q$ e $q$ ) e $\Sigma_{\circ}^{\prime \prime}(q)$ ( composto de $q$ e $\diamond$ ). Portanto, temos 1 situação referente a carta $q, 1$ situação referentes ao conjunto $S_{\circ}, 2$ situações referentes ao conjunto $\Sigma_{\circ}$ e 3 situações referentes a última carta $(x, \diamond$ ou $q)$. Pelo princípio multiplicativo, temos $1 \cdot 1 \cdot 2 \cdot 3=6$ partes a serem escritas e somadas de tal maneira que nenhuma combinação dessas deixe de ser calculada. Os três primeiros casos abordados em $G_{4}(q)$

$$
\begin{array}{|ll|l|l|l|l|l|l|l|l|l|l|l|l|l|l|l|l|l|}
\hline q & S_{\circ}(q) & \Sigma_{\circ}^{\prime \prime}(q) x & S_{\circ}(q) & \Sigma_{\circ}^{\prime \prime}(q) \diamond \\
\hline
\end{array}
$$

podem ser contados pela linha

$$
\left(\begin{array}{l}
4 \\
2
\end{array}\right)\left(\begin{array}{c}
52-N_{q} \\
1
\end{array}\right)\left(\begin{array}{l}
2 \\
1
\end{array}\right)\left(\begin{array}{c}
N_{q}-4 \\
1
\end{array}\right)\left[\left(\begin{array}{c}
52-N_{q}-1 \\
1
\end{array}\right)+\left(\begin{array}{c}
N_{q}-4-1 \\
1
\end{array}\right)+\left(\begin{array}{l}
1 \\
1
\end{array}\right)\right]
$$

O primeiro binômio $\left(\begin{array}{l}4 \\ 2\end{array}\right)$ representa a escolha dos naipes do $q$ que elegemos como divisor e também do $q$ que compõe o par de $S_{\circ}(q)$, sendo possível escolher dois em quatro opções de naipes. Contando os naipes é o mesmo que se contar as cartas. Existe uma relação intríceca entre naipe e valor da carta.

A segunda carta de $S_{\circ}(q)$, sendo uma carta não múltipla de $q$, um $x$, tem suas possibilidades contadas retirando de todas as 52 cartas do baralho as cartas múltiplas de $q$. Quando, de todas as 
cartas, retiramos os múltiplos o que resta são os não múltiplos. Assim calculamos as possibilidades de $x$, nesta posição, por $\left(\begin{array}{c}52-N_{q} \\ 1\end{array}\right)$.

Na sequência aparece $q$ para que calculemos as possibilidades de ocorrência. Calculamos separado dos dois primeiros, pois se encontra em $\omega_{4}, \omega_{5}$ e $\omega_{6}$ e não em $\omega_{1}, \omega_{2}$ e $\omega_{3}$ como os demais. Como dois deles já foram utilizados em $\omega_{1}, \omega_{2}$ e $\omega_{3}$ então temos um possibilidade em duas (e não em 4), dado por $\left(\begin{array}{l}2 \\ 1\end{array}\right)$.

A segunda carta de $\omega_{4}, \omega_{5}$ e $\omega_{6}$ é um múltiplo de $q$, um $\diamond$. Todos os múltiplos de $q$ estão contemplados em $N_{q}$, inclusive o próprio $q$. $\operatorname{Em} N_{q}$, cada carta está representada quatro vezes por se considerar os quatro naipes. Se queremos tirar uma carta com um determinado naipe de $N_{q}$ devemos fazer $\left(N_{q}-1\right)$. Mas se queremos retirar de $N_{q}$ uma carta, independente de seu naipe, devemos fazer $N_{q}-4$. Para calcular as possibilidades de se obter um múltiplo diferente de $q$, utilizamos $\left(\begin{array}{c}N_{q}-4 \\ 1\end{array}\right)$.

Cada um dos binômios presentes em

$$
\left[\left(\begin{array}{c}
52-N_{q}-1 \\
1
\end{array}\right)+\left(\begin{array}{c}
N_{q}-4-1 \\
1
\end{array}\right)+\left(\begin{array}{l}
1 \\
1
\end{array}\right)\right]
$$

representam, respectivamente a escolha de uma das cartas $x, \diamond$ e $q$ na última posição de $\omega_{4}, \omega_{5}$ e $\omega_{6}$. Contamos $x$ por $\left(\begin{array}{c}52-N_{q}-1 \\ 1\end{array}\right)$ dado que são 52 cartas no baralho e destas devemos retirar todas que são múltiplas, $N_{q}$, e uma não múltipla que já foi considerada nos cálculos anteriores. A parte $\left(\begin{array}{c}N_{q}-4-1 \\ 1\end{array}\right)$ representa a escolha de um múltiplo de $N_{q}$, dado que não podemos utilizar nenhum dos quatro $q$ e um múltiplo já foi considerado nos cálculos anteriores. Como a carta $q$ já foi considerada por três vezes, restou apenas uma delas para se escolher na última posição, o que justifica a escolha $\left(\begin{array}{l}1 \\ 1\end{array}\right)$.

Os casos abordados em $G_{4}$

$$
\begin{array}{|ll|l|l|l|l|l|l|l|l|l|l|l|l|l|l|l|l|l}
\hline q & S_{\circ}(q) & \Sigma_{\circ}^{\prime}(q) x & S_{\circ}(q) & \Sigma_{\circ}^{\prime}(q) \diamond & \Sigma_{\circ}^{\prime}(q) & q \\
\hline
\end{array}
$$

podem ser contados pela linha

$$
\left(\begin{array}{l}
4 \\
2
\end{array}\right)\left(\begin{array}{c}
52-N_{q} \\
1
\end{array}\right)\left(\begin{array}{l}
2 \\
2
\end{array}\right)\left[\left(\begin{array}{c}
52-N_{q}-1 \\
1
\end{array}\right)+\left(\begin{array}{c}
N_{q}-4 \\
1
\end{array}\right)+0\right]
$$

A sequência $\left(\begin{array}{l}4 \\ 2\end{array}\right)\left(\begin{array}{c}52-N_{q} \\ 1\end{array}\right)$ pode ser igualmente justificada como anteriormente. Trata-se da escolha das três primeira cartas. Como a terceira e quarta cartas são $q$ e duas delas foram consideradas no primeiro binômio, temos duas possibilidades de escolha entre as duas que restaram, logo $\left(\begin{array}{l}2 \\ 2\end{array}\right)$.

Cada um dos binômios presentes em

$$
\left[\left(\begin{array}{c}
52-N_{q}-1 \\
1
\end{array}\right)+\left(\begin{array}{c}
N_{q}-4 \\
1
\end{array}\right)+0\right]
$$

representam, respectivamente a escolha de uma das cartas $x, \diamond$ e $q$ na última posição de $\omega_{4}, \omega_{5}$ e $\omega_{6}$. Contamos $x$ por $\left(\begin{array}{c}52-N_{q}-1 \\ 1\end{array}\right)$ dado que são 52 cartas no baralho e destas devemos retirar todas que são múltiplas, $N_{q}$, e uma não múltipla que já foi considerada nos cálculos anteriores. A parte $\left(\begin{array}{c}N_{q}-4 \\ 1\end{array}\right)$ representa a escolha de um múltiplo qualquer de $N_{q}$, com excessão dos quatro $q$. Como a carta $q$ já foi considerada por quatro vezes, não restou cartas desse tipo para a última posição, o que justifica o aparececimento do zero. Colocamos o 0 para podermos refletir sobre o porquê da ausência do último binômio.

Desenvolvendo e simplificando a expressão para \# $\left(G_{4}(q)\right)$ obtem-se

$$
\#\left(G_{4}(q)\right)=564\left(N_{q}-4\right)\left(52-N_{q}\right)+282\left(52-N_{q}\right) .
$$

Portanto, utilizando a Tabela 2 e somando em $q$ de 1 até 13 temos \# $\left(G_{4}\right)=1087392$ e assim

$$
\mathbb{P}\left\{G_{4}\right\}=\frac{1087392}{407170400} \approx 0,00267061 .
$$


Demonstração do Lema 2.19. Seja $q \in\{1, \ldots, 13\}$. A cardinalidade do evento $G_{5}(q)$ é

$$
\begin{aligned}
& \left(\begin{array}{l}
4 \\
1
\end{array}\right)\left(\begin{array}{l}
4 \\
2
\end{array}\right) \Sigma_{x}^{\prime \prime \prime}(q)\left[\left(\begin{array}{l}
4 \\
2
\end{array}\right) \Sigma_{x}^{\prime \prime \prime}(q)-1\right]\left[\left(\begin{array}{c}
52-N_{q} \\
1
\end{array}\right)+\left(\begin{array}{c}
N_{q}-4-4 \\
1
\end{array}\right)+\left(\begin{array}{l}
3 \\
1
\end{array}\right)\right] \\
& +\left(\begin{array}{l}
4 \\
1
\end{array}\right)\left(\begin{array}{l}
4 \\
2
\end{array}\right) \Sigma_{x}^{\prime \prime \prime}(q)\left(\begin{array}{l}
4 \\
2
\end{array}\right) \Sigma_{x}^{i v}(q)\left[\left(\begin{array}{c}
52-N_{q}-2 \\
1
\end{array}\right)+\left(\begin{array}{c}
N_{q}-4-2 \\
1
\end{array}\right)+\left(\begin{array}{l}
3 \\
1
\end{array}\right)\right] \\
& +\left(\begin{array}{l}
4 \\
1
\end{array}\right)\left[\left(\begin{array}{l}
4 \\
2
\end{array}\right) \Sigma_{x}^{\prime \prime \prime}(q)\left(\begin{array}{c}
\Sigma_{x}^{\prime \prime \prime}(q)-1 \\
2
\end{array}\right)\left(\begin{array}{l}
4 \\
1
\end{array}\right)\left(\begin{array}{l}
4 \\
1
\end{array}\right)+\left(\begin{array}{l}
4 \\
2
\end{array}\right) \Sigma_{x}^{\prime \prime \prime}(q)\left(\left(\begin{array}{c}
\Sigma_{x}^{\prime \prime \prime}(q) \\
2
\end{array}\right)-\left(\begin{array}{c}
\Sigma_{x}^{\prime \prime \prime}(q)-1 \\
2
\end{array}\right)\right)\left(\begin{array}{l}
2 \\
1
\end{array}\right)\left(\begin{array}{l}
4 \\
1
\end{array}\right)\right] \\
& {\left[\left(\begin{array}{c}
52-N_{q} \\
1
\end{array}\right)+\left(\begin{array}{c}
N_{q}-4-4 \\
1
\end{array}\right)+\left(\begin{array}{l}
3 \\
1
\end{array}\right)\right]} \\
& +\left(\begin{array}{l}
4 \\
1
\end{array}\right)\left(\begin{array}{l}
4 \\
2
\end{array}\right) \Sigma_{x}^{\prime \prime \prime}(q)\left(\begin{array}{l}
4 \\
1
\end{array}\right)\left(\begin{array}{l}
4 \\
1
\end{array}\right) \Sigma_{x}^{\prime \prime}(q)\left[\left(\begin{array}{c}
52-N_{q}-2 \\
1
\end{array}\right)+\left(\begin{array}{c}
N_{q}-4-2 \\
1
\end{array}\right)+\left(\begin{array}{l}
3 \\
1
\end{array}\right)\right] \\
& +\left(\begin{array}{l}
4 \\
1
\end{array}\right)\left(\begin{array}{l}
4 \\
2
\end{array}\right) \Sigma_{x}^{i v}(q)\left(\begin{array}{l}
4 \\
2
\end{array}\right) \Sigma_{x}^{\prime \prime \prime}(q)\left[\left(\begin{array}{c}
52-N_{q}-2 \\
1
\end{array}\right)+\left(\begin{array}{c}
N_{q}-4-2 \\
1
\end{array}\right)+\left(\begin{array}{l}
3 \\
1
\end{array}\right)\right] \\
& +\left(\begin{array}{l}
4 \\
1
\end{array}\right)\left(\begin{array}{l}
4 \\
2
\end{array}\right) \sum_{x}^{i v}(q)\left[\left(\begin{array}{l}
4 \\
2
\end{array}\right) \Sigma_{x}^{i v}(q)-1\right]\left[\left(\begin{array}{c}
52-N_{q}-4 \\
1
\end{array}\right)+\left(\begin{array}{c}
N-4 \\
1
\end{array}\right)+\left(\begin{array}{l}
3 \\
1
\end{array}\right)\right] \\
& +\left(\begin{array}{l}
4 \\
1
\end{array}\right)\left(\begin{array}{l}
4 \\
2
\end{array}\right) \Sigma_{x}^{i v}(q)\left(\begin{array}{l}
4 \\
1
\end{array}\right)\left(\begin{array}{l}
4 \\
1
\end{array}\right) \Sigma_{x}^{\prime}(q)\left[\left(\begin{array}{c}
52-N_{q}-2 \\
1
\end{array}\right)+\left(\begin{array}{c}
N_{q}-4-2 \\
1
\end{array}\right)+\left(\begin{array}{l}
3 \\
1
\end{array}\right)\right] \\
& +\left(\begin{array}{l}
4 \\
1
\end{array}\right) H_{q}^{\prime}\left[\left(\begin{array}{c}
52-N_{q}-4 \\
1
\end{array}\right)+\left(\begin{array}{c}
N_{q}-4 \\
1
\end{array}\right)+\left(\begin{array}{l}
3 \\
1
\end{array}\right)\right] \\
& +\left(\begin{array}{l}
4 \\
1
\end{array}\right)\left[\left(\begin{array}{l}
4 \\
2
\end{array}\right) \Sigma_{x}^{\prime \prime \prime}(q)\left(\begin{array}{c}
\Sigma_{x}^{\prime \prime \prime}(q)-1 \\
2
\end{array}\right)\left(\begin{array}{l}
4 \\
1
\end{array}\right)\left(\begin{array}{l}
4 \\
1
\end{array}\right)+\left(\begin{array}{l}
4 \\
2
\end{array}\right) \Sigma_{x}^{\prime \prime \prime}(q)\left(\left(\begin{array}{c}
\Sigma_{x}^{\prime \prime \prime}(q) \\
2
\end{array}\right)-\left(\begin{array}{c}
\Sigma_{x}^{\prime \prime \prime}(q)-1 \\
2
\end{array}\right)\right)\left(\begin{array}{l}
2 \\
1
\end{array}\right)\left(\begin{array}{l}
4 \\
1
\end{array}\right)\right] \\
& {\left[\left(\begin{array}{c}
52-N_{q} \\
1
\end{array}\right)+\left(\begin{array}{c}
N_{q}-4-4 \\
1
\end{array}\right)+\left(\begin{array}{l}
3 \\
1
\end{array}\right)\right]} \\
& +\left(\begin{array}{l}
4 \\
1
\end{array}\right)\left(\begin{array}{l}
4 \\
1
\end{array}\right)\left(\begin{array}{l}
4 \\
1
\end{array}\right) \Sigma_{x}^{\prime}(q)\left(\begin{array}{l}
4 \\
2
\end{array}\right) \Sigma_{x}^{i v}(q)\left[\left(\begin{array}{c}
52-N_{q}-2 \\
1
\end{array}\right)+\left(\begin{array}{c}
N_{q}-4-2 \\
1
\end{array}\right)+\left(\begin{array}{l}
3 \\
1
\end{array}\right)\right] \\
& +\left(\begin{array}{l}
4 \\
1
\end{array}\right) H_{q}^{\prime \prime}\left[\left(\begin{array}{c}
52-N_{q} \\
1
\end{array}\right)+\left(\begin{array}{c}
N_{q}-4-4 \\
1
\end{array}\right)+\left(\begin{array}{l}
3 \\
1
\end{array}\right)\right] \\
& +\left(\begin{array}{l}
4 \\
1
\end{array}\right)\left(\begin{array}{l}
4 \\
1
\end{array}\right)\left(\begin{array}{l}
4 \\
1
\end{array}\right) \Sigma_{x}^{\prime}(q)\left(\begin{array}{l}
4 \\
1
\end{array}\right)\left(\begin{array}{l}
4 \\
1
\end{array}\right) \Sigma_{x}^{\prime \prime}(q)\left[\left(\begin{array}{c}
52-N_{q}-2 \\
1
\end{array}\right)+\left(\begin{array}{c}
N_{q}-4-2 \\
1
\end{array}\right)+\left(\begin{array}{l}
3 \\
1
\end{array}\right)\right] \\
& +\left(\begin{array}{l}
4 \\
1
\end{array}\right)\left(\begin{array}{l}
4 \\
1
\end{array}\right)\left(\begin{array}{l}
4 \\
1
\end{array}\right) \Sigma_{x}^{\prime \prime}(q)\left(\begin{array}{l}
4 \\
2
\end{array}\right) \Sigma_{x}^{\prime \prime \prime}(q)\left[\left(\begin{array}{c}
52-N_{q}-2 \\
1
\end{array}\right)+\left(\begin{array}{c}
N_{q}-4-2 \\
1
\end{array}\right)+\left(\begin{array}{l}
3 \\
1
\end{array}\right)\right] \\
& +\left(\begin{array}{l}
4 \\
1
\end{array}\right) H_{q}^{\prime}\left[\left(\begin{array}{c}
52-N_{q}-4 \\
1
\end{array}\right)+\left(\begin{array}{c}
N_{q}-4 \\
1
\end{array}\right)+\left(\begin{array}{l}
3 \\
1
\end{array}\right)\right] \\
& +\left(\begin{array}{l}
4 \\
1
\end{array}\right)\left(\begin{array}{l}
4 \\
1
\end{array}\right)\left(\begin{array}{l}
4 \\
1
\end{array}\right) \Sigma_{x}^{\prime \prime}(q)\left(\begin{array}{l}
4 \\
1
\end{array}\right)\left(\begin{array}{l}
4 \\
1
\end{array}\right) \Sigma_{x}^{\prime}(q)\left[\left(\begin{array}{c}
52-N_{q}-2 \\
1
\end{array}\right)+\left(\begin{array}{c}
N_{q}-4-2 \\
1
\end{array}\right)+\left(\begin{array}{l}
3 \\
1
\end{array}\right)\right] \\
& +\left(\begin{array}{l}
4 \\
1
\end{array}\right) H_{q}^{\prime \prime \prime}\left[\left(\begin{array}{c}
52-N_{q}-4 \\
1
\end{array}\right)+\left(\begin{array}{c}
N_{q}-4 \\
1
\end{array}\right)+\left(\begin{array}{l}
3 \\
1
\end{array}\right)\right]
\end{aligned}
$$

Ao calcular a cardinalidade de alguns dos eventos relativos a $G_{5}(q)$, nos deparamos com situações que foram possíveis de serem resolvidas contando caso a caso, porém difíceis de se generalizar, o que resultou em valores denotados por $H_{q}, H_{q}^{\prime}, H_{q}^{\prime \prime}$ e $H_{q}^{\prime \prime \prime}$ incluídos na Tabela 5. Note que em $G_{1}(q)$ foi utilizado $H_{q}$ e que em $G_{5}(q)$ foram utilizados os demais. Desenvolvendo e simplificando esta última expressão obtemos

$$
\#\left(G_{5}(q)\right)=188\left(2 H_{q}^{\prime}+H_{q}^{\prime \prime}+H_{q}^{\prime \prime \prime}+2\left(32 \Sigma_{x}^{\prime}(q)\left(8 \Sigma_{x}^{\prime \prime}(q)+3 \Sigma_{x}^{i v}(q)\right)\right.\right.
$$




$$
\begin{aligned}
& +3\left(\Sigma_{x}^{\prime \prime \prime}(q)\left(15+32 \Sigma_{x}^{\prime \prime}(q)+2 \Sigma_{x}^{\prime \prime \prime}(q)\left(8 \Sigma_{x}^{\prime \prime \prime}(q)-13\right)\right)\right. \\
& \left.\left.+\left(12 \Sigma_{x}^{\prime \prime \prime}(q)-1\right) \Sigma_{x}^{i v}(q)+6\left(\Sigma_{x}^{i v}\right)^{2}\right)\right)
\end{aligned}
$$

Somando em $q$ de 1 até 13 , com o auxílio da Tabela 3 e da Tabela 5 , temos \# $\left(G_{5}\right)=367979168$,

\begin{tabular}{|c|c|c|c|c|}
\hline$q$ & $H_{q}$ & $H_{q}^{\prime}$ & $H_{q}^{\prime \prime}$ & $H_{q}^{\prime \prime \prime}$ \\
\hline$A$ & 0 & 0 & 1125904 & 0 \\
\hline 2 & 0 & 12096 & 16480 & 95184 \\
\hline 3 & 9120 & 0 & 1538 & 92160 \\
\hline 4 & 11568 & 4032 & 144 & 38896 \\
\hline 5 & 17472 & 0 & 0 & 46448 \\
\hline 6 & 14736 & 2016 & 0 & 27504 \\
\hline 7 & 19008 & 0 & 0 & 33984 \\
\hline 8 & 19008 & 1632 & 0 & 19344 \\
\hline 9 & 14272 & 0 & 0 & 14976 \\
\hline 10 & 12144 & 672 & 0 & 11376 \\
\hline$J$ & 12128 & 0 & 0 & 11504 \\
\hline$Q$ & 10576 & 576 & 0 & 8544 \\
\hline K & 10560 & 0 & 0 & 8544 \\
\hline
\end{tabular}
portanto

TABEla 5. Cardinalidade do conjuntos $H_{q}, H_{q}^{\prime \prime}, H_{q}^{\prime \prime}$ e $H_{q}^{\prime \prime \prime}$.

Demosntração do Lema 2.20. Seja $q \in\{1, \ldots, 13\}$. A cardinalidade do evento $G_{6}(q)$ é

$$
\begin{aligned}
& \left(\begin{array}{l}
4 \\
1
\end{array}\right)\left(\begin{array}{l}
4 \\
2
\end{array}\right) \Sigma_{x}^{\prime \prime \prime}(q)\left(\begin{array}{l}
3 \\
1
\end{array}\right)\left(\begin{array}{c}
N_{q}-4-2 \\
1
\end{array}\right)\left[\left(\begin{array}{c}
52-N_{q} \\
1
\end{array}\right)+\left(\begin{array}{c}
N_{q}-4-3 \\
1
\end{array}\right)+\left(\begin{array}{l}
2 \\
1
\end{array}\right)\right] \\
& +\left(\begin{array}{l}
4 \\
1
\end{array}\right)\left(\begin{array}{l}
4 \\
2
\end{array}\right) \Sigma_{x}^{\prime \prime \prime}(q)\left(\begin{array}{l}
3 \\
2
\end{array}\right)\left[\left(\begin{array}{c}
52-N_{q} \\
1
\end{array}\right)+\left(\begin{array}{c}
N_{q}-4-2 \\
1
\end{array}\right)+\left(\begin{array}{l}
1 \\
1
\end{array}\right)\right] \\
& +\left(\begin{array}{l}
4 \\
1
\end{array}\right)\left(\begin{array}{l}
4 \\
2
\end{array}\right) \Sigma_{x}^{i v}(q)\left(\begin{array}{l}
3 \\
1
\end{array}\right)\left(\begin{array}{c}
N_{q}-4 \\
1
\end{array}\right)\left[\left(\begin{array}{c}
52-N_{q}-2 \\
1
\end{array}\right)+\left(\begin{array}{c}
N_{q}-4-1 \\
1
\end{array}\right)+\left(\begin{array}{l}
2 \\
1
\end{array}\right)\right] \\
& +\left(\begin{array}{l}
4 \\
1
\end{array}\right)\left(\begin{array}{l}
4 \\
2
\end{array}\right) \Sigma_{x}^{i v}(q)\left(\begin{array}{l}
3 \\
2
\end{array}\right)\left[\left(\begin{array}{c}
52-N_{q}-2 \\
1
\end{array}\right)+\left(\begin{array}{c}
N_{q}-4 \\
1
\end{array}\right)+\left(\begin{array}{l}
1 \\
1
\end{array}\right)\right] \\
& +\left(\begin{array}{l}
4 \\
1
\end{array}\right)\left(\begin{array}{l}
4 \\
1
\end{array}\right)\left(\begin{array}{l}
4 \\
1
\end{array}\right) \Sigma_{x}^{\prime}(q)\left(\begin{array}{l}
3 \\
1
\end{array}\right)\left(\begin{array}{c}
N_{q}-4-2 \\
1
\end{array}\right)\left[\left(\begin{array}{c}
52-N_{q} \\
1
\end{array}\right)+\left(\begin{array}{c}
N_{q}-4-3 \\
1
\end{array}\right)+\left(\begin{array}{l}
2 \\
1
\end{array}\right)\right] \\
& +\left(\begin{array}{l}
4 \\
1
\end{array}\right)\left(\begin{array}{l}
4 \\
1
\end{array}\right)\left(\begin{array}{l}
4 \\
1
\end{array}\right) \Sigma_{x}^{\prime}(q)\left(\begin{array}{l}
3 \\
2
\end{array}\right)\left[\left(\begin{array}{c}
52-N_{q} \\
1
\end{array}\right)+\left(\begin{array}{c}
N_{q}-4-2 \\
1
\end{array}\right)+\left(\begin{array}{l}
1 \\
1
\end{array}\right)\right] \\
& +\left(\begin{array}{l}
4 \\
1
\end{array}\right)\left(\begin{array}{l}
4 \\
1
\end{array}\right)\left(\begin{array}{l}
4 \\
1
\end{array}\right) \Sigma_{x}^{\prime \prime}(q)\left(\begin{array}{c}
3 \\
1
\end{array}\right)\left(\begin{array}{c}
N_{q}-4 \\
1
\end{array}\right)\left[\left(\begin{array}{c}
52-N_{q}-2 \\
1
\end{array}\right)+\left(\begin{array}{c}
N_{q}-4-1 \\
1
\end{array}\right)+\left(\begin{array}{l}
2 \\
1
\end{array}\right)\right] \\
& +\left(\begin{array}{l}
4 \\
1
\end{array}\right)\left(\begin{array}{l}
4 \\
1
\end{array}\right)\left(\begin{array}{l}
4 \\
1
\end{array}\right) \Sigma_{x}^{\prime \prime}(q)\left(\begin{array}{l}
3 \\
2
\end{array}\right)\left[\left(\begin{array}{c}
52-N_{q}-2 \\
1
\end{array}\right)+\left(\begin{array}{c}
N_{q}-4 \\
1
\end{array}\right)+\left(\begin{array}{l}
1 \\
1
\end{array}\right)\right]
\end{aligned}
$$

Desenvolvendo e simplificando tem-se

$$
\#\left(G_{6}(q)\right)=1128\left(8\left(N_{q}-5\right) \Sigma_{x}^{\prime}(q)+8\left(N_{q}-3\right) \Sigma_{x}^{\prime \prime}(q)+3\left(N_{q}-5\right) \Sigma_{x}^{\prime \prime \prime}(q)+3\left(N_{q}-3\right) \Sigma_{x}^{i v}(q)\right)
$$


Somando em $q$ de 1 até 13, com o auxílio da Tabela 2 e da Tabela 3, temos $\#\left(G_{6}\right)=42327072$ e assim

$$
\mathbb{P}\left\{G_{6}\right\}=\frac{42327072}{407170400} \approx 0,103954
$$

Demonstração do Lema 2.21. Seja $q \in\{1, \ldots, 13\}$. A cardinalidade do evento $G_{7}(q)$ é

$$
\begin{aligned}
& \left(\begin{array}{l}
4 \\
3
\end{array}\right)\left(\begin{array}{l}
4 \\
2
\end{array}\right) \Sigma_{x}^{\prime \prime \prime}(q)\left[\left(\begin{array}{c}
52-N_{q} \\
1
\end{array}\right)+\left(\begin{array}{c}
N_{q}-4-2 \\
1
\end{array}\right)+\left(\begin{array}{l}
1 \\
1
\end{array}\right)\right] \\
& +\left(\begin{array}{l}
4 \\
3
\end{array}\right)\left(\begin{array}{l}
4 \\
2
\end{array}\right) \Sigma_{x}^{i v}(q)\left[\left(\begin{array}{c}
52-N_{q}-2 \\
1
\end{array}\right)+\left(\begin{array}{c}
N_{q}-4 \\
1
\end{array}\right)+\left(\begin{array}{l}
1 \\
1
\end{array}\right)\right] \\
& +\left(\begin{array}{l}
4 \\
3
\end{array}\right)\left(\begin{array}{l}
4 \\
1
\end{array}\right)\left(\begin{array}{l}
4 \\
1
\end{array}\right) \Sigma_{x}^{\prime}(q)\left[\left(\begin{array}{c}
52-N_{q} \\
1
\end{array}\right)+\left(\begin{array}{c}
N_{q}-4-2 \\
1
\end{array}\right)+\left(\begin{array}{l}
1 \\
1
\end{array}\right)\right] \\
& +\left(\begin{array}{l}
4 \\
3
\end{array}\right)\left(\begin{array}{l}
4 \\
1
\end{array}\right)\left(\begin{array}{l}
4 \\
1
\end{array}\right) \Sigma_{x}^{\prime \prime}(q)\left[\left(\begin{array}{c}
52-N_{q}-2 \\
1
\end{array}\right)+\left(\begin{array}{c}
N_{q}-4 \\
1
\end{array}\right)+\left(\begin{array}{l}
1 \\
1
\end{array}\right)\right] \\
& +\left(\begin{array}{l}
4 \\
2
\end{array}\right)\left[\left(\begin{array}{c}
N_{q}-4-4 \\
1
\end{array}\right)\left(\begin{array}{l}
4 \\
2
\end{array}\right) \Sigma_{x}^{\prime \prime \prime}(q)+\left(\begin{array}{l}
4 \\
3
\end{array}\right) \Sigma_{x}^{\prime \prime \prime}(q)\right]\left[\left(\begin{array}{c}
52-N_{q} \\
1
\end{array}\right)+\left(\begin{array}{c}
N_{q}-4-3 \\
1
\end{array}\right)+\left(\begin{array}{l}
2 \\
1
\end{array}\right)\right] \\
& +\left(\begin{array}{l}
4 \\
2
\end{array}\right)\left(\begin{array}{c}
N_{q}-4 \\
1
\end{array}\right)\left(\begin{array}{l}
4 \\
2
\end{array}\right) \Sigma_{x}^{i v}(q)\left[\left(\begin{array}{c}
52-N_{q}-2 \\
1
\end{array}\right)+\left(\begin{array}{c}
N_{q}-4-1 \\
1
\end{array}\right)+\left(\begin{array}{l}
2 \\
1
\end{array}\right)\right] \\
& +\left(\begin{array}{l}
4 \\
2
\end{array}\right)\left[\left(\begin{array}{l}
3 \\
1
\end{array}\right)\left(\begin{array}{l}
2 \\
1
\end{array}\right)\left(\begin{array}{l}
4 \\
1
\end{array}\right)\left(\begin{array}{l}
4 \\
1
\end{array}\right) \Sigma_{x}^{\prime}(q)+\left(\begin{array}{c}
N_{q}-4-\left(\begin{array}{l}
4 \\
1
\end{array}\right)\left(\begin{array}{l}
2 \\
1
\end{array}\right) \\
1
\end{array}\right)\left(\begin{array}{l}
4 \\
1
\end{array}\right)\left(\begin{array}{l}
4 \\
1
\end{array}\right) \Sigma_{x}^{\prime}(q)\right]\left[\left(\begin{array}{c}
52-N_{q} \\
1
\end{array}\right)\right. \\
& \left.+\left(\begin{array}{c}
N_{q}-4-3 \\
1
\end{array}\right)+\left(\begin{array}{l}
2 \\
1
\end{array}\right)\right] \\
& +\left(\begin{array}{l}
4 \\
2
\end{array}\right)\left(\begin{array}{c}
N_{q}-4 \\
1
\end{array}\right)\left(\begin{array}{l}
4 \\
1
\end{array}\right)\left(\begin{array}{l}
4 \\
1
\end{array}\right) \Sigma_{x}^{\prime \prime}(q)\left[\left(\begin{array}{c}
52-N_{q}-2 \\
1
\end{array}\right)+\left(\begin{array}{c}
N_{q}-4-1 \\
1
\end{array}\right)+\left(\begin{array}{l}
2 \\
1
\end{array}\right)\right] .
\end{aligned}
$$

Simplificando e desenvolvendo os produtos da expressão acima obtemos

$$
\begin{aligned}
\#\left(G_{7}(q)\right)= & 188\left(8\left(3 N_{q}-10\right) \Sigma_{x}^{\prime}(q)+8\left(3 N_{q}-10\right) \Sigma_{x}^{\prime \prime}(q)\right. \\
& \left.+9 N_{q}\left(\Sigma_{x}^{\prime \prime \prime}(q)+\Sigma_{x}^{i v}(q)\right)-30\left(2 \Sigma_{x}^{\prime \prime \prime}(q)+\Sigma_{x}^{i v}(q)\right)\right)
\end{aligned}
$$

e assim, com a ajuda das Tabelas 2 e 3, \# $\left(G_{7}\right)=21482384$, logo

$$
\mathbb{P}\left\{G_{7}\right\}=\frac{21482384}{407170400} \approx 0,0527602 .
$$

Demonstração do Lema 2.22. Seja $q \in\{1, \ldots, 13\}$. A cardinalidade do evento $G_{8}(q)$ é

$$
\begin{aligned}
\#\left(G_{8}(q)\right)= & \left(\begin{array}{l}
4 \\
2
\end{array}\right)\left(\begin{array}{c}
N_{q}-4 \\
1
\end{array}\right)\left(\begin{array}{l}
2 \\
1
\end{array}\right)\left(\begin{array}{c}
N_{q}-4-1 \\
1
\end{array}\right)\left[\left(\begin{array}{c}
52-N_{q} \\
1
\end{array}\right)+\left(\begin{array}{c}
N_{q}-4-2 \\
1
\end{array}\right)+\left(\begin{array}{l}
1 \\
1
\end{array}\right)\right] \\
& +\left(\begin{array}{l}
4 \\
2
\end{array}\right)\left(\begin{array}{c}
N_{q}-4 \\
1
\end{array}\right)\left(\begin{array}{l}
2 \\
2
\end{array}\right)\left[\left(\begin{array}{c}
52-N_{q} \\
1
\end{array}\right)+\left(\begin{array}{c}
N_{q}-4-1 \\
1
\end{array}\right)\right] \\
& +\left(\begin{array}{l}
4 \\
3
\end{array}\right)\left(\begin{array}{l}
1 \\
1
\end{array}\right)\left(\begin{array}{c}
N_{q}-4 \\
1
\end{array}\right)\left[\left(\begin{array}{c}
52-N_{q} \\
1
\end{array}\right)+\left(\begin{array}{c}
N_{q}-4-1 \\
1
\end{array}\right)\right]
\end{aligned}
$$

Simplificando esta expressão chegamos a

$$
\#\left(G_{8}(q)\right)=94\left(N_{q}-4\right)\left(6 N_{q}-25\right),
$$

Somando em $q \in\{1, \ldots, 13\}$, com o auxílio da Tabela 2 obtemos \# $\left(G_{8}\right)=1651392$, portanto

$$
\mathbb{P}\left\{G_{8}\right\}=\frac{1651392}{407170400} \approx 0,00405578 .
$$




\section{Pré-requisitos: Divisibilidade e Probabilidade}

Apresentamos alguns resultados elementares sobre divisibilidade e teoria de probabilidade utilizados no decorrer do trabalho. Os textos em Ross, 2010 e Carvalho et al., 2006 podem ser consultados para uma exposição mais aprofundada.

4.1. Divisibilidade. O termo número nesta seção refere-se a um inteiro, isto é, um membro do conjunto $\mathbb{Z}=\{\ldots,-1,0,1, \ldots\}$. Sejam $a$ e $b$ dois números. Dizemos que $a$ divide $b, a \mid b$, se existe um número $c$ tal que $b=c a$. Caso contrário escrevemos $a \nmid b$.

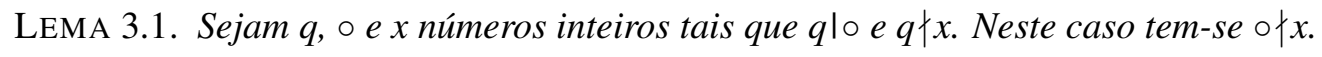

Demonstração. A demosntração é por contradição. Suponhamos que $\circ \mid x$, ou seja, existe $a$ tal que $x=a \circ$. Como $q \mid \circ$, então existe $b$ tal que $\circ=b q$, portanto $x=a b q$, ou seja existe um número $k=a b$ tal que $x=k q$, isto é $q \mid x$.

Os seguintes critérios de divisibilidade foram utilizados ao longo deste trabalho, em particular para determinarmos os valores de $N_{q}$ apresentados na Tabela 2. A demostração de alguns destes critérios pode ser encontrada em Burton, 2010.

$\mathbf{1} \mid \boldsymbol{p}$ : todo número $p$ pode ser dividido por 1 . 8 ;

2|p: se, e somente se, o algarismo das unidades de $p$ for qualquer um dos números $0,2,4,6$ ou

3|p: se, e somente se, a soma dos algarismos de $p$ também for $\mathrm{n}$ divisível por 3.

4|p: se, e somente se, $p$ terminar em 00 ou também se o número formado pelos dois últimos números da direita for divisível por 4.

5|p: se, e somente se, o algarismo das unidades de $\mathrm{p}$ for 0 ou 5.

6|p: se, e somente se, $2 \mid p$ e $3 \mid p$.

7|p: se, e somente se, ao duplicarmos o valor do algarismo das unidade de $p$ e subtrair o resultado do novo número obtido ao se eliminar o algarismo das unidades de $p$, o resultado for uma número divisível por 7 .

8|p: se, e somente se, terminar em 000 ou também se o número formado pelos três últimos números da direita for divisível por 8 .

9|p: se, e somente se, a soma dos algarismos de $p$ também for divisível por 9.

10|p: se, e somente se, o algarismo das unidades de $p$ for 0 .

11|p: se, e somente se, 11 dividir a diferença entre a soma dos valores absolutos dos algarismos em posição par pelos soma dos valores absolutos dos algarismos de posição ímpar de $p$.

12|p: se, e somente se, $3 \mid p$ e $4 \mid p$.

15|p: se, e somente se, $3 \mid p$ e $5 \mid p$.

25|p: se, e somente se, $p$ terminar em $00,25,50$ ou 75.

\subsection{Combinatória e Probabilidade.}

DEFINIÇÃo 3.2. Seja $\Omega$ o conjunto formado pelos possíveis resultados de um experimento aleatório. Chamamos $\Omega$ de espaço amostral e qualquer elemento de $\Omega$, denotado por $\omega$, de evento elementar.

Consideramos neste trabalho $\Omega$ como sendo um conjunto finito.

DEFINIÇÃo 3.3. A classe formada por todos os subconjuntos de $\Omega$ é denotada por $\wp$. Qualquer elemento de $\wp$ é chamado de evento.

DEFINIÇão 3.4. Uma função de probabilidade ou simplesmente uma probabilidade definida em $(\Omega, \wp)$ é a função $\mathbb{P}: \wp \rightarrow \mathbb{R}$ tal que

(i) $\mathbb{P}(\Omega)=1$, 
(ii) $0 \leq \mathbb{P}(E) \leq 1$, para qualquer $E \in \wp$,

(iii) para quaisquer eventos $E_{n}, n \geq 1$, tais que $E_{i} \cap E_{j}=\varnothing, \forall i \neq j$, tem-se $\mathbb{P}\left(\cup_{n} E_{n}\right)=\sum_{n} \mathbb{P}\left(E_{n}\right)$. Chamamos a terna $(\Omega, \wp, \mathbb{P})$ de espaço de probabilidade.

Duas ferramentas básicas utilizada no decorrer deste trabalho são o Princípio Fundamental da Enumeração ou Princípio da Multiplicação e o Princípio de Adição, enunciados da seguinte maneira.

PRINCÍPIO FUndAMENTAL DA ENUMERAÇÃO. Se uma tarefa $t_{1}$ pode ser realizada de $n_{1}$ maneiras e se, uma vez realizada a tarefa $t_{1}$, a tarefa $t_{2}$ pode ser realizada de $n_{2}$ maneiras então o número de maneiras de se realizarem as tarefas $t_{1}$ e $t_{2}$ é $n_{1} n_{2}$.

PRINCÍPIO DE Adição. Sejam $A$ e $B$ dois conjuntos disjuntos, com $n$ e $m$ elementos respectivamente, então $A \cup B$ possui $n+m$ elementos.

Para qualquer evento $E$ denotamos a sua cardinalidade por \#(E). Suponhamos que \# $(\Omega)=n \mathrm{e}$ $\#(E)=k, k \leq n$. O número de maneiras de formarmos o evento $E$ ao escolher $k$ elementos de $\Omega$ sem reposição e sem considerar a ordem das escolhas é determinado pelo coeficiente binomial

$$
\left(\begin{array}{l}
n \\
k
\end{array}\right)=\frac{n !}{k !(n-k) !}
$$

O seguinte resultado elementar justifica grande parte dos cálculos considerados nesta dissertação.

TeOrema 3.5. Seja $(\Omega, \wp, \mathbb{P})$ um espaço de probabilidade com $\Omega$ finito e $\mathbb{P}$ simêtrica ${ }^{1}$, isto é, $\mathbb{P}\{\omega\}=c, 0 \leq c \leq 1$, para todo $\omega \in \Omega$. Para qualquer evento $E \in \wp$ tem-se

$$
\mathbb{P}\{E\}=\#(E) / \#(\Omega) .
$$

\footnotetext{
1 ou equiprovável ou uniforme
} 



\section{CAPíTULO 4}

\section{Considerações Finais}

Ao longo da história da humanidade podemos ver uma forte relação entre a necessidade que o homem tem de resolver problemas cotidianos e a busca de respostas para esses problemas tendo, muitas vezes, como suporte a Matemática. Dentre muitos desafios, um atual é a aprendizagem de Matemática. Eis que surge um problema: como aprender Matemática recorrendo a ela mesma? Neste caso, entendemos ser necessário utilizar algumas estratégias e recursos.

Dentro da perspectiva de auxiliar na aprendizagem da Matemática por meio de estratégias e recursos, desenvolvemos o jogo Resto Zero. Mais do que caracterizar o jogo, descrever suas convenções e oferecer alguns exemplos, procuramos calcular probabilidades que pudessem validar o fato do jogo oferecer muitas situações possíveis de serem exploradas e realizadas. Acreditamos que essa característica é muito importante, pois de nada vale um jogo que pretende promover a aprendizagem dos alunos se não oferece oportunidades reais de aprendizagem.

Ao oferecer um ambiente lúdico de aprendizagem, antes de exigir do aluno habilidades desenvolvidas no âmbito da Matemática, é importante conversar com o mesmo para que se sinta seguro e que se conscientize que ter uma postura competitiva e acertiva são fatores fundamentais para seu progresso durante o jogo. Contudo, se o aluno tem essa postura e, ao jogar, nota que o próprio jogo impõe a todo momento situações difíceis de serem transpostas, ficará desmotivado.

Com os resultados obtidos, entendemos ser viável a utilização do jogo mesmo com alunos que tenham dificuldades maiores. Os cálculos que fizemos mostraram que existe um leque amplo de possibilidades que são possíveis de serem desenvolvidas. O aluno tem a seu favor uma probabilidade maior que 68\% de encontrar uma "divisão simples" possível de ser realizada e, considerando os casos da "divisão composta pela soma", as probabilidades nunca são nulas, chegando a $90 \%$ no caso $G_{5}$, de encontrar uma divisão também possível de ser realizada. Note que consideramos apenas quocientes inteiros e que não entramos em cálculos referentes à subtração, multiplicação e divisão de duas cartas da mesa. Considerando essas relações, aumentam as chances do aluno de encontrar situações possíveis de serem realizadas.

Outras situações pontuais merecem destaque, como ter um Às na mão ou um 2. O Às é divisor de qualquer carta ou da soma de duas cartas da mesa. Já por paridade, sempre será possível uma adição entre duas das três cartas da mesa cujo resultado será par e, consequentemente, divisível por 2. Veja que se duas cartas forem ímpares: ímpar + ímpar $=$ par; se duas cartas forem par: par + par $=$ par.

Mais casos interessantes vão sendo descobertos pelos alunos. Por exemplo, se duas cartas da mesa são iguais, basta fazer a subtração entre elas que o resultado será um dividendo universal, o zero.

Importante dentre os critérios de divisibilidade é que o aluno entenda sozinho, ou se for o caso através de orientação, que se $p$ for primo só poderá ser divido por um (Ás) ou por uma carta de mesmo valor $p$.

Outra coisa a se observar é que já escolhida uma carta dentre $\omega_{4}, \omega_{5}$ e $\omega_{6}$ para ser dividida por outra dentre $\omega_{1}, \omega_{2}$ e $\omega_{3}$, mais uma de $\omega_{4}, \omega_{5}$ e $\omega_{6}$ pode ser captada através da multiplicação, pois se $p$ for divisível um de seus múltiplos também o é.

Outros critérios podem ser utilizados, não sendo apenas estes os existentes. Contudo uma lista grande de regras poderá mais atrapalhar do que ajudar. Saber os critérios básicos é muito importante. Notamos no dia-a-dia, por exemplo, a dificuldade que os alunos de todos os anos 
apresentam ao simplificar frações. Existem alunos que não sabem por onde começar uma simples simplificação. E acreditamos ser neste sentido a importância de aplicar o jogo. Motivados pela competitividade os alunos que dominam os critérios básicos aumentam a chance de vencer.

No entanto, nenhum material que tenha como finalidade a aprendizagem de um aluno cumpre seu papel sem os encaminhamentos e as intervenções do professor. Neste ponto, o jogo Resto Zero não poderia ser diferente. Seu desenvolvimento com resultados eficientes necessita de comandas claras, planejamento de aula, questionamentos que levem o aluno a pensar sobre suas estratégias e jogadas, além, claro, de motivação e compromisso com a aprendizagem. 


\section{Bibliografia}

BRASIL. Lei $n^{\circ}$ 9394, de 20 de dezembro de 1996.

BRASIL. Secretaria de Educação Fundamental. Parâmetros Curriculares Nacionais: matemática. Brasil: MEC/SEF, 1997.

Burton, D. (2010). Elementary Number Theory. McGraw-Hill Education, NY, USA, 7a Edição.

Carvalho, P. C. P., de Oliveira Morgado, A. C., Fernandez, P., e Pitombeira, J. B. (2006). Análise Combinatória e Probabilidade. Coleção do Professor de Matemática. SBM, Rio de Janeiro, RJ, 9a Edição.

de Carvalho, D. (1994). Metodologia do ensino da matemática. Coleção Magistério-2o grau: Série Formação do professor. Cortez Editora.

Dinello, R. A. (2007). Expressão Ludocriativa. UniUBE, Universidade de Uberaba, Uberaba,MG.

Gusmão, V. (1996). Usando Jogos em Treinamentos. Unorp, Centro Universitário do Norte Paulista, São José do Rio Preto, SP.

Eves, H. (2005). Introdução à história da matemática. Editora da Unicamp, Campinas, SP. 1a reimpressão.

Plataforma Foco Aprendizagem, http://www. focoaprendizagem.educacao.sp.gov.br/. Acesso em 23 de fevereiro de 2017.

Ross, S. (2010). Probabilidade - Um Curso Moderno com Aplicações. Bookman, Porto Alegre, RS, 8a Edição.

SÃO PAULO (Estado). Secretaria da Educação. Currículo do Estado de São Paulo. São Paulo: SEE, 2010.

Smole, K. S., Diniz, M. I., e Milani, E. (2006). Jogos de Matemática de $6^{\circ}$ a $9^{\circ}$ ano. Cadernos do Mathema. Artmed, 1a Edição. 